\title{
Cochrane
}

Library

Cochrane Database of Systematic Reviews

\section{Action observation for upper limb rehabilitation after stroke} (Review)

Borges LRDM, Fernandes ABGS, Melo LP, Guerra RO, Campos TF

Borges LRDM, Fernandes ABGS, Melo LP, Guerra RO, Campos TF.

Action observation for upper limb rehabilitation after stroke.

Cochrane Database of Systematic Reviews 2018, Issue 10. Art. No.: CD011887.

DOI: 10.1002/14651858.CD011887.pub2.

www.cochranelibrary.com 
TABLE OF CONTENTS

HEADER

ABSTRACT

PLAIN LANGUAGE SUMMARY

SUMMARY OF FINDINGS

2

BACKGROUND

OBJECTIVES

METHODS

RESULTS

Figure 1.

Figure 2.

Figure 3.

DISCUSSION

AUTHORS' CONCLUSIONS

ACKNOWLEDGEMENTS

REFERENCES

CHARACTERISTICS OF STUDIES

DATA AND ANALYSES

Analysis 1.1. Comparison 1 Action observation therapy versus control: effect on arm function, Outcome 1 Arm function. .......

Analysis 1.2. Comparison 1 Action observation therapy versus control: effect on arm function, Outcome 2 Subgroup analysis: age.

Analysis 1.3. Comparison 1 Action observation therapy versus control: effect on arm function, Outcome 3 Subgroup analysis: type of stroke.

Analysis 1.4. Comparison 1 Action observation therapy versus control: effect on arm function, Outcome 4 Subgroup analysis: time post stroke.

Analysis 1.5. Comparison 1 Action observation therapy versus control: effect on arm function, Outcome 5 Subgroup analysis: dose of treatment.

Analysis 1.6. Comparison 1 Action observation therapy versus control: effect on arm function, Outcome 6 Subgroup analysis: type of control group.

Analysis 1.7. Comparison 1 Action observation therapy versus control: effect on arm function, Outcome 7 Subgroup analysis: duration of observation.

Analysis 1.8. Comparison 1 Action observation therapy versus control: effect on arm function, Outcome 8 Arm function sensitivity analysis: without high ROB for allocation concealment.

Analysis 1.9. Comparison 1 Action observation therapy versus control: effect on arm function, Outcome 9 Arm function sensitivity analysis: without high ROB for incomplete outcome data.

Analysis 1.10. Comparison 1 Action observation therapy versus control: effect on arm function, Outcome 10 Arm function sensitivity analysis: home-based action observation training (video therapy).

Analysis 1.11. Comparison 1 Action observation therapy versus control: effect on arm function, Outcome 11 Arm function sensitivity analysis: real demonstration.

Analysis 2.1. Comparison 2 Action observation therapy versus control: effect on hand function, Outcome 1 Hand function. .... Analysis 2.2. Comparison 2 Action observation therapy versus control: effect on hand function, Outcome 2 Subgroup analysis: age.

Analysis 2.3. Comparison 2 Action observation therapy versus control: effect on hand function, Outcome 3 Subgroup analysis: time post stroke.

Analysis 2.4. Comparison 2 Action observation therapy versus control: effect on hand function, Outcome 4 Subgroup analysis: duration of observation.

Analysis 2.5. Comparison 2 Action observation therapy versus control: effect on hand function, Outcome 5 Hand function sensitivity analysis: without high ROB for incomplete outcome data.

Analysis 3.1. Comparison 3 Action observation therapy versus control: effect on ADL, Outcome 1 Dependence on activities of daily living.

Analysis 3.2. Comparison 3 Action observation therapy versus control: effect on ADL, Outcome 2 Sensitivity analysis: without high ROB for allocation concealment.

Analysis 3.3. Comparison 3 Action observation therapy versus control: effect on ADL, Outcome 3 Sensitivity analysis: without high ROB for incomplete outcome data. 
Analysis 3.4. Comparison 3 Action observation therapy versus control: effect on ADL, Outcome 4 Sensitivity analysis: removing peripheral studies.

ADDITIONAL TABLES

APPENDICES

CONTRIBUTIONS OF AUTHORS

DECLARATIONS OF INTEREST

SOURCES OF SUPPORT 
[Intervention Review]

\section{Action observation for upper limb rehabilitation after stroke}

Lorenna RDM Borges ${ }^{1}$, Aline BGS Fernandes¹, Luciana Protásio Melo¹, Ricardo O Guerra², Tania F Campos

1Department of Physical Therapy, Federal University of Rio Grande do Norte, Natal, Brazil. 2PhD Program in Physical Therapy, Federal

University of Rio Grande do Norte, Natal, Brazil

Contact address: Lorenna RDM Borges, Department of Physical Therapy, Federal University of Rio Grande do Norte, Av. Senador Salgado Filho, 3000., Natal, Rio Grande do Norte, 59078-970, Brazil. lorennamacedo@gmail.com, lorennamacedo@hotmail.com.

Editorial group: Cochrane Stroke Group.

Publication status and date: New, published in Issue 10, 2018.

Citation: Borges LRDM, Fernandes ABGS, Melo LP, Guerra RO, Campos TF. Action observation for upper limb rehabilitation after stroke. Cochrane Database of Systematic Reviews 2018, Issue 10. Art. No.: CD011887. DOI: 10.1002/14651858.CD011887.pub2.

Copyright @ 2018 The Cochrane Collaboration. Published by John Wiley \& Sons, Ltd.

\section{A B S T R A C T}

\section{Background}

Action observation $(\mathrm{AO})$ is a physical rehabilitation approach that facilitates the occurrence of neural plasticity through the activation of the mirror-neural system, promoting motor recovery in people with stroke.

\section{Objectives}

To assess whether action observation enhances motor function and upper limb motor performance and cortical activation in people with stroke.

\section{Search methods}

We searched the Cochrane Stroke Group Trials Register (last searched 4 September 2017), the Central Register of Controlled Trials (24 October 2017), MEDLINE (1946 to 24 October 2017), Embase (1974 to 24 October 2017) and five additional databases. We also searched trial registries and reference lists.

\section{Selection criteria}

Randomized controlled trials (RCTs) of AO, alone or associated with physical practice in adults after stroke. The primary outcome was upper limb motor function. Secondary outcomes included dependence on activities of daily living (ADL), motor performance, cortical activation, quality of life, and adverse effects.

\section{Data collection and analysis}

Two review authors independently selected trials according to the pre-defined inclusion criteria, extracted data, assessed risk of bias, and applied the GRADE approach to assess the quality of the evidence. The reviews authors contacted trial authors for clarification and missing information.

\section{Main results}

We included 12 trials involving 478 individuals. A number of trials showed a high risk of bias and others an unclear risk of bias due to poor reporting. The quality of the evidence was 'low' for most of the outcomes and 'moderate' for hand function, according to the GRADE system. In most of the studies, AO was followed by some form of physical activity. Primary outcome: the impact of AO on arm function showed a small significant effect (standardized mean difference (SMD) $0.36,95 \% \mathrm{Cl} 0.13$ to 0.60 ; 8 studies; 314 participants; low-quality evidence); and a large significant effect (mean difference (MD) 2.90, 95\% Cl 1.13 to 4.66 ; 3 studies; 132 participants; moderate-quality evidence) on hand function. Secondary outcomes: there was a large significant effect for ADL outcome (SMD 0.86, 95\% Cl 0.11 to $1.61 ; 4$ studies, 226 participants; low-quality evidence). We were unable to pool other secondary outcomes to extract the evidence. Only two studies reported adverse effects without significant adverse AO events. 


\section{Authors' conclusions}

We found evidence that $A O$ is beneficial in improving upper limb motor function and dependence in activities of daily living (ADL) in people with stroke, when compared with any control group; however, we considered the quality of the evidence to be low. We considered the effect of $A O$ on hand function to be large, but it does not appear to be clinically relevant, although we considered the quality of the evidence as moderate. As such, our confidence in the effect estimate is limited because it will likely change with future research.

\section{PLAIN LANGUAGE SUMMARY}

\section{Action observation for arm rehabilitation after stroke}

\section{Review question}

We sought to compare the effects of action observation on arm and hand function after stroke with an alternative intervention or no intervention.

\section{Background}

Stroke is one of the leading causes of death and disability worldwide. Individuals who survive a stroke have difficulty moving their arms, which can lead to problems with everyday activities and reduced participation in daily situations. Action observation (AO) is a physical rehabilitation approach proposed for arm rehabilitation, in which stroke survivor observes a healthy individual performing a task, either on video or in person, followed or not by execution of the same task. This safe technique can be performed without expensive and complicated equipment and requires minimal therapist supervision. Studies show that AO activates brain areas similar to those activated when performing the same action, and may favor movement recovery after stroke.

\section{Study characteristics}

We identified 12 studies involving 478 individuals after stroke. Most used video sequences and AO followed by some form of physical activity, using a range of activities, with task complexity increased over the course of training or when it was easy for the participant to carry out. The evidence is current to October 2017.

\section{Key results}

Studies tested whether the use of AO compared with an alternative intervention or no intervention resulted in participants' improved ability to use their arms and hands, and found that AO therapy resulted in better arm (eight trials) and hand function (three trials).

\section{Quality of the evidence}

We classified the quality of the evidence as moderate for hand function, low for arm function and dependence on activities of daily living, and very low for motor performance and quality of life. Participants could engage in AO safely, since adverse events were not significant in scale or magnitude. The quality of the evidence for each outcome was limited due to the small number of study participants, low study quality, and poor reporting of study details. 
SUMMARY OF FINDINGS

Summary of findings for the main comparison. Action observation therapy versus control: effect on upper limb function post-treatment for upper limb rehabilitation after stroke

Action observation therapy versus control: effect on upper limb function post-treatment for upper limb rehabilitation after stroke

Patient or population: people with upper limb rehabilitation after stroke

Settings: clinical and home

Intervention: action observation therapy versus control: effect on upper limb function post-treatment

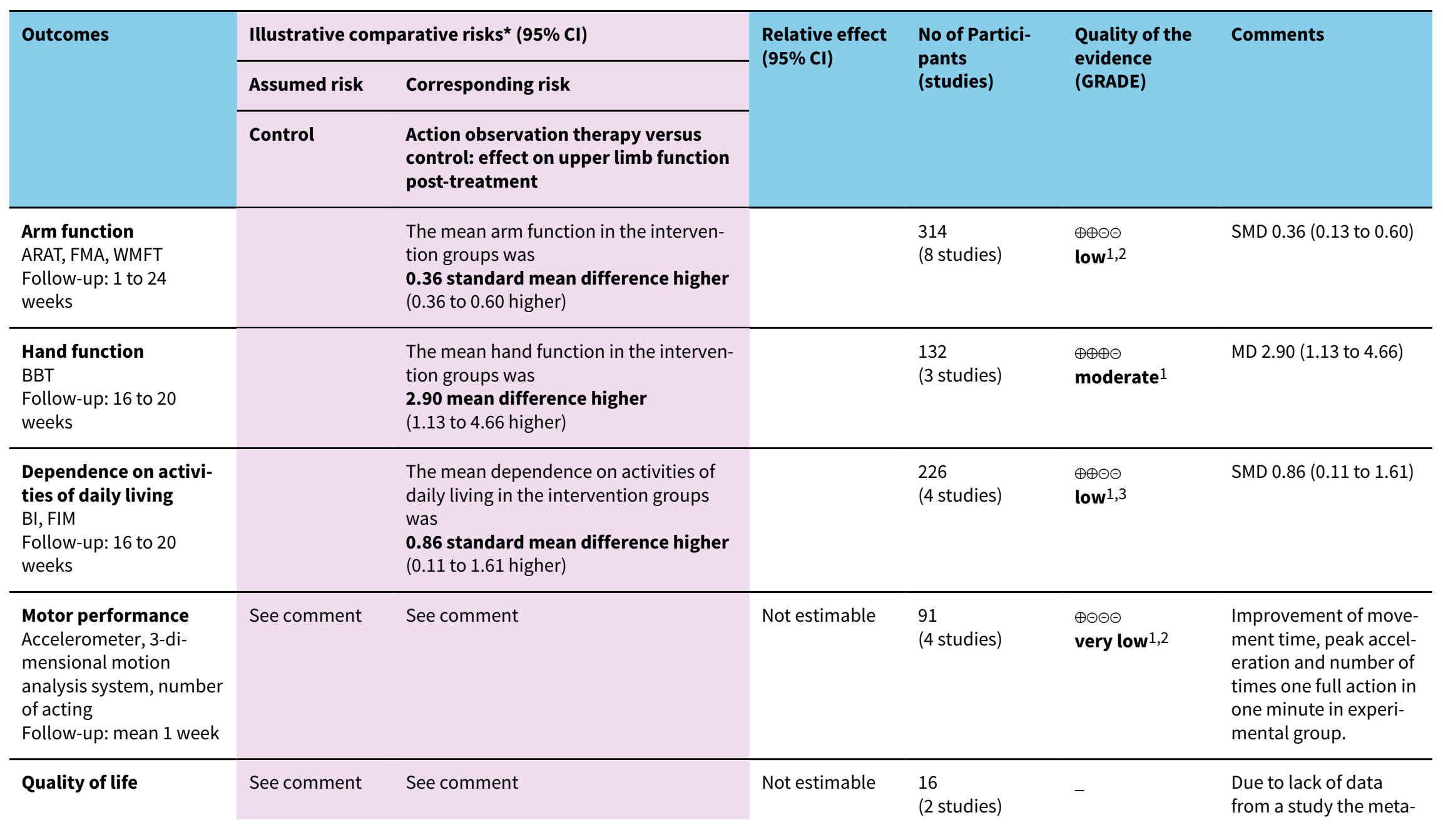




\begin{tabular}{l|l|l|ll}
\hline Adverse effect & See comment & See comment & Not estimable & $\begin{array}{l}16 \\
\text { (2 studies) }\end{array}$
\end{tabular}

*The basis for the assumed risk (e.g. the median control group risk across studies) is provided in footnotes. The corresponding risk (and its $95 \%$ confidence interval) is based on the assumed risk in the comparison group and the relative effect of the intervention (and its $95 \% \mathrm{Cl}$ ).

Cl: Confidence interval;

GRADE Working Group grades of evidence

High quality: Further research is very unlikely to change our confidence in the estimate of effect.

Moderate quality: Further research is likely to have an important impact on our confidence in the estimate of effect and may change the estimate.

Low quality: Further research is very likely to have an important impact on our confidence in the estimate of effect and is likely to change the estimate.

Very low quality: We are very uncertain about the estimate.

1 Downgraded due to several ratings with 'unclear' or even 'high' risk of bias to allocation concealment, incomplete outcome data or selective reporting.

2 Small total population size $(<400)$.

3 Unexplained heterogeneity (> 50\%).

ARAT: Action Research Arm Test

BBT: Box and Block test

BI: Barthel Index

FMA: Fugl-Meyer Assessment

FIM: Functional Independence Measure

MD: mean difference

SMD: standard mean difference

WMFT: Wolf Motor Function Tes 


\section{B A C K G R O U N D}

\section{Description of the condition}

Every year, stroke is responsible for 5.5 million deaths and 44 million disabilities worldwide (Mukherjee 2011). In 2010, it was considered the second most common cause of death and third most common cause of disability-adjusted life-years (DALYs), according to the Global Burden of Diseases, Injuries and Risk factors study (GBD 2010; Lozano 2012; Murray 2012). It is predicted that in 2030 there will be 70 million stroke survivors (Feigin 2014). People who survive the initial ictus exhibit long-term motor impairment, limited functional activities, and reduced participation in daily situations (Langhorne 2009). The motor damage to the upper limb has a significant impact on the functional performance of these people. Studies show that $60 \%$ of people with severe or complete upper limb impairment are unable to perform any movement up to six months after stroke, indicating poor functional prognosis (Kwakkel 2003; van Kuijk 2009). Thus, upper limb recovery after stroke is crucial for executing activities of daily living.

\section{Description of the intervention}

Motor recovery after stroke occurs as a consequence of neural plasticity. A range of neurorehabilitation techniques aims to facilitate the occurrence of neural plasticity to compensate for functional impairments in affected people. Among the techniques proposed for upper limb motor rehabilitation in people with stroke is a physical rehabilitation approach called action observation (AO). Considered a multisensory approach encompassing motor somatosensory and cognitive rehabilitation (Johansson 2011), this approach has demonstrated an important role in the motor recovery stroke survivors by activating the mirror-neural system (MNS) of the brain (Buccino 2014). It consists of one person observing a healthy individual performing a motor task, either on a video (Calvo-Merino 2005), or a real demonstration (Cowles 2012). For example, the stroke survivor is instructed to watch a video showing an adult stretching out his hand to pick up a cup, bringing the cup to his mouth, and then returning the cup to its initial position - the act of drinking. After observing the video sequence for a time, the individuals may or may not be asked to perform the same action.

Action observation has been applied alone, or in association with other practices such as imitation and engagement in physical actions and training of functional activities aimed at stimulating motor relearning (Garrison 2010; Small 2012).

\section{How the intervention might work}

There is growing evidence that motor areas can be recruited not only when actions are actually executed, but also when they are exercised mentally or simply observed (Jeannerod 2001). The neurophysiological basis for this finding is the mirror-neuron system (MNS), formed by the rostral portion of the inferior parietal lobe (aIPL), pars opercularis of the inferior frontal gyrus (IFG), and ventral portion of the premotor cortex (VPM) (Garrison 2010). It is hypothesized that the motor area engagement that occurs in the real execution of the action is the same that takes place during the observation of this action, and that action observation would therefore induce neural plasticity in people with stroke by promoting activation of the damaged motor circuits (Garrison 2013). Added to plasticity, MNS activation - given its distribution in the brain - provides multiple access to different brain areas, facilitating motor relearning (Small 2012). For this reason, it is suggested that this MNS activation may serve as an alternative means to rearrange damaged, but not completely lost, circuits, thereby rebuilding voluntary motor function (Garrison 2013).

\section{Why it is important to do this review}

This pathology may lead to a number of neurological disorders requiring long-term restorative and rehabilitative treatment. It is important to seek cheap and easy-to-apply therapies that are accessible to this population, in addition to promoting better and shorter recovery. This review is important because it involves current therapy with easy access, whose neurophysiological basis is neural plasticity, to provide evidence of its effectiveness. Given the evidence of plasticity through MNS activation during $A O$, it is necessary to determine the effect of this process on the acquisition of new motor skills or relearning of lost motor skills, resulting in improved upper limb performance in people with stroke. Motor learning is a change in an individual's ability to perform a skill (Magill 1989). The change emerges as a result of physical action and is characterized by a relatively permanent improvement in performance (Magill 1989). Motor skill acquisition occurs in three stages (cognitive, associative and autonomous), during which cognitive demand decreases gradually, while physical demand is constant throughout the process (Fitts 1967). Since learning a motor skill is conceptually dependent on physical action, the question arises as to how AO (and its different applications) influences the learning process. Thus this review may clarify relevant aspects on how $\mathrm{AO}$ should be applied in order to promote significant improvements in upper limb motor function, whether it should be applied separately or in association with physical action, in which stage of stroke, and the optimum dosage to be prescribed, among other questions. To that end, experimental studies that use this approach to promote motor learning in people with stroke must be pooled and systematized. Given that randomized clinical studies provide better evidence, the results of a number of investigations on the therapy in question must be carefully assessed, in order to assess the effectiveness and effects of this intervention. This would assist the rehabilitation therapist's decision-making when treating upper limb motor function.

\section{O B JECTIVES}

To assess whether action observation enhances motor function and upper limb motor performance and cortical activation in people with stroke.

\section{METHODS}

\section{Criteria for considering studies for this review}

\section{Types of studies}

We planned to review published and unpublished randomized controlled trials (RCTs), including those published only as abstracts. We also examined cluster-RCTs and cross-over trials with random allocation, analyzing data from the first period. We did not include quasi-randomized or non-randomized trials, but rather those where random allocation was accomplished by using a randomnumber generator, referring to a random-number table, and using sequentially-numbered opaque sealed envelopes. We accepted studies in any language and from any year. 


\section{Types of participants}

We included studies whose participants were clinically diagnosed with stroke and upper limb motor deficit. Participants were 18 years or older, of both sexes, with any degree of stroke impairment severity and at any stage of the disease.

\section{Types of interventions}

We selected studies that included the following interventions.

1. AO alone or associated with physical activity, imitation or training of functional tasks versus other therapies.

2. AO alone or associated with physical activity, imitation or training of functional tasks versus conventional physiotherapy.

3. AO alone or associated with physical activity, imitation or training of functional tasks versus placebo.

4. AO alone or associated with physical activity, imitation or training of functional tasks versus no therapy.

We considered the AO technique as the observation of another individual performing a motor action through videos or in real time. We did not include studies using mirror therapy in this review.

\section{Types of outcome measures}

We extracted the outcomes of interest from the baseline and the evaluation at the end of the intervention period (short term) and follow-up (long term). Our list of outcome measures was not exhaustive. When we found studies with other relevant outcome measures, we included them and documented these findings. Moreover, when we identified a study in which more than one measurement instrument found the same outcome, we used the one included on our list.

\section{Primary outcomes}

Upper limb motor function, measured by the following instruments: 1) arm function: Motor Assessment Scale (upper limb component); Frenchay Arm Test; Motor Activity Log; Wolf Motor Function Test; Action Research Arm Test; Fugl-Meyer Assessment; 2) hand function: Motor Assessment scale (hand component); Box and Block Test; Jebsen Test of Hand Function and Peg Test.

\section{Secondary outcomes}

1. Dependence on activities of daily living, assessed by the following instruments: Functional Independence Measure; Barthel Index; Rankin Scale.

2. Motor performance measured by kinematic analysis, highlighting the following variables: velocity and angular analysis of movement.

3. Cortical activation: we considered studies that used Functional Magnetic Resonance; Transcranial Magnetic Stimulation; Electroencephalography; and Positron Emission Tomography.

4. Quality of life, restricted participation, or both: London Handicap Scale (LHS); SF-36; EQ5D; and Stroke Impact Scale.

5. Adverse effects including pain, muscle weakness, fatigue and death.

\section{Search methods for identification of studies}

See the Cochrane Stroke Group's search methods. We searched for trials in all languages and arranged for the translation of relevant articles where necessary.

\section{Electronic searches}

We searched the Cochrane Stroke Group Trials Register (last searched 4 September 2017) and the following electronic bibliographic databases and trial registers.

1. Cochrane Central Register of Controlled Trials (CENTRAL; 2017, Issue 9) in the Cochrane Library (searched 24 October 2017; Appendix 1).

2. MEDLINE (Ovid) (from 1946 to 24 October 2017; Appendix 2).

3. Embase (Ovid) (from 1980 to 24 October 2017; Appendix 3).

4. CINAHL EBSCO (from 1982 to 24 October 2017; Appendix 4).

5. LILACS (Latin American and Caribbean Health Sciences Literature to May 2016; Appendix 5).

6. Allied and Complementary Medicine Database (AMED) (Ovid) (from 1985 to 24 October 2017; Appendix 6).

7. Physiotherapy Evidence Database (PEDro: www.pedro.org.au; searched November 2017; Appendix 7).

8. Rehabdata (www.naric.com/?q=en/REHABDATA; searched November 2017; Appendix 8).

We developed the MEDLINE search strategy with the help of the Cochrane Stroke Group Information Specialist (Appendix 2), and adapted it for the other databases (Appendix 1; Appendix 3; Appendix 4; Appendix 5; Appendix 6; Appendix 7; Appendix 8).

We searched the following trial registries for ongoing studies.

1. US National Institutes of Health Ongoing Trials Register ClinicalTrials.gov (www.clinicaltrials.gov; searched November 2017; Appendix 9).

2. Stroke Trials Registry (www.strokecenter.org/trials; searched November 2017; Appendix 10).

3. ISRCTN Registry (www.isrctn.com; searched November 2017; Appendix 11).

4. Australian New Zealand Clinical Trials Registry (www.anzctr.org.au; searched November 2017; Appendix 12).

5. World Health Organization (WHO) International Clinical Trials Registry Platform (www.who.int/ictrp/en; searched November 2017; Appendix 13).

\section{Searching other resources}

In an effort to identify further published, unpublished and ongoing trials, we:

1. screened reference lists of all relevant articles;

2. used Science Citation Index Cited Reference search for forward tracking of important articles;

3. contacted trialists, experts and researchers in our field of study;

4. handsearched journals (International Journal of Neurorehabilitation, Neurorehabilitation and Neural Repair, and Stroke) and conference proceedings (International Stroke Conference 2011 to 2017; American Society of Neurorehabilitation Annual Meeting 2014 to 2016; International Conference and Exhibition on Physical Medicine and Rehabilitation 2013 to 2016; and Physiotherapy UK 2015);

5. searched for PhD and MSc theses (using Latin American and Caribbean Health Sciences Literature: LILACS). 


\section{Data collection and analysis}

\section{Selection of studies}

Two review authors (AF and LM) independently screened the titles and abstracts of records obtained from the electronic searches and excluded those that were obviously irrelevant. We obtained the full text of the remaining records and the same two review authors selected studies for inclusion according to the predefined inclusion criteria. If any methodological question raised doubts about whether the study met the inclusion criteria, we contacted the study authors for clarification. If there was disagreement regarding the selection of studies, we attempted to reach a consensus through discussion. If this was impossible, we asked another review author (TC) to decide if the study should be included. We recorded reasons for exclusion and completed a PRISMA flowchart (Moher 2009).

\section{Data extraction and management}

The same review authors (AF and LM) were responsible for data extraction. To record these data, we used a form we created, based on the 'Cochrane Consumers and Communication Review Group Data Extraction Template', which we tested (piloted) in two studies. Where there was incomplete or unclear data, we contacted the study authors for clarification. The same two review authors (AF and LM) discussed any disagreements encountered in order to reach a consensus; and if we could not reach consensus, another review author (TC) ruled on the issue. One review author (AF) entered all extracted data into Review Manager 5 (RevMan 5) (Review Manager 2014); and another author (LM) working independently checked the data to confirm accuracy. These data refer to the following.

1. General information: title of the review, name of the review author who completed the form, and study ID.

2. Methods used: objectives, study design, instruments used, study duration, type of randomization, allocation concealment, blind assessors, inclusion and exclusion criteria, institutions or study centers involved, study site, removal and abandonment of participants, and year of the study.

3. Participants: population description, sample size, age, sex, initial upper limb impairment, severity level of stroke and type of stroke, diagnostic criteria, phase (acute, subacute, and chronic), presence of communication or cognitive impairments.

4. Intervention: therapies used in association and in comparison, type of task, number and duration of the sessions and time of the sessions, methods used in the control group, and the profession of the person that applied the therapy.

5. Results: primary and secondary outcomes for each assessment and reassessment, methods and instrumentation for assessment, timing of outcome assessment, and adverse events.

6. Notes: contact with authors (information obtained or not), article in a language other than English, study financing and noteworthy conflicts of interest of study authors.

\section{Assessment of risk of bias in included studies}

We assessed risk of bias using the 'Risk of bias' tool described in the Cochrane Handbook for Systematic Reviews of Interventions (Higgins 2011). Two review authors (AF and LM) independently assessed risk of bias and discussed disagreements and, if necessary, we asked another review author (TC) to come to a conclusion. We used a form containing the following 'Risk of bias' criteria.

1. Random sequence generation.

2. Allocation concealment.

3. Blinding of participants and personnel.

4. Blinding of outcome assessment.

5. Incomplete outcome data.

6. Selective outcome reporting.

7. Other bias.

We classified each criterion, characterizing it as high, low, or uncertain risk of bias. We inserted this information into the 'Risk of bias' table produced for each study, along with the reason for each decision. We used Table 8.5.d from the Cochrane Handbook for Systematic Reviews of Interventions, which provides criteria for making judgements regarding risk of bias in each of the seven domains of the tool (Higgins 2011). We contacted trial authors for clarification and to request missing information. We considered the risk of bias of the studies and their contribution to the treatment effect.

\section{Measures of treatment effect}

We measured treatment effect using mean difference (MD) and standardized mean difference (SMD) for the continuous outcomes, with 95\% confidence intervals (Cls). According to Higgins 2011, if studies are clinically diverse then a meta-analysis may be meaningless, and genuine differences in effects may be obscured. Often it is nonsensical to combine all included studies in a single meta-analysis: if there is a mix of comparisons of different treatments with different comparators, each combination may need to be considered separately (Higgins 2011). Then we performed a meta-analysis using RevMan 5 only if there was clinical and methodological similarity between studies, so that they could be pooled for analysis (Review Manager 2014). One review author (LB) conducted this judgement. In case of doubt, a third review author (TC) made the final decision. We based clinical similarity on population characteristics such as age range, type of stroke, stroke severity, and stage of stroke (acute, subacute and chronic). We considered similar methodology when the type of intervention and outcomes (motor function, dependence of daily living, and others), even if measured by different instruments, were repeated between studies. We used the random-effects model in our analysis.

\section{Unit of analysis issues}

\section{Cross-over trials}

We included one cross-over study, using only the first period for analysis.

\section{Cluster-randomized trials}

There were no cluster-randomized trials.

\section{Dealing with missing data}

We contacted study authors when possible to verify key study characteristics and to obtain missing numerical outcome data. When this was not possible, and the missing data were thought to introduce serious bias, we performed a sensitivity analysis to explore the impact of including such studies in the overall assessment of results. 


\section{Assessment of heterogeneity}

We assessed heterogeneity visually by observing the nonoverlapping of confidence intervals in the forest plots. Once identified, we quantified heterogeneity by the $\mathrm{I}^{2}$ statistic. When heterogeneity was caused by one or two studies with peripheral results that were in conflict with the rest of the studies, we carried out analyses with and without these studies, as part of the sensitivity analysis.

\section{Assessment of reporting biases}

If we had identified at least 10 studies, we planned to construct a funnel plot. However, there were not enough studies to do so.

\section{Data synthesis}

We conducted a meta-analysis when the studies could be combined. The review authors used the random-effects model. We planned to do an analysis of AO (alone or associated with physical practice) versus any other control (active or inactive control). When it was not possible to perform a meta-analysis, we demonstrated the results with tables and a narrative synthesis, where we presented outcomes and results or objectives, according to each treatment category.

\section{'Summary of findings' table}

We created a Summary of findings for the main comparison table using the following outcomes: upper limb motor function, motor performance, dependence for activities of daily living, cortical activation, quality of life or restricted participation, and adverse effects. We used the five GRADE considerations (study limitations, consistency of effect, imprecision, indirectness and publication bias) to assess the quality of a body of evidence as it relates to the studies contributing data to the review for the outcomes. In particular, we downgraded the quality of evidence by one level when studies exhibited high risk of bias, the total sample size was small $(n<400)$, or when heterogeneity was inexplicably high (> 50\%).Two review authors (LB and TC) independently assessed the quality of the evidence.

We used the GRADEpro Guideline Development Tool to prepare the table (GRADEpro GDT).

\section{Subgroup analysis and investigation of heterogeneity}

We planned to carry out the following subgroup analyses.

1. Age.

2. Type of stroke.

3. Time post stroke: acute (less than one month post stroke), subacute (between one and six months post stroke) and chronic (more than six months after stroke).

4. Length of treatment period or dose of treatment.

5. Type of treatment: $A O$ alone and $A O$ associated with physical practice (activity, imitation or training of functional tasks).

\section{Sensitivity analysis}

As previously explained, we performed sensitivity analyses when we suspected that missing data could introduce important bias, and also to assess heterogeneity caused by studies with peripheral results. Furthermore we planned to carry out the following sensitivity analyses, excluding studies with a high risk of bias. We considered a study as having a high risk of bias if the following criteria were not met.

1. Allocation concealment.

2. Blinding of outcome assessment.

\section{RE S U L T S}

\section{Description of studies}

See Characteristics of included studies; Characteristics of excluded studies

\section{Results of the search}

The searches of electronic databases and trial registers produced 5826 unique references for screening. After excluding non-relevant citations, we obtained the full texts of 40 papers; of these, we included 12 trials in the qualitative analysis and nine trials in the quantitative analysis of the review; Figure 1 shows the study flow diagram of the selected studies. 
Figure 1. Figure 1. Study flow diagram.

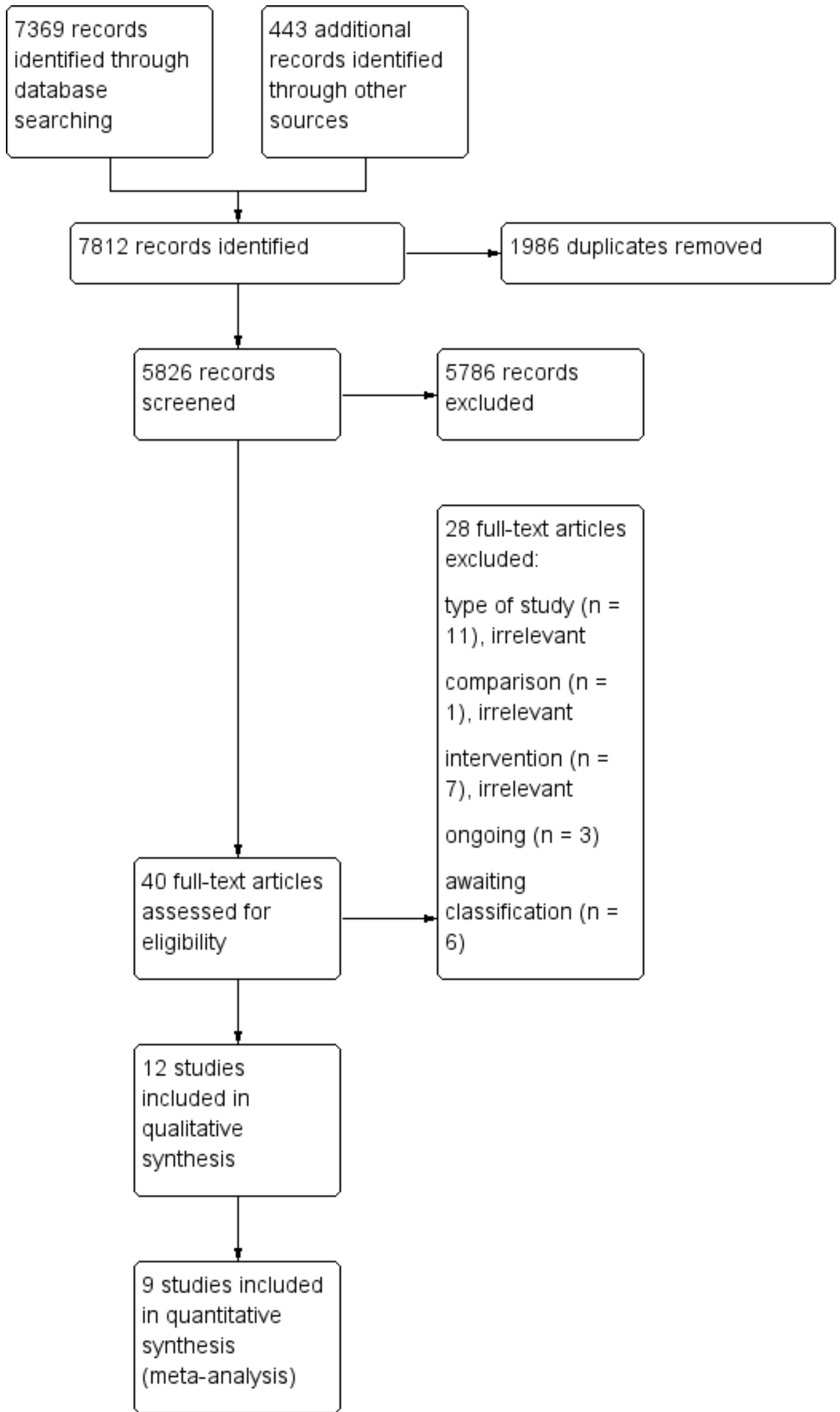




\section{Included studies}

We identified 12 randomized controlled trials (RCTs) that met the inclusion criteria (Celnik 2008; Cowles 2012; Dettmers 2014; Ertelt 2007; Franceschini 2012; Fu 2017; Harmsen 2015; Kim 2015; Kim 2016a; Kuk 2016; Lee 2013; Zhu 2015). The studies were all randomized trials and one was a cross-over randomized trial (Celnik 2008). We contacted eight authors for clarification about the methodology (how allocation concealment, random sequence generation, and blinding were performed) and results data. Four of the authors replied.

We found two publications which we judged to be two reports of the same study (see study references for Franceschini 2012); while there were some differences in reported outcome measures and numbers of participants (Franceschini 2012 paper with 102 participants; Sale 2014 paper with 67 participants), we considered that these were the same population of participants and therefore did not enter them as separate studies, since the use of duplicate data may lead to overestimating the effects of intervention. We opted to use the study report with the largest sample size, considering this to provide the most comprehensive results.

\section{Sample characteristics}

We included 12 studies involving a total of 478 stroke patients in the review. Only Kim 2015 did not characterize the sample. The mean age of the participants ranged from $56.28( \pm 9.75)$ to 77.2 $( \pm 10.4)$ years. The sample consisted of 217 men and 168 women. Five studies included participants in the acute and subacute phase of stroke (Cowles 2012; Franceschini 2012; Fu 2017; Kim 2016a; Zhu 2015); and five in the chronic phase (Celnik 2008; Ertelt 2007; Harmsen 2015; Kuk 2016; Lee 2013). Dettmers 2014 included participants in the acute, subacute and chronic phase. Initial upper limb impairment was severe (Cowles 2012, Franceschini 2012; Zhu 2015) and moderate (Ertelt 2007; Harmsen 2015; Kim 2016a), but one study included participants with mild, moderate and severe paresis (Dettmers 2014); the remaining trials did not specify initial upper limb impairment.

Six studies specified stroke etiology: two recruited only participants with ischemic stroke (Ertelt 2007; Fu 2017); and four recruited participants with ischemic and hemorrhagic stroke (Franceschini 2012; Harmsen 2015; Kim 2016a; Kuk 2016). Only in the Dettmers 2014 study was treatment applied in the participants' homes without direct researcher supervision. Five were carried out in a hospital setting or in rehabilitation centers (Cowles 2012; Ertelt 2007; Fu 2017; Kim 2016a; Zhu 2015); the others did not record treatment location.

\section{Interventions}

The following comparisons were used for the trials (Table 1).

Participants in only five trials did not undergo physiotherapy or occupational therapy in addition to the conduct proposed for the groups (Celnik 2008; Ertelt 2007; Harmsen 2015; Kuk 2016; Lee 2013). In all the studies AO was followed by some type of physical activity, largely functional tasks. Most of the investigations used variable practice, increasing the complexity of the tasks over the course of training or when the participant demonstrated ease in carrying out the action. Constant practice of a motor activity was observed in two studies, one that trained upper limb reach and the other the water-drinking task (Harmsen 2015; Lee 2013). In another study, after the observation, the execution of motor tasks was carrying wooden blocks from one box to another, similar to Box and Block Test (Kuk 2016).

In one study one of the groups merely observed the action while imagining performing the task observed (Lee 2013). In another study, the individuals did not undergo functional task training, but did perform thumb movements. Furthermore the movements were carried out simultaneously to observation and considered congruent when performed in the same direction as the observed movement, and incongruent when movement was in the opposite direction to that observed (Celnik 2008). Kim 2015 did not clearly explain whether the individuals performed the observed task after AO. However this likely occurred, since the study authors reported the experimental group as having undergone a training program ("purposeful action observation training program"), which can be understood as being some type of physical activity after the observed activity.

All the trials used video sequences to apply AO therapy except Cowles 2012, which used real demonstrations of the task prescribed by the therapist, and the Kim 2015 investigation, which did not report how therapy was applied. Four studies used firstperson perspective in applying AO (Celnik 2008; Cowles 2012; Franceschini 2012; Harmsen 2015), and three used third-person perspective (Dettmers 2014; Fu 2017; Lee 2013). One study did not specify the perspective used in AO (Kim 2015), and the others reported having used two (Kuk 2016), and three (Ertelt 2007; Kim 2016a; Zhu 2015), different perspectives.

Three studies assessed the short-term effects of $\mathrm{AO}$, with assessment and reassessment on the same day (Celnik 2008; Harmsen 2015; Kuk 2016). Four studies assessed the effects after conclusion of therapy via follow-up at one week (Lee 2013), two months (Ertelt 2007), four to five months (Franceschini 2012), and six months (Dettmers 2014). The Dettmers 2014 and Ertelt 2007 studies conducted follow-up only for the experimental group.

Training varied between one day and eight weeks of therapy, with 10 to 90 minutes per session. Total treatment duration was 20 minutes in Kuk 2016, 30 minutes in Celnik 2008 and Harmsen 2015, 150 minutes in Lee 2013, 600 minutes in Franceschini 2012, 800 minutes in Kim 2016a, 900 minutes in Kim 2015 and Cowles 2012, 960 minutes in Fu 2017, 1440 minutes in Zhu 2015, 1620 minutes in Ertelt 2007, and 2520 minutes in Dettmers 2014. The protocol used in most of the studies divided the functional tasks into smaller parts and provided between one and six minutes of observation for each motor sequence, followed by two to six minutes of practice for the action observed. Other details regarding the intervention are presented in Table 2.

\section{Outcomes}

In relation to the outcomes used, eight trials included upper limb motor function (Cowles 2012; Dettmers 2014; Ertelt 2007; Franceschini 2012; Fu 2017; Kim 2015; Kim 2016a; Zhu 2015); and only four exhibited functional dependence for activities of daily living (ADL) as an additional outcome (Franceschini 2012; Fu 2017; Kim 2016a; Zhu 2015). Motor performance was assessed in three studies involving several variables (Celnik 2008; Harmsen 2015; Lee 2013). Cortical activation was observed in four studies, using transcranial magnetic stimulation (TMS) (Celnik 2008; Fu 2017), 
functional magnetic resonance imaging (fMRI) (Ertelt 2007), and electroencephalography (EEG) (Kuk 2016).

Two studies included quality of life as an outcome (Dettmers 2014; Ertelt 2007); one had adverse events, attention level, and fatigue as outcomes (Celnik 2008); while another monitored pain in the experimental group, but without quantifying it (Cowles 2013).

A number of instruments were used to quantify primary and secondary outcomes. With respect to the primary outcome (upper limb motor function), subdivided into the arm and hand, the following were used for the arm: Action Research Arm Test (ARAT) (Cowles 2012); Wolf Motor Function Test (WMFT) (Dettmers 2014; Ertelt 2007; Fu 2017; Kim 2015); Motor Activity Log (MAL) (Dettmers 2014); Frenchay Arm Test (FAT) (Ertelt 2007; Franceschini 2012); and the Fugl-Meyer Test (FM) (Franceschini 2012; Fu 2017; Kim 2016a; Zhu 2015). The motor function outcome of the hand was assessed by the Nine-Hole Peg Test (NHPT) (Dettmers 2014), and Box and Block test (BBT) (Franceschini 2012; Kuk 2016).

All the secondary outcomes specified in this review were present in the included studies. The following instruments were used to measure dependence on activities of daily living: Functional Independence Measure (FIM) motor items (Franceschini 2012), and the Modified Barthel Index (MBI)/Barthel Index (BI) (Fu 2017; Kim 2016a; Zhu 2015). Motor performance, measured by kinematic analysis and an accelerometer, was determined in the Celnik 2008 study, which considered angular difference, angular dispersion, and peak acceleration as measures. Harmsen 2015 also used an accelerometer to measure motor performance considering reaching time, whereas Kim 2015 considered average velocity, trajectory ratio, and motion angle, measured by a 3 dimensional motion analysis system. In Lee 2013, the number of times the drinking task was performed in one minute was measured. Heterogeneity of the variables used to characterize motor performance precluded combining them in analysis and comparing them.

Cortical activation was determined by motor-evoked potential (MEP) amplitudes, latency and center-motion conduction time provoked by TMS (Celnik 2008; Fu 2017). Ertelt 2007 used fMRI to analyze the effects of action observation therapy. Kuk 2016 used EEG for investigating the mirror neuron system activation during AO. The Stroke Impact Scale (SIS) was applied to measure quality of life (Dettmers 2014; Ertelt 2007).

Adverse effect was quantified in one of the trials using the visual analogue scale, which focused on the level of attention and fatigue during the interventions (Celnik 2008). Other adverse effects, such as upper limb pain (overuse syndrome), were monitored for verbal or behavioral manifestations (e.g. grimacing, postural guarding), and for a decrease of at least two measurement levels in the Motricity Index (MI), the scale that quantifies muscle weakness (Cowles 2012).

\section{Excluded studies}

We excluded 19 studies for various reasons. Five are waiting to be classified, and three are ongoing.

\section{Risk of bias in included studies}

Two authors independently assessed the methodological quality of the included trials using the 'Risk of bias' tool: see Characteristics of included studies, Risk of bias summary (Figure 2), and Risk of bias graph (Figure 3). Not all the investigations followed CONSORT recommendations, a guideline for reporting randomized trials. For this reason, we emailed the authors for clarification in the event of questions about the methodology of the trial. 
Figure 2. Figure 2. Risk of bias summary: review authors' judgements about each risk of bias item for each included study.

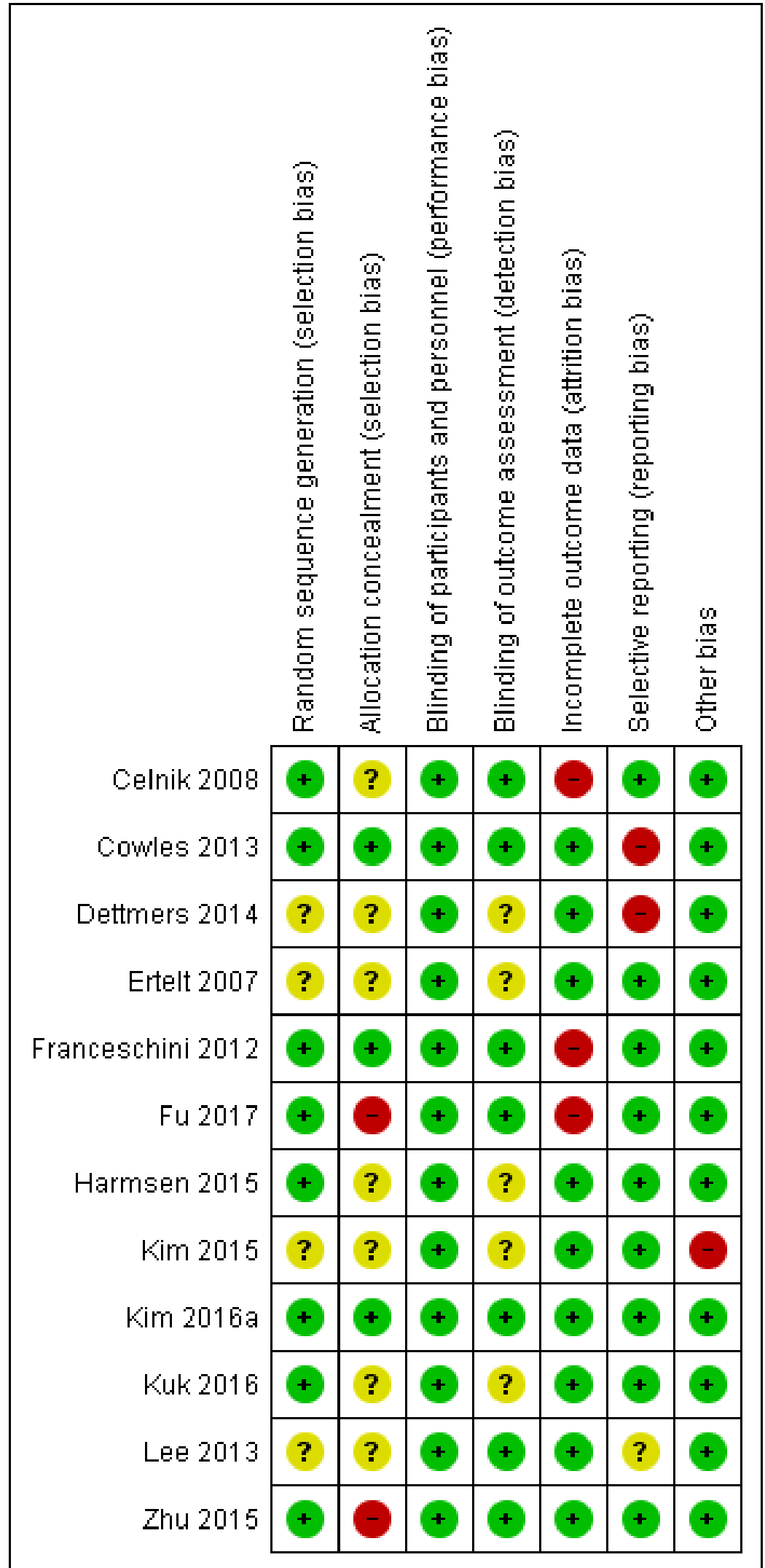


Figure 3. Figure 3 Risk of bias graph: review authors' judgements about each risk of bias item presented as percentages across all included studies.

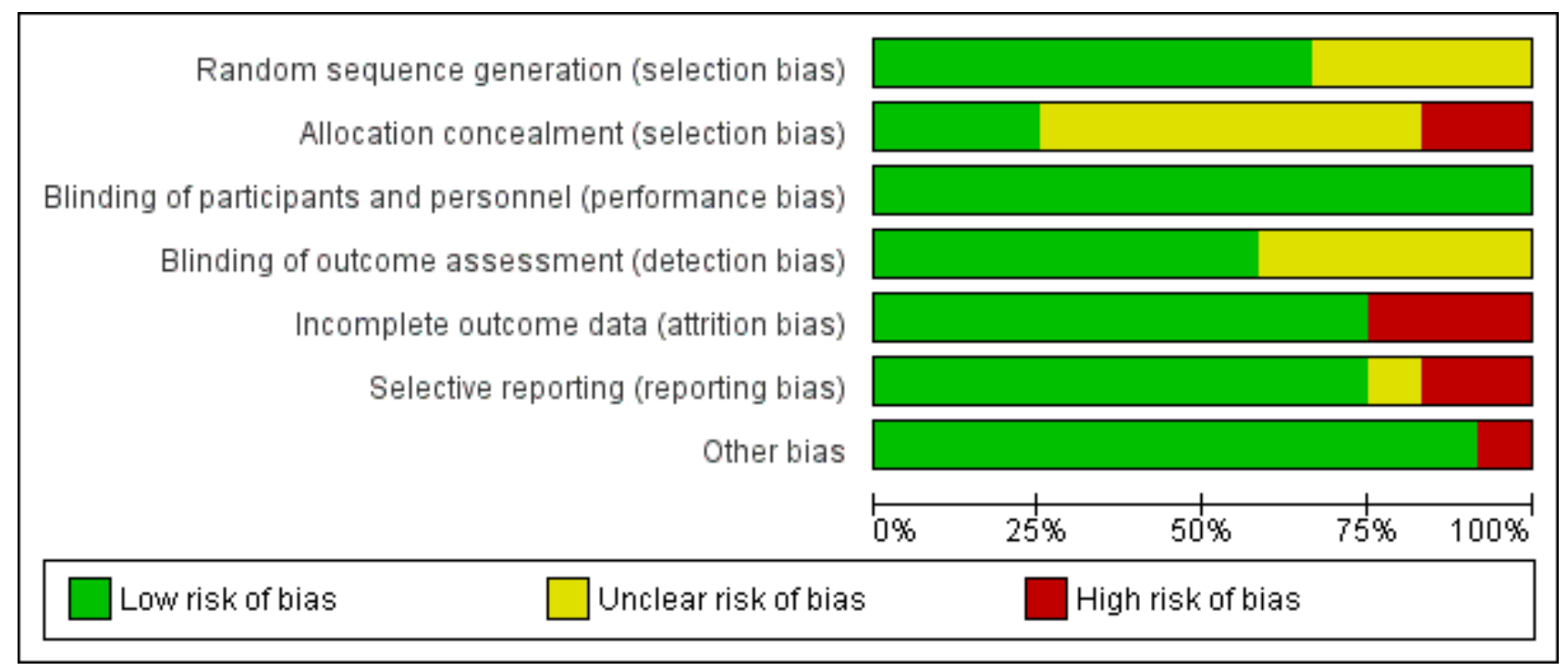

\section{Allocation}

We judged random sequence generation as adequate in eight trials (Celnik 2008; Cowles 2013; Franceschini 2012; Fu 2017; Harmsen 2015; Kim 2016a; Kuk 2016; Zhu 2015), while the other four exhibited unclear risk of bias for this criterion (Dettmers 2014; Ertelt 2007; Kim 2015; Lee 2013).

Three of the 12 studies appropriately described the allocation concealment of participants to groups and we deemed these to be at low risk (Cowles 2013; Franceschini 2012; Kim 2016a); we considered only two studies at high risk (Fu 2017; Zhu 2015).

\section{Blinding}

No trials were able to blind participants or personnel. However, this type of blinding is impossible to apply with this therapy, and since therapist and participant were aware of the treatment they were performing, we considered there to be low potential to negatively influence the effect of the therapy and, therefore, judged them to be at low risk of bias.

Seven studies reported blinding the outcome assessor (Celnik 2008; Cowles 2013; Franceschini 2012; Fu 2017; Kim 2016a; Lee 2013; Zhu 2015); we considered the other trials to be at unclear risk of bias.

\section{Incomplete outcome data}

We deemed nine trials to have low risk of bias in relation to this criterion (Cowles 2013; Dettmers 2014; Ertelt 2007; Harmsen 2015; Kim 2015; Kim 2016a; Kuk 2016; Lee 2013; Zhu 2015), and considered three at high risk due to an imbalance in the number of participants in each group considered for analysis as well as the amount of losses in the sample (Celnik 2008; Franceschini 2012; Fu 2017).

\section{Selective reporting}

Two studies exhibited high risk of selective reporting (Cowles 2013; Dettmers 2014), while one was unclear (Lee 2013); and we considered the remaining nine at low risk of bias (two were recorded on trial registry sites).

\section{Other potential sources of bias}

Eleven studies were free of other potential sources of bias and we considered these to be at low risk. We considered one study to be at high risk of bias (Kim 2015), related to the lack of clarity about outcome assessment time (Figure 2).

\section{Effects of interventions}

See: Summary of findings for the main comparison Action observation therapy versus control: effect on upper limb function post-treatment for upper limb rehabilitation after stroke

See: Summary of findings for the main comparison

We could use data from nine studies in meta-analysis (Cowles 2013; Dettmers 2014; Ertelt 2007; Fu 2017; Kim 2015; Kim 2016a; Kuk 2016; Franceschini 2012; Zhu 2015). The others evaluated parameters from the same outcome that were not comparable to each other in meta-analysis (Celnik 2008; Harmsen 2015; Lee 2013).

\section{Action observation therapy versus control: effect on arm function}

\subsection{Arm function}

Eight studies (314 participants) provided post-intervention assessment data for arm motor function (Cowles 2013; Dettmers 2014; Ertelt 2007; Fu 2017; Kim 2015; Kim 2016a; Franceschini 2012; Zhu 2015). Dettmers 2014 used two scales to assess upper limb motor function: the MAL and the WMFT. We could use only the WMFT data (the only data provided by the study authors) for metaanalysis. In the study by Ertelt 2007, the WMFT scale used the measure of time, such that the shorter the time the better the motor function, explaining the negative value in the analysis. We opted to use WMFT data instead of the FAT scale because the WMFT assesses upper limb motor function using 15 functional tasks (measuring the time to perform activities), a higher number than the FAT scale, 
which contains only five tasks. The latter also displays a lower range of scores (total score varies from 0 to 5 ) than the WMFT, which allows a maximum time of two minutes per task (score ranges from 0 to 30).

The data used for the meta-analysis of this outcome refer to the ARAT (Cowles 2013), WMFT (Kim 2015), and FMA instruments (Franceschini 2012; Fu 2017; Kim 2016a; Zhu 2015).

In the meta-analysis, the impact of $\mathrm{AO}$ on arm function showed a small significant effect (SMD $0.36,95 \% \mathrm{Cl} 0.13$ to 0.60 ). We observed no statistical heterogeneity $\left(\mathrm{I}^{2}=6 \%\right.$ ) (low-quality evidence) (Analysis 1.1).

\subsection{Subgroup analysis: age}

We analyzed the subgroups considering the mean age of the study participants. We compared studies in which the mean age was more than 60 years with those in which participants were younger than 60 years. The intergroup difference was not significant $\left(\mathrm{I}^{2}=0, \mathrm{df}=1\right.$, $P$ value $=0.55)$ (Analysis 1.2)

\subsection{Subgroup analysis: type of stroke}

We compared trials in which the sample consisted only of participants diagnosed with ischemic stroke to others with samples of participants with either ischemic or hemorrhagic stroke, and with a group containing studies in which the study authors did not specify the type of stroke. The intergroup difference was not significant $\left(I^{2}=2.9 \%, d f=2, P\right.$ value $\left.=0.36\right)$ (Analysis 1.3$)$.

\subsection{Subgroup analysis: post-stroke time}

We conducted subgroup analysis between trials that recruited participants in the acute, subacute, and chronic phases and those with any phase of the disease. There was no significant intergroup difference $\left(I^{2}=0, d f=2, P\right.$ value $\left.=0.79\right)$ (Analysis 1.4) .

\subsection{Subgroup analysis: treatment dose}

We compared studies that provided more and less than 1000 minutes of therapy, and observed no significant intergroup difference $\left(I^{2}=0, d f=1, P\right.$ value $\left.=0.83\right)$ (Analysis 1.5) .

\subsection{Subgroup analysis: type of control group}

With respect to the groups used to compare AO therapy, seven trials compared $\mathrm{AO}$ with placebo - that is, the participants watched images of geometric figures and texts, among others. Two studies used conventional physiotherapy for comparison purposes (Cowles 2012; Zhu 2015), two compared AO only with movements similar to those performed in the experimental group (Celnik 2008; Lee 2013), and two used no specific treatment (Dettmers 2014; Lee 2013). Thus we decided to conduct subgroup analysis, comparing the types of control groups used. The intergroup difference was not significant $\left(I^{2}=25.8 \%, d f=2, P\right.$ value $\left.=0.26\right)$ (Analysis 1.6) .

\subsection{Subgroup analysis: duration of observation}

We compared studies that provided more than three minutes of observation for each motor action with those that provided less than three minutes. We observed no significant intergroup difference $\left(I^{2}=67.8, d f=1, P\right.$ value $\left.=0.08\right)$ (Analysis 1.7$)$.

\subsection{Arm function - sensitivity analyses: without high ROB for allocation concealment}

Two studies showed a high risk of bias for arm function, considering the allocation concealment criterion (Fu 2017; Zhu 2015), while none exhibited high risk of bias for blinding of outcome assessment. Thus we performed sensitivity analysis, considering this bias, as proposed in the protocol. The effect increased slightly (SMD 0.38, 95\% Cl 0.03 to 0.73) (Analysis 1.8).

\subsection{Arm function - sensitivity analysis: without high ROB for incomplete outcome data}

Additionally, three studies exhibited high risk of bias for incomplete outcome data (Celnik 2008; Fu 2017; Franceschini 2012), two for selective reporting (Cowles 2013; Dettmers 2014), and one for other bias (Kim 2015). Thus we carried out sensitivity analysis to determine whether the effect of AO was influenced by these biases (including allocation concealment), and the effect increased (SMD $1.08,95 \% \mathrm{Cl} 0.39$ to 1.78 ) (Analysis 1.9).

\subsection{Arm function - sensitivity analysis: home-based action observation training (video therapy)}

We conducted another sensitivity analysis excluding only Dettmers 2014, since it used a different methodology. In this study, treatment occurred at the participant's home (home-based action observation training with video therapy), without researcher supervision. The small significant effect demonstrated that $A O$ therapy intervention was more effective than in the control group (SMD $0.38,95 \% \mathrm{Cl} 0.10$ to 0.66 ). There was low statistical heterogeneity (Analysis 1.10).

\subsection{Arm function - sensitivity analysis: real demonstration}

Cowles 2013 was the only study in which action observation was demonstrated live and not via video presentation. We conducted sensitivity analysis excluding this study in order to observe whether there was a change in effect size, noting a slight increase from 0.36 to 0.39 (SMD $0.39,95 \% \mathrm{Cl} 0.13$ to 0.66 ) (Analysis 1.11).

\subsection{Arm function - follow-up}

Three studies assessed the lasting effects of therapy on upper limb function at follow-up (Dettmers 2014; Ertelt 2007; Franceschini 2012); two assessed only the experimental group (Dettmers 2014; Ertelt 2007). These factors precluded a meta-analysis.

In the Dettmers 2014 study, follow-up was carried out six months after the end of treatment using questionnaires (MAL and WMFT) only for the group submitted to action observation therapy, employing video and the placebo group. Participants from the conventional care group could not be included in the follow-up analysis. Fourteen of 18 participants from the video group $(\mathrm{AO})$ and 11 of 18 from the text group maintained their gains in quality and extent of movement, as measured by the MAL. The study author did not record WMFT data in the follow-up.

Ertelt 2007 applied two scales in the follow-up: WMFT and FAT. A comparison between the results of these clinical scales at the end of treatment and at follow-up in a subgroup of seven participants (experimental) showed no statistically significant decline in clinical status ( $P$ value $<0.7$ ).

Franceschini 2012 conducted follow-up four to five months after treatment (T2). Despite improvement in the groups over time, no 
significant difference was found between the study groups in terms of FMA in Franceschini 2012.

\section{Action observation therapy versus control: effect on hand function}

\subsection{Hand function}

Four studies assessed motor hand function after intervention (Dettmers 2014; Franceschini 2012; Kim 2016a; Kuk 2016), but Dettmers 2014 presented the data in graphs, making it difficult to establish the average and standard deviation and, even after contacting the author, we could not obtain the data related to this outcome.

We pooled the data presented by the three study authors who used BBT to assess this outcome (Franceschini 2012; Kim 2016a; Kuk 2016; 132 participants). The impact of $A O$ on hand function showed a large significant effect (MD 2.90, 95\% Cl 1.13 to 4.66) with moderate-quality evidence. We observed no statistical heterogeneity $\left(I^{2}=0 \%\right)$ (Analysis 2.1$)$.

\subsection{Subgroup analysis: age}

In the subgroup analysis considering age, there was no statistical intergroup difference $\left(I^{2}=0 \%, d f=1, P\right.$ value $\left.=0.46\right)$ (Analysis 2.2).

\subsection{Subgroup analysis: time post stroke}

In the subgroup analysis of the effect of therapy on hand function, there was no significant intergroup difference in disease phases (acute/subacute and chronic phase) $\left(\mathrm{I}^{2}=0 \%, \mathrm{df}=1, \mathrm{P}\right.$ value $\left.=0.74\right)$ (Analysis 2.3).

\subsection{Subgroup analysis: duration of observation}

With respect to duration of the observation, there was no statistically significant difference between subgroups $\left(I^{2}=67.8 \%\right.$, df $=1, \mathrm{P}$ value $=0.08)($ Analysis 2.4) .

\subsection{Hand function - sensitivity analysis: without high ROB for incomplete outcome data}

We conducted sensitivity analysis for hand function, disregarding Franceschini 2012, which showed high risk of bias for incomplete outcome data. The effect of therapy remained significant (MD 2.73, $95 \% \mathrm{Cl} 0.91$ to 4.55 ) (Analysis 2.5).

\subsection{Hand function - follow-up}

The only study that conducted follow-up and provided data for this outcome was Franceschini 2012, which showed a statistically significant difference between initial assessment of hand function (T0) and at follow-up (T2) in the experimental group ( $P$ value $=0.01$ ) The improvement in motor function achieved by the $\mathrm{AO}$ group at the end of the experiment (T1) persisted in the follow-up four to five months later $(P$ value $=0.76)$.

\section{Action observation therapy versus control: effect on ADL}

\subsection{Dependence on activities of daily living}

Four studies (226 participants) presented "dependence in activities of daily living" as the outcome using different scales: FIM (Franceschini 2012); MBI (Fu 2017; Kim 2016a); and BI (Zhu 2015). There was a large significant effect: SMD $0.86,95 \% \mathrm{Cl} 0.11$ to 1.61 , but high heterogeneity $\left(I^{2}=84 \%\right)$ (low-quality evidence) (Analysis 3.1).

\subsection{Sensitivity analysis: without high ROB for allocation concealment}

We performed sensitivity analysis of the dependence in activities of daily living outcome, excluding studies with a high risk for allocation concealment (Fu 2017; Zhu 2015). The effect of the therapy increased significantly (SMD $7.39,95 \% \mathrm{Cl} 5.02$ to 9.76) (Analysis 3.2).

\subsection{Sensitivity analysis: without high ROB for incomplete outcome data}

Two studies that assessed this outcome exhibited high risk of bias for incomplete outcome data (Franceschini 2012; Fu 2017), We carried out sensitivity analysis and observed that the effect of the therapy increased significantly (SMD $7.78,95 \% \mathrm{Cl} 5.41$ to 10.15) (Analysis 3.3).

\subsection{Sensitivity analysis: removing peripheral studies}

In the meta-analysis related to this outcome, the confidence intervals did not overlap on the forest plots, which were quantified, showing considerable heterogeneity $\left(\mathrm{I}^{2}=84 \%\right)$. After removing the peripheral studies, heterogeneity decreased; however, the effect became non-significant (SMD 3.78, $95 \% \mathrm{Cl}-1.55$ to 9.11) (Analysis 3.4).

\subsection{Dependence on activities of daily living - follow-up}

Only Franceschini 2012 conducted a follow-up for this outcome. Although both groups improved, we detected no significant intergroup difference.

\section{Action observation therapy versus control: effect on motor performance}

Four studies assessed motor performance (91 participants), but the fact that different kinematic variables were used precluded comparing them in analysis. One of the these used the TMS protocol, which tests the formation of motor memories, to determine the effects of physical therapy (PT) alone and in combination with $\mathrm{AO}$ in two different forms: congruent (PT + congruent $\mathrm{AO}$ ), where participants had to perform trained thumb movements simultaneously with the observed thumb movements, both in the same direction; and incongruent (PT + incongruent $\mathrm{AO})$, to reflect the fact that trained and observed movements were in approximately opposite directions. Motor training performance consistency was monitored in all the sessions by measuring three kinematic parameters: 1) the angular difference between TMSevoked movement directions at baseline and during training; 2) the angular dispersion of training movement directions; and 3) the magnitude of the first peak acceleration of the trained movements (Celnik 2008). Another study assessed motor performance using the variable 'movement time' to investigate whether a mirror therapybased $\mathrm{AO}$ protocol contributes to learning a simple upper arm motor task after stroke (Harmsen 2015).

In Kim 2015, average velocity, trajectory ratio, and motion angle were the variables selected to measure the kinematic patterns of the upper limb before and after therapy. There was a statistically significant improvement between pre- and post-intervention average velocity and trajectory ratio values in the experimental group. However, the intergroup difference was not statistically significant $(P$ value $>0.05)$. 
One study did not assess the kinematics of motor performance, but rather the number of times the drinking task was performed in one minute (Lee 2013). The AO group watched a video of the task, the physical practice group performed the action, the combined group watched a video of the task and performed the action, and the control group performed neither action observation nor physical execution.

\section{Action observation therapy versus control: effect on cortical activation}

Three studies evaluated cortical activation after AO therapy. Ertelt 2007 applied fMRI to analyze the effects of AO therapy on motor system reorganization, using an independent sensorimotor task consisting of handling an object. When using the affected hand to handle objects, the control group, which had undergone placebo observation followed by hand and arm movements, showed practically no change in brain activity between pre-test and post-test treatment. By contrast, the experimental group exhibited numerous and significant differences between preand post-treatment brain activations. Activation was observed in large components of the sensorimotor network, including the supplementary motor area, bilateral ventral premotor cortex, bilateral superior and inferior parietal areas, and bilateral cerebellum.

Changes in brain activation were greater in the experimental than in the control groups, showing a significant increase in activation in the non-affected hemisphere in the ventral premotor cortex, the SMA, insula and superior temporal gyrus, and in the affected hemisphere in the ventral premotor cortex, supramarginal gyrus, and superior temporal gyrus.

Celnik 2008 measured motor cortical excitability, recording the MEP amplitudes of muscles mediating movements in the trained (MEP agonist) and baseline (MEP antagonist) directions, as well as the post/pre (baseline) MEP amplitude ratio (MEP post/preintervention) to provide information on the effects of each intervention on the relative weight of corticospinal influence on agonist and antagonist muscles for the TMS-evoked movement directions. At post-intervention, in the PT + congruent AO session, MEP agonist showed a slight increase while MEP antagonist decreased. This difference in excitability is reflected by a statistically significant change in the MEP post/pre-intervention ratio ( $P$ value $<0.02$ ). Thus the study authors found that observing another participant performing training motions in the same direction and in phase with physically trained individuals enhanced motor memory formation compared with physical training alone.

One study used the evaluation of MEP, which was determined using a transcranial magnetic stimulator (Fu 2017). The study author calculated latency, amplitude, and center-motion conduction time (СMCT: difference between cortex and spinal latency), finding an increase in amplitude and decrease in latency and CMCT. These changes were statistically higher in the experimental than the control group.

The MEP results reported by Celnik 2008 and Fu 2017 could not be pooled in meta-analysis, because data from the first period of the cross-over were not available for this outcome in the Celnik 2008 study.
Kuk 2016 analyzed cortical activation using EEG data from poststroke participants, only in the experimental group, in each session of AO, while they were watching the video clip. Sequential executions of the observed action after AO therapy were not EEGmonitored. The results revealed the selective activation of the mirror neuron system, with the middle frontal gyrus less active.

\section{Action observation therapy versus control: effect on quality of} life

Quality of life was assessed in two studies (16 participants). We were unable to obtain Stroke Impact Scale (SIS) data (mean and standard deviation) from the Dettmers 2014 study in order to carry out analysis. However, the video-group (video AO) improved on the SIS ( $P$ value $<0.044)$ from pre- to post-treatment.

In the Ertelt 2007 study, comparison of subjective self-assessment test scores before and after treatment (SIS) demonstrated significant differences only in the experimental group ( $P$ value $<0.0125$ ). Intergroup (treatment and control group) comparison of SIS scores showed significant differences $(P$ value $=0.0025)$. Experimental group participants improved by 277.4 points (SD \pm 177), whereas controls raised their SIS score by 252.5 points (SD \pm 25.33).

\subsection{Quality of life - follow-up}

In the Dettmers 2014 study, 14 of 18 participants from the video group and 11 of 18 from the text group completed the questionnaires after six months. Subjective self-assessment (SIS) improved further in the video group, but not in the text group ( $P$ value not reported).

Ertelt 2007 assessed the long-term effects of AO therapy only in the experimental group (seven participants). Follow-up was conducted eight weeks after the intervention and comparisons between the results of SIS assessment at the end of treatment and at followup in the subgroup of seven participants showed no statistically significant decline in clinical status ( $P$ value $<0.7)$.

\section{Action observation therapy versus control: effect on adverse effects}

This outcome was investigated in two studies (16 participants). The visual analogue scale (VAS) was used in the Celnik 2008 trial to measure attention and fatigue level, with scores varying from 1 to 7 , where 1 equaled the worst response and 7 equaled the best response (least fatigue or best attention). The author reported that attention and fatigue level did not influence the findings, since there was no significant difference between attention ( $P$ value $=0.17)$ or fatigue scores $(P$ value $=0.40)$ during the different intervention sessions. One participant did not conclude the experimental protocol due to a headache caused by TMS, not by the therapy.

In the Cowles 2012 study, participants were monitored during the experiment in order to detect the overuse syndrome. To that end participant accounts of upper limb pain - either verbal or behavioral, (e.g. grimacing, postural guarding) - and decreases of at least two measurement levels in the MI were recorded. No adverse events occurred in either group. With respect to MI, both groups ( $A O$ followed by PP and conventional PT) improved their score between baseline and outcome, but the intergroup difference was not significant. 


\section{DISCUSSION}

\section{Summary of main results}

The aim of this review was to evaluate the effect of action observation (AO) therapy on motor function and upper limb motor performance as well as cortical activation in patients with stroke. We included 12 trials with 478 participants in this review. Overall, the quality of the evidence for outcomes was moderate to very low. The main results are presented in Summary of findings for the main comparison.

Overall, the use of $A O$ increased the arm function of individuals after stroke compared with other physiotherapy interventions or placebo. Thus, considering the quality of the GRADE evidence, AO may improve the arm motor function of patients with stroke (low quality).

The gain in arm motor function at the end of $\mathrm{AO}$ therapy persisted at follow-up.

We observed no difference in therapy effect in the upper limb, considering age, type of stroke, post-stroke time, and treatment dose, type of control group, and duration of observation.

Although the effect of $\mathrm{OA}$ on hand function was considered large (MD 2.90, 95\% Cl 1.13 to 4.66), it does not appear to be clinically relevant, given that the minimum detectable difference was six blocks per minute for the BBT (Chen 2009). Furthermore, the evidence was considered moderate according to GRADE: that is, further research is likely to have an important impact on our confidence in the effect estimate, which may change.

We were unable to pool the results of motor performance, cortical activation, quality of life, or adverse effects.

Only four studies assessed dependence in activities of daily living, and analysis demonstrated a significant effect, albeit with substantial heterogeneity. According to GRADE, we considered the quality of the evidence that $A O$ may improve this outcome in stroke patients to be low.

Despite being the outcome of a number of studies, the variables selected to measure motor performance were different between trials, causing significant heterogeneity, and precluding intergroup comparison. An increase in the magnitude of the first acceleration peak for the trained movements, decline in movement time, and rise in the number of drinking tasks completed in one minute were the motor performance gains obtained by the AO group. The following variables did not improve in the experimental intervention: average velocity, trajectory ratio, motion angle, angular difference, and angular dispersion. Motor performance, as measured by the number of drinking tasks completed in one minute, was sustained one week after intervention. Despite the positive findings for some of the variables, there is not enough evidence to confirm that $\mathrm{AO}$ therapy has an effect on motor performance.

With respect to cortical activation and changes in the nervous system, one study demonstrated that the motor improvement in the participants that underwent $\mathrm{AO}$ therapy was favored by reactivation of motor areas containing the action observation/ action execution matching system. Another concluded that AO therapy could improve motor nerve excitability and another found that $A O$ enhanced motor memory formation. The last study demonstrated that $\mathrm{AO}$ therapy might alter cortical activation patterns.

Two studies assessed quality of life using a subjective scale, but could not be pooled in the meta-analysis to observe the combined effect of the therapy. However both studies obtained better results for quality of life after the intervention. Likewise only two studies considered adverse effects, which could not be pooled in the metaanalysis. Nevertheless these studies showed no significant adverse effect of $\mathrm{AO}$.

\section{Overall completeness and applicability of evidence}

We found few studies that tested the effectiveness of $A O$ using randomized controlled clinical trials (12 studies); furthermore the studies had a relatively small sample size. Since none of the studies included only participants with hemorrhagic stroke, we were unable to form a subgroup with only this population of participants. The mean age of the participants varied widely.

The most common outcome was arm motor function, and few studies assessed other important outcomes for people with stroke, such as hand motor function, dependence in activities of daily living, quality of life, and adverse effects. Although cortical activation is not an outcome directly expressed by patients, it is particularly important to researchers and clinicians since it provides evidence that motor gains result from better brain activation. There is also a need to better monitor adverse effects such as pain, fatigue, and attention deficit, in order to determine the effectiveness of AO therapy - that is, whether the benefits outweigh any adverse effect.

Nearly all the studies used physical exercise after the observation of a task. This restricts the applicability of therapy for people with some degree of motricity in the affected upper limb; and although some trials included participants in the acute phase, it was not possible to observe the effect of AO therapy on individuals who were unable to perform the movements. Therefore it would be advisable to test whether applying AO alone, with no physical activity, would show any benefit for totally paralyzed patients. Moreover the outcome of $\mathrm{AO}$ alone versus $\mathrm{AO}$ followed by physical activity should be compared, in order to determine whether the gains derive only from physical activity that occurs after observation.

Despite confirming that $\mathrm{AO}$ can improve the efficacy and effectiveness of arm motor function based on the results of this review, researchers did not quantify the costs of its application. Based on the methodology used, AO requires low-cost instruments (camera, television, or computer) and is easily accessed by therapists. There is, however, still no evidence proving its effectiveness.

\section{Quality of the evidence}

The number of studies (only nine in the meta-analysis) and sample sizes included in this review were small. Some trials showed a high risk of bias for allocation concealment, incomplete outcome data, selective reporting, and other types of bias related to lack of information. We observed unclear risk of bias in studies with important criteria such as randomization, allocation concealment, and blinded researchers, resulting from poor reporting and lack of clarification from the authors. The effect estimate was also 
inaccurate. Nevertheless, most of the results were consistent (low heterogeneity) and exhibited good external validity. According to the GRADE system, the quality of evidence remains 'low' or 'very low' for most of the outcomes, except for hand function, which showed moderate-quality evidence (Summary of findings for the main comparison)

\section{Potential biases in the review process}

Two authors independently reviewed the studies, obtaining and extracting data, with a third review author available to resolve disagreements as needed, thereby minimizing bias. We are confident that we have identified all relevant studies; however there is a small possibility that we failed to identify additional (published or unpublished) papers. Moreover some analyses could not determine the effect of $\mathrm{AO}$ on a number of outcomes (quality of life and adverse effects), since not all study authors could provide the required data. Another limitation of this review is that some of the studies had methodological shortcomings, such as allocation concealment, incomplete outcome data, and selective reporting. These biases can lead to underestimation or overestimation of the true intervention effect, according to the Cochrane Handbook for Systematic Reviews of Interventions (Higgins 2011).

\section{Agreements and disagreements with other studies or reviews}

We found only one systematic review on AO therapy: Sarasso 2015 analyzed studies investigating the effects of $A O$ therapy on different motor abilities in diseases such as stroke (upper and lower limb), Parkinson's disease, cerebral palsy, and post-surgical orthopedic conditions, in 663 people (20 RCTs). This search included articles up to July 2015, while our review involved studies up to September 2017. Three key terms (action observation, rehabilitation, and motor function) were used to generate a list of search terms, which were combined into a search strategy adapted to each database. Six studies involving stroke patients with upper limb impairment were also included in our review (Cowles 2012; Ertelt 2007; Franceschini 2012; Harmsen 2015; Kim 2015; Lee 2013). We believe that due to our more recent and comprehensive search strategy, we were able to identify a larger number of studies in which AO was used to rehabilitate the upper limb of people with stroke. The conclusion of the Sarasso 2015 review suggested the efficacy of AO therapy in improving motor functions both in neurological and orthopedic diseases. Despite not having conducted statistical analysis, the author concluded there was an improvement in the motor function of patients, corroborating our findings.

\section{AUTHORS' CONCLUSIONS}

\section{Implications for practice}

The results of this review show that AO may improve the arm motor function of post-stroke patients when compared with any control group. AO therapy improves hand motor function, but the evidence showed that the improvements were not clinically relevant.
There is no convincing evidence that the intervention affects dependence in activities of daily living, motor performance, cortical activation, or quality of life after stroke. There is little evidence in the literature of any harm or side effects.

The quality of GRADE-based evidence in this review varied from low to moderate, due to the high risk of bias and small sample sizes. This means that our confidence in the estimated effect is limited and that the true effect may be substantially different. Thus, AO may improve arm and hand motor function and dependence in the activities of daily living. However confidence in this effect is limited, but may be confirmed in future clinical trials.

\section{Implications for research}

To improve the quality of the evidence (GRADE) regarding the effect of $A O$ on upper limb rehabilitation in people with stroke, new randomized controlled clinical trials should be conducted, with greater methodological rigor in order to reduce the risk of bias, using a larger sample and standardized outcome assessment instruments to increase consistency. A guideline specifying the main evaluation tools for each outcome would be useful in standardizing the findings, given the variety of existing instruments.

Furthermore studies have exhibited methodological problems, such as lack of clarity, which hinders assessment of bias and quality. In order to minimize this shortcoming, research should follow the CONSORT recommendations (Moher 2001), which contain guidelines for writing randomized clinical trials in the area of health. Data presentation should also be clear to allow easy interpretation and pooling of quantitative data.

It is important that the authors of future studies characterize their samples in more detail in order to attest the applicability of $A O$ in specific situations, according to the etiology and phase of stroke, degree of upper limb impairment and brain hemisphere affected. Other information regarding the form of therapy application is also necessary in assessing its effect, such as whether therapy was administered through videos or live demonstrations, which perspective was used, and treatment setting and dose. Studies should include follow-up assessment to determine if the effects are long lasting.

\section{ACKNOWLEDGEMENTS}

We thank Josh Cheyne for helping with search strategies and database searches; the Cochrane Center of Brazil, represented by the researchers Cristiane Rufino and Carolina Cruz (TSC Information Specialist from Cochrane Brazil), for their help in adapting search strategies for other research bases; Hazel Fraser for resolving questions raised during the review; Alex Pollock, Gillian Mead and Richard Parker for their editorial review and recommendations; and Thalita Medeiros and Gabriella Suellen for sharing their experience and knowledge of systematic review methodology. 


\section{REFERE N CE S}

\section{References to studies included in this review}

Celnik 2008 \{published and unpublished data\}

Celnik P, Webster B, Glasser DM, Cohen LG. Effects of action observation on physical training after stroke. Stroke 2008;39(6):1814-20. [DOI: 10.1161/STROKEAHA.107.508184]

\section{Cowles 2013 \{published and unpublished data\}}

Cowles T, Clark A, Mares K, Peryer G, Stuck R, Pomeroy V. Observation-to-imitate plus practice could add little to physical therapy benefits within 31 days of stroke: translational randomized controlled trial. Neurorehabilitation and Neural Repair 2013;27(2):173-82. [DOI: 10.1177/1545968312452470]

\section{Dettmers 2014 \{published and unpublished data\}}

Dettmers C, Nedelko V, Hassa T, Starrost K, Schoenfeld MA. Video therapy: promoting hand function after stroke by action observation training - a pilot randomized controlled rial. International Journal of Physical Medicine and Rehabilitation 2014;2(189):2. [2329-9096 ]

\section{Ertelt 2007 \{published and unpublished data\}}

Ertelt D, Hemmelmann C, Dettmers C, Ziegler A, Binkofski F. Observation and execution of upper-limb movements as a tool for rehabilitation of motor deficits in paretic stroke patients: protocol of a randomized clinical trial. BMC Neurology 2012;12(1):42. [DOI: 10.1186/1471-2377-12-42]

Franceschini 2012 \{published and unpublished data\}

* Franceschini M, Ceravolo MG, Agosti M, Cavallini P, Bonassi S, Dall'Armi V, et al. Clinical relevance of action observation in upper-limb stroke rehabilitation a possible role in recovery of functional dexterity. A randomized clinical trial. Neurorehabilitation and Neural Repair 2012;26(5):456-62. [DOI: 10.1177/1545968311427406]

Sale P, Ceravolo MG, Franceschini M. Action observation therapy in the subacute phase promotes dexterity recovery in righthemisphere stroke patients. BioMed Research International 2014;2014:1-7. [DOI: 10.1155/2014/457538]

\section{Fu 2017 \{published data only\}}

Fu J, Zeng M, Shen F, Cui Y, Zhu M, Gu X, et al. Effects of action observation therapy on upper extremity function, daily activities and motion evoked potential in cerebral infarction patients. Medicine 2017;96(42):1-6.

Harmsen 2015 \{published and unpublished data\}

Harmsen WJ, Bussmann JB, Selles RW, Hurkmans HL, Ribbers GM. A mirror therapy-based action observation protocol to improve motor learning after stroke. Neurorehabilitation and Neural Repair 2015;29(6):509-16. [DOI: 10.1177/1545968314558598]

Kim 2015 \{published data only\}

* Kim E, Kim K. Effect of purposeful action observation on upper extremity function in stroke patients. Journal of Physical Therapy Science 2015;27(9):2867-9. [DOI: 10.1589/jpts.27.2867]
Kim E, Kim K. Effects of purposeful action observation on kinematic patterns of upper extremity in individuals with hemiplegia. Journal of Physical Therapy Science 2015;27(6):1809-11. [DOI: 10.1589/.jpts.27.1809]

Kim 2016a \{published data only\}

Kim C, Bang D. Action observation training enhances upper extremity function in subacute stroke survivor with moderate impairment: a double-blind, randomized controlled pilot trial. Journal of the Korean Society of Physical Medicine 2016;11(1):133-40. [10.13066/kspm.2016.11.1.133]

\section{Kuk 2016 \{published data only\}}

Kuk E, Kim J, Oh D, Hwang H. Effects of action observation therapy on hand dexterity and EEG-based cortical activation patterns in patients with post-stroke hemiparesis. Topics in Stroke Rehabilitation 2016;23(5):318-25. [DOI: 10.1080/10749357.2016.1157972]

\section{Lee 2013 \{published and unpublished data\}}

Lee D, Roh H, Park J, Lee S, Han S. Drinking behavior training for stroke patients using action observation and practice of upper limb function. Journal of Physical Therapy Science 2013;25(5):611-4. [DOI: 10.1589/.jpts.25.611]

Zhu 2015 \{published and unpublished data\} Zhu MH, Wang J, Gu XD, Shi MF, Zeng M, Wang CY, et al. Effect of action observation therapy on daily activities and motor recovery in stroke patients. International Journal of Nursing Sciences 2015;2(3):279-82. [DOI: 10.1016/j.ijnss.2015.08.006]

\section{References to studies excluded from this review}

Brunner 2014 \{published data only\}

Brunner IC, Skouen JS, Ersland L. Plasticity and response to action observation: a longitudinal FMRI study of potential mirror neurons in patients with subacute stroke. Neurorehabilitation and Neural Repair 2014;28(9):874-84. [DOI: $10.1177 / 1545968314527350]$

\section{Cha 2015 \{published data only\}}

Cha Y, Yoo E, Jung M, Park S, Park J, Lee J. Effects of mental practice with action observation training on occupational performance after stroke. Journal of Stroke and Cerebrovascular Diseases 2015;24(6):1405-13.

\section{Chang 2017 \{published data only\}}

Chang M, Kim H, Kim K, Oh J, Jang C, Yoon T. Effects of observation of hand movements reflected in a mirror on cortical activation in patients with stroke. Journal of Physical Therapy Science 2017;29(1):38-42.

\section{Emmerson 2017 \{published data only\}}

Emmerson K, Harding K, Taylor N. Home exercise programmes supported by video and automated reminders compared with standard paper-based home exercise programmes in patients with stroke: a randomized controlled trial. Clinical Rehabilitation 2017;31(8):1068-77. 
Ertelt 2012 \{published data only\}

Ertelt D, Hemmelmann C, Dettmers C, Ziegler A, Binkofsk F. Observation and execution of upper-limb movements as a tool for rehabilitation of motor deficits in paretic stroke patients: protocol of a randomized clinical trial. BMC Neurology 2012;12(1):42. [DOI: 10.1186/1471-2377-12-42]

\section{Franceschini 2010 \{published data only\}}

Franceschini M, Agosti M, Cantagallo A, Sale P, Mancuso M, Buccino G. Mirror neurons: action observation treatment as a tool in stroke rehabilitation. European Journal of Physical and Rehabilitation Medicine 2010;46(4):517-23. [MEDLINE: 20414184]

\section{Frenkel-Toledo 2014 \{published data only\}}

Frenkel-Toledo S, Bentin S, Perry A, Liebermann D, Soroker N. Mirror-neuron system recruitment by action observation: effects of focal brain damage on mu suppression. Neurolmage 2014;87:127-37.

\section{Kim 2013a \{published data only\}}

Kim J, Chung E, Lee B. A study of analysis of the brain wave with respected to action observation and motor imagery: a pilot randomized controlled trial. Physical Therapy Science 2013;25(7):779-82. [DOI: 10.1589/jpts.25.779]

\section{Kim 2013b \{published data only\}}

Kim JH, Lee BH. Action observation training for functional activities after stroke: a pilot randomized controlled trial. NeuroRehabilitation 2013;33(4):565-74. [DOI: 10.3233/ NRE-130991]

\section{Kim 2014 \{published data only\}}

Kim SS, Kim TH, Lee BH. Effects of action observational training on cerebral hemodynamic changes of stroke survivors: a fTCD study. Journal of Physical Therapy Science 2014;26(3):331-4. [10.1589/jpts.26.331]

\section{Kim 2016b \{published data only\}}

Kim T, Kim S, Lee B. Effects of action observational training plus brain-computer interface-based functional electrical stimulation on paretic arm motor recovery in patient with stroke: a randomized controlled trial. Occupational Therapy International 2016;23(1):39-47. [DOI: 10.1002/oti.1403]

\section{Liepert 2014 \{published data only\}}

Liepert J, Greiner J, Dettmers C. Motor excitability changes during action observation in stroke patients. Journal of Rehabilitation Medicine 2014;46(5):400-5. [DOI: 10.2340/16501977-1276]

\section{Lubart 2017 \{published data only\}}

Lubart A, Leibovitz A, Peleg L, Yarovoy A, Gal G, Mizrahi E, et al. Action observation of motor skills followed by immediate sleep enhances the motor rehabilitation of older adults with stroke. Journal of Geriatric Physical Therapy 2017; Vol. [Epub ahead of print]. [2152-0895]

\section{Marangon 2014 \{published data only\}}

Marangon M, Priftis K, Fedeli M, Masiero S, Tonin P, Piccione F. Lateralization of motor cortex excitability in stroke patients during action observation: a TMS study. BioMed Research International 2014; Vol. 2014.

Sale 2012 \{published data only\}

Sale P, Franceschini M. Action observation and mirror neuron network: a tool for motor stroke rehabilitation. European Journal of Physical and Rehabilitation Medicine 2012;48(2):313-8. [22522432]

Sugg 2015 \{published data only\}

Sugg K, Muller S, Winstein C, Hathorn D, Dempsey A. Does action observation training with immediate physical practice improve hemiparetic upper-limb function in chronic stroke? Neurorehabilitation and Neural Repair 2015;29(9):807-17. [DOI: 10.1177/1545968314565512]

Sun 2016 \{published data only\}

Sun Y, Wei W, Luo Z, Gan H, Hu X. Improving motor imagery practice with synchronous action observation in stroke patients. Topics in Stroke Rehabilitation 2016;23(4):245-53.

\section{Szameitat 2012 \{published data only\}}

Szameitat A, Shen S, Conforto A, Sterr A. Cortical activation during executed, imagined, observed, and passive wrist movements in healthy volunteers and stroke patients. Neurolmage 2012;62(1):266-80.

Wright 2014 \{published data only\}

Wright D, Williams J, Holmes P. Combined action observation and imagery facilitates corticospinal excitability. Frontiers in Human Neuroscience 2014;8:951.

\section{References to studies awaiting assessment}

Gu 2013 \{published data only\}

Gu Y, Kim B. An impact of action-observation training and task-oriented training on activities of daily living of stroke patients. Journal of the Korean Society of Integrative Medicine 2013;1(3):19-28. [10.15268/ksim.2013.1.3.019]

Jin-Woo 2011 \{published data only\}

Jin-Woo J, Soon BY, Lee MK. The effect of action observation training on upper extremity function in chronic stroke patients. Journal of Korean Society of Occupational Therapy 2011;19:1524.

\section{Kim 2010 \{published data only\}}

Kim J, Yang B, Lee M. The effect of action observational physical training on manual dexterity in stroke patients. Physical Therapy Korea 2010;17(2):17-24.

\section{Ko 2014 \{published data only\}}

Ko HE, Park JJ, Lee KJ, Lee EH, Oh MH. The effect of actionobservational physical training based on mirror neuron system on upper extremity function and activities of daily living in stroke patient. Journal of the Korea Institute of Electronic Communication Sciences 2014;9(1):123-30. [DOI: 10.13067/ JKIECS.2014.9.1.123] 


\section{Lee 2016 \{published data only\}}

Lee H, Kim H, Kwon H, Cho Y, Lee S. Effects off the distant action observation training program on function restorations of chronic stroke patients. Journal of Korean Society of Occupational Therapy 2016;24(1):1-13. [DOI: 10.14519/ jksot.2016.24.1.01]

\section{Yun 2011 \{published data only\}}

Yun TW, Lee MK. The change of mu rhythm during action observation in people with stroke. Journal of the Korean Society of Physical Medicine 2011;6(3):361-8.

\section{References to ongoing studies}

NCT02235350 \{published data only\}

NCT02235350. Study on the effectiveness of action observation treatment (AOT) as a rehabilitation tool in acute stroke patients and in chronic stroke patients with apraxia: a randomized controlled trial. http://clinicaltrials.gov/ct2/show/study/ NCT02235350 (first received 9 September 2014). [NCT02235350]

NCT02871700 \{published data only\}

NCT02871700. Comparative efficacy study of action observation therapy and mirror therapy after stroke: rehabilitation outcomes and neural mechanisms by MEG. http:// clinicaltrials.gov/ct2/show/record/NCT02871700 (accessed October 2016) (first received 18 August 2016). [NCT02871700]

\section{RBR-26q4z9 \{published data only\}}

RBR-26q4z9. Comparative study between action observation training and hydrotherapy in upper limb recovery after stroke: randomized clinical trial. http://ensaiosclinicos.gov.br/rg/ RBR-26q4z9/ (first received 22 April 2015).

\section{Additional references}

\section{Buccino 2014}

Buccino G. Action observation treatment: a novel tool in neurorehabilitation. Philosophical Transactions of the Royal Society B: Biological Sciences 2014;369(1644):20130185.

\section{Calvo-Merino 2005}

Calvo-Merino B, Glaser DE, Grèzes J, Passingham RE, Haggard P. Action observation and acquired motor skills: an FMRI study with expert dancers. Cerebral Cortex 2005;15(8):1243-9.

\section{Chen 2009}

Chen HM, Chen CC, Hsueh IP, Huang SL, Hsieh CL. Test-retest reproducibility and smallest real difference of 5 hand function tests in patients with stroke. Neurorehabilitation and Neural Repair 2009;23(5):435-40.

\section{Cowles 2012}

Cowles T, Clark A, Mares K, Peryer G, Stuck R, Pomeroy V. Observation-to-imitate plus practice could add little to physical therapy benefits within 31 days of stroke: translational randomized controlled trial. Neurorehabilitation and Neural Repair 2012;27(2):173-82.

\section{Feigin 2014}

Feigin VL, Forouzanfar MH, Krishnamurthi R, Mensah GA, Connor M, Bennett DA, et al. Global and regional burden of stroke during 1990-2010: findings from the Global Burden of Disease Study 2010. Lancet 2014;383(9913):245-55.

\section{Fitts 1967}

Fitts PM, Posner MI. Human Performance. Belmont: Brooks/ Colemann, 1967.

\section{Garrison 2010}

Garrison KA, Winstein CJ, Aziz-zadeh L. The mirror neuron system: a neural substrate for methods in stroke rehabilitation. Neurorehabilitation and Neural Repair 2010;24(5):404-12.

\section{Garrison 2013}

Garrison KA, Aziz-zadeh L, Wong SW, Liew SL, Winstein CJ. Modulating the motor system by action observation after stroke. Stroke 2013;44(8):2247-53.

\section{GRADEpro GDT}

GRADEpro GDT: GRADEpro Guideline Development Tool [Software]. McMaster University, 2015 (developed by Evidence Prime, Inc). Available from www.gradepro.org.

\section{Higgins 2011}

Higgins JP, Green S (editors). Cochrane Handbook for Systematic Reviews of Interventions Version 5.1.0 [updated March 2011]. The Cochrane Collaboration, 2011. Available from handbook.cochrane.org.

\section{Jeannerod 2001}

Jeannerod M. Neural simulation of action: a unifying mechanism for motor cognition. Neurolmage 2001;14(1):S103-9.

\section{Johansson 2011}

Johansson BB. Current trends in stroke rehabilitation. A review with focus on brain plasticity. Acta Neurologica Scandinavica 2011;123(3):147-59.

\section{Kwakkel 2003}

Kwakkel G, Kollen BJ, van der Grond J, Prevo AJ. Probability of regaining dexterity in the flaccid upper limb impact of severity of paresis and time since onset in acute stroke. Stroke 2003;34(9):2181-6.

\section{Langhorne 2009}

Langhorne $\mathrm{P}$, Coupar F, Pollock A. Motor recovery after stroke: a systematic review. Lancet Neurology 2009;8(8):741-54.

\section{Lozano 2012}

Lozano R, Naghavi M, Foreman K, Lim S, Shibuya K, Aboyans V, et al. Global and regional mortality from 235 causes of death for 20 age groups in 1990 and 2010: a systematic analysis for the Global Burden of Disease Study 2010. Lancet 2012;380(9859):2095-128.

\section{Magill 1989}

Magill RA. Motor Learning: Concepts and Applications. 3rd Edition. Dubuque: Wm C Brown, 1989. 


\section{Moher 2001}

Moher D, Schulz KF, Altman DG. The CONSORT statement: revised recommendations for improving the quality of reports of parallel group randomized trials. BMC Medical Research Methodology 2001;1(1):2. [DOI: 10.1016/S0140-6736(00)04337-3]

\section{Moher 2009}

Moher D, Liberati A, Tetzlaff J, Altman DG. Preferred reporting items for systematic reviews and meta-analyses: the PRISMA statement. Annals of Internal Medicine 2009;151(4):264-9.

\section{Mukherjee 2011}

Mukherjee D, Patil CH. Epidemiology and global burden of stroke. World Neurosurgery 2011;76(65):585-90.

\section{Murray 2012}

Murray CJ, Vos T, Lozano R, Naghavi M, Flaxman AD, Michaud C, et al. Disability-adjusted life years (DALYs) for 291 diseases and injuries in 21 regions, 1990-2010: a systematic analysis for the Global Burden of Disease Study 2010. Lancet 2012;380(9859):2197-223.

\section{Review Manager 2014 [Computer program]}

Nordic Cochrane Centre, The Cochrane Collaboration. Review Manager 5 (RevMan 5). Version 5.3. Copenhagen: Nordic Cochrane Centre, The Cochrane Collaboration, 2014.

\section{CHARACTERISTICS OF STUDIES}

Characteristics of included studies [ordered by study ID]

\section{Sarasso 2015}

Sarasso E, Gemma M, Agosta F, Filippi M, Gatti R. Action observation training to improve motor function recovery: a systematic review. Archives of Physiotherapy 2015;5(1):14. [DOI: 10.1186/s40945-015-0013-x]

\section{Small 2012}

Small SL, Buccino G, Solodkin A. The mirror neuron system and treatment of stroke. Developmental Psychobiology 2012;54(3):293-310.

\section{van Kuijk 2009}

van Kuijk AA, Pasman JW, Hendricks HT, Zwarts MJ, Geurts AC. Predicting hand motor recovery in severe stroke: the role of motor evoked potentials in relation to early clinical assessment. Neurorehabilitation and Neural Repair 2009;23(1):45-51.

\section{References to other published versions of this review Borges 2015}

Borges LR, Melo LP, Fernandes AB, Guerra RO, Campos TF. Action observation for upper limb rehabilitation after stroke. Cochrane Database of Systematic Reviews 2015, Issue 9. [DOI: 10.1002/14651858.CD011887]

* Indicates the major publication for the study

Celnik 2008

\begin{tabular}{ll}
\hline Methods & Randomized cross-over trial \\
\hline Participants & Methods of recruitment were not reported by authors \\
& $\begin{array}{l}\text { p participants in a cross-over design with } 3 \text { arms: } 9 \text { physical training group; } 9 \text { physical training and con- } \\
\text { gruent action observation group; } 9 \text { physical training and incongruent action observation group }\end{array}$ \\
& Inclusion criteria: stroke patients with single unilateral cortical or subcortical lesions \\
& Exclusion criteria: there were no exclusion criteria described in the study \\
& Mean (SD) age: not reported by authors \\
& Stroke details: not reported by authors \\
& Stroke phase: chronic
\end{tabular}

Physical training and congruent action observation group observed a video displaying thumb movements in the same direction to that physically practiced simultaneously

Physical training and incongruent action observation group observed a video displaying thumb movements in a direction opposite to that physically practiced simultaneously

Sessions were 30 minutes, 3 blocks of 10 minutes each separated by 2-minute rest 
Celnik 2008 (Continued)

Corticomotor excitability: MEP of agonist and antagonist muscles

\section{Notes}

\section{Risk of bias}

\begin{tabular}{lll}
\hline Bias & Authors' judgement & Support for judgement \\
\hline $\begin{array}{l}\text { Random sequence genera- } \\
\text { tion (selection bias) }\end{array}$ & Low risk & $\begin{array}{l}\text { Author's answer: "The allocation was generated randomly using Excel creating } \\
\text { a random session order for each of the subjects and conditions." }\end{array}$ \\
\hline $\begin{array}{l}\text { Allocation concealment } \\
\text { (selection bias) }\end{array}$ & Unclear risk & The author did not make clear whether there was allocation concealment \\
\hline $\begin{array}{l}\text { Blinding of participants } \\
\begin{array}{l}\text { and personnel (perfor- } \\
\text { mance bias) } \\
\text { All outcomes }\end{array}\end{array}$ & Low risk & No blinding, but the outcome is not likely to be influenced by lack of blinding \\
\hline
\end{tabular}

\begin{tabular}{lll}
$\begin{array}{l}\text { Blinding of outcome as- } \\
\begin{array}{l}\text { sessment (detection bias) } \\
\text { All outcomes }\end{array}\end{array}$ & Low risk & $\begin{array}{l}\text { Author's answer: "The outcome measures were analyzed by a blinded individ- } \\
\text { ual who did not participate in the data acquisition." }\end{array}$ \\
\hline $\begin{array}{l}\text { Incomplete outcome data } \\
\text { (attrition bias) } \\
\text { All outcomes }\end{array}$ & High risk & $\begin{array}{l}\text { One participant could not complete the protocol due to TMS-related } \\
\text { headache. The reasons were provided, but the exclusion of } 1 / 9 \text { participants in } \\
\text { a cross-over design, with } 3 \text { arms, may have affected reliability of study results }\end{array}$ \\
\hline $\begin{array}{l}\text { Selective reporting (re- } \\
\text { porting bias) }\end{array}$ & Low risk & $\begin{array}{l}\text { There is no trial registration, but the outcomes are significant, and there is no } \\
\text { selective reporting within the study. }\end{array}$ \\
\hline Other bias & Low risk & \\
\hline
\end{tabular}

\section{Cowles 2013}

\begin{tabular}{ll}
\hline Methods & Randomized, controlled, observer-blind efficacy trial \\
\hline Participants & All participants were recruited from an inpatient stroke unit \\
& 29 participants: 15 experimental group, 14 control group \\
& Inclusion criteria: adults who had suffered a stroke between 3 and 31 days before recruitment but with \\
an intact premotor area (ability to encode observed human actions); able to produce some movement & in a substantially paretic upper limb as assessed by a score of at least 18 on the MI but unable to pro- \\
& duce a grip force of more than $65 \%$ of that of the ipsilesional side; free from observable contralesional \\
upper limb movement deficits attributable to pathology other than stroke & \\
& $\begin{array}{l}\text { Exclusion criteria: patients who had no ability to imitate action with their ipsilesional limb. This abili- } \\
\text { ty was assessed by the research therapist who performed an upper limb activity } 3 \text { times, and potential } \\
\text { participants were asked to observe and then perform the activity. This assessment was digitally filmed } \\
\text { and saved onto a computer. An independent assessor viewed the recordings and judged the accuracy } \\
\text { of imitation. }\end{array}$
\end{tabular}

Mean (SD) age: 77.2 (SD 10.4) years

Stroke details: not reported by authors

Stroke phase: acute 
Cowles 2013 (Continued)

Interventions
Experimental group additionally watched functional tasks with intent to imitate for 1 to 2 minutes; and then for 4 to 6 minutes performed the activity simultaneously with the therapist

Control group received conventional physical therapy

Sessions were $2 \times 30$-minute sessions, with 10 -minute rest, for 15 working days

Outcomes

Outcomes recorded at baseline and within 3 working days of the end of intervention

Ability to voluntarily contract paretic muscle: MI

Upper limb motor function: ARAT

Notes

\section{Risk of bias}

\begin{tabular}{|c|c|c|}
\hline Bias & Authors' judgement & Support for judgement \\
\hline $\begin{array}{l}\text { Random sequence genera- } \\
\text { tion (selection bias) }\end{array}$ & Low risk & Group allocation was computer generated \\
\hline $\begin{array}{l}\text { Allocation concealment } \\
\text { (selection bias) }\end{array}$ & Low risk & $\begin{array}{l}\text { Details of group allocation were placed into sequentially-numbered, opaque, } \\
\text { sealed envelopes }\end{array}$ \\
\hline $\begin{array}{l}\text { Blinding of participants } \\
\text { and personnel (perfor- } \\
\text { mance bias) } \\
\text { All outcomes }\end{array}$ & Low risk & No blinding, but the outcome is not likely to be influenced by lack of blinding \\
\hline $\begin{array}{l}\text { Blinding of outcome as- } \\
\text { sessment (detection bias) } \\
\text { All outcomes }\end{array}$ & Low risk & All measures were made by an assessor blinded to treatment allocation \\
\hline $\begin{array}{l}\text { Incomplete outcome data } \\
\text { (attrition bias) } \\
\text { All outcomes }\end{array}$ & Low risk & $\begin{array}{l}29 \text { participants were randomized. Outcome measures were completed on } 13 \\
\text { participants in the CPT group and } 9 \text { in the OTI + PP group ( } 22 \text { participants). } \\
\text { Reasons for attrition were provided: moved out of area (one in CG and } 4 \text { in EG); } \\
\text { withdrew from trial ( } 1 \text { in EG); medically unwell ( } 1 \text { in EG); } 1 \text { of the participants } \\
\text { in the control group failed to fully comprehend the instructions for the MI at } \\
\text { baseline so this score was missing. Reasons for missing outcome data unlikely } \\
\text { to be related to true outcome. }\end{array}$ \\
\hline & & $\begin{array}{l}\text { Where participants withdrew before outcome they were not included in the } \\
\text { analysis, and imputation was not used }\end{array}$ \\
\hline
\end{tabular}

Selective reporting (re- High risk
porting bias)

The study protocol is available but not all of the study's pre-specified primary outcomes have been reported. Registered on the Current Controlled Trials Database - ISCRTN 51553998: www.controlled-trials.com/ISR CTN51553998/51553998.

Other bias Low risk

\section{Dettmers 2014}

\begin{tabular}{ll}
\hline Methods & Pilot randomized controlled trial \\
\hline Participants & Participants were recruited from 2 hospitals
\end{tabular}


Inclusion criteria: minimal function of the hand (ability to grip a small object and to release it (extension against gravity at wrist $=20^{\circ}$ and at metacarpophalangeal and interphalangeal joints of each of the fingers $=10^{\circ}$ ), sufficient language abilities to complete the study's questionnaires, and sufficient cognitive ability to understand and follow instructions for training, distance to the participant's home restricted to $300 \mathrm{~km}$ to allow for a follow-up examination

Exclusion criteria: prominent cognitive deficits (MMSE < 24), major depression (BDI > 5), major aphasia (Token Test), apraxia (FAST), neglect (Albert's Neglect Test), hemianopia, prior infarct, leucoencephalopathy and age below 18 or over 75 years, severe psychiatric disease, severe pulmonary or cardiovascular disease, epilepsy, severe joint deformity (neurological examination) and severe pain

Mean (SD) age: video group: 62.79 (no SD reported), text group: 53.89 (14.74), usual care group: 58.83 (11.25).

Stroke details: video group: 6 embolic, 4 lacunar, 2 hemodynamic, and 7 unknown etiology; text group: 9 embolic, 4 lacunar, 1 hemodynamic and 5 unknown etiology; usual care group: 7 embolic, 5 lacunar, 2 hemodynamic and 4 unknown etiology

Stroke phase: acute, subacute, and chronic

\section{Interventions}

Video group: home-based training. Participants received a DVD displaying 10 object-related motor tasks of varying difficulty, each lasting 5 minutes and were requested to imitate the motor tasks, time not reported

Text group: home-based training. Participants performed the same tasks with written instructions without observation/imitation

Usual care group: discharged without specific homework

Participants were instructed to train 1 hour per day for 6 weeks (video and text groups)

Outcomes Outcomes recorded at baseline, post-intervention, and at 6 months from treatment conclusion

Upper limb motor function: WMFT- time and quality of movements

Hand function: NHPT

Activities of daily living: MAL - quality of movement and amount of use

Quality of life: SIS

\section{Notes \\ Risk of bias}

Bias Authors' judgement Support for judgement

Random sequence genera- Unclear risk Randomization was done, but there was no information of how it was done tion (selection bias)

\begin{tabular}{lll}
\hline $\begin{array}{l}\text { Allocation concealment } \\
\text { (selection bias) }\end{array}$ & Unclear risk & There was no information about allocation concealment \\
\hline $\begin{array}{l}\text { Blinding of participants } \\
\begin{array}{l}\text { and personnel (perfor- } \\
\text { mance bias) }\end{array}\end{array}$ & Low risk & $\begin{array}{l}\text { No blinding, but the outcome was not likely to be influenced by lack of blind- } \\
\text { ing }\end{array}$ \\
All outcomes &
\end{tabular}

\begin{tabular}{lll}
\hline $\begin{array}{l}\text { Blinding of outcome as- } \\
\text { sessment (detection bias) }\end{array}$ & Unclear risk & $\begin{array}{l}\text { WMFT assessment was performed by a blind physiotherapist (low risk). There } \\
\text { was no information about blinding other assessment instruments }\end{array}$
\end{tabular}


Dettmers 2014 (Continued)

All outcomes

Incomplete outcome data Low risk (attrition bias)

All outcomes
1 participant was excluded during the intervention because of a recurrent stroke (video group). 1 participant from the text-group was unwilling to come to the re-evaluation. Another 2 participants refused to come to re-evaluation (usual care group). Nevertheless, the reasons were provided and they had no direct relationship with the outcomes studied, and there was no substantial imbalance in final number of participants in each group considered for analysis

Selective reporting (re- High risk
porting bias)

Considering the description of the methodology, the follow-up investigation was scheduled 12 months after the training, using MAL and WMFT questionnaires. However, the results concerning the follow-up showed that the data were assessed 6 months after the end of the treatment and used as questionnaires the SIS and MAL, when the data of WMFT were not available

Other bias Low risk -

Ertelt 2007

Methods $\quad$ Randomized clinical trial

Participants

Participants were recruited from the local Rehabilitation Center

16 participants: 8 experimental, 8 control

Inclusion criteria: confirmed diagnosis of a first-ever ischemic stroke in the territory of the medial cerebral artery, sustained more than 6 months prior to entering the study

Exclusion criteria: patients older than 76 years, with hemorrhagic stroke or ischemic lesions in the territory of posterior or anterior cerebral artery, impaired level of consciousness (confusion, stupor, coma), severe to moderate aphasia, anosognosia or neglect, amnesia or dementia, depression

Mean (SD) age: experimental group: 57.16 (8.73) years and control group: 55.40 (10.77) years

Stroke details: first ischemic stroke in the territory of the medial cerebral artery

Stroke phase: chronic

Interventions

Experimental group ("action observation therapy"): carefully watched video sequences containing daily life hand and arm actions for 6 minutes that were followed by repetitive practice of the observed actions for another 6 minutes using the same objects as shown in the video film

Control group: matched the experimental treatment with the exception that the participants watched sequences of geometric symbols and letters instead of action sequences

Sessions were 90 minutes, 18 rehabilitation sessions on consecutive working days

Outcomes Outcomes recorded at baseline, post-intervention, and 8 weeks after the end of intervention

Upper limb function: FAT, WMFT

Quality of life: SIS

Functional imaging: fMRI measurements

\section{Notes}

\section{Risk of bias}


Ertelt 2007 (Continued)

\begin{tabular}{lll} 
Bias & Authors' judgement & Support for judgement \\
\hline $\begin{array}{l}\text { Random sequence genera- } \\
\text { tion (selection bias) }\end{array}$ & Unclear risk & Randomization was done, but no information of how it was done \\
\hline $\begin{array}{l}\text { Allocation concealment } \\
\text { (selection bias) }\end{array}$ & Unclear risk & Authors did not report if there was allocation concealment \\
\hline $\begin{array}{l}\text { Blinding of participants } \\
\begin{array}{l}\text { and personnel (perfor- } \\
\text { mance bias) }\end{array}\end{array}$ & Low risk & No blinding, but the outcome is not likely to be influenced by lack of blinding \\
All outcomes &
\end{tabular}

\begin{tabular}{lll}
\hline $\begin{array}{l}\text { Blinding of outcome as- } \\
\text { sessment (detection bias) } \\
\text { All outcomes }\end{array}$ & Unclear risk & Authors did not report if there was blinding of outcome assessment \\
\hline $\begin{array}{l}\text { Incomplete outcome data } \\
\text { (attrition bias) } \\
\text { All outcomes }\end{array}$ & Low risk & $\begin{array}{l}\text { There was no exclusion of participants after randomization. fMRI measure- } \\
\text { ments were analyzed in 7 participants in the experimental group and } 6 \text { partici- } \\
\text { pants in the control group }\end{array}$ \\
\hline $\begin{array}{l}\text { Selective reporting (re- } \\
\text { porting bias) }\end{array}$ & Low risk & $\begin{array}{l}\text { There is no trial registration, but the outcomes were significant, and there was } \\
\text { no selective reporting within the study }\end{array}$ \\
\hline Other bias & Low risk & \\
\hline
\end{tabular}

Franceschini 2012

Methods Randomized controlled observer-blind trial

Participants

Eligible hemiparetic stroke survivors from 13 rehabilitation centers were recruited

Franceschini 2012 paper:

102 participants: 53 experimental, 49 control

Inclusion criteria: participants with first-ever stroke, enrolled 30 days $( \pm 7)$ after the event onset with ischemia or primary hemorrhage, right-handed prior to stroke

Exclusion criteria: posterior circulation infarction, subarachnoid hemorrhage, severe forms of neglect and anosognosia (number of errors in Bell Barrage test $\geq 15$ ), impaired comprehension (Token test score $\leq 17$ ), history of endogenous depression or serious psychiatric disorders, and severe visual deficits (restricting the access to visual stimuli)

Mean (SD) age: experimental group: 67.0 (12.4) years; control group: 65.7 (11.9) years

Stroke details: etiology - control group: 9 hemorrhagic, 40 ischemic; experimental group: 16 hemorrhagic, 37 ischemic. Lesion side: control group: 18 right, 24 left; experimental group: 22 right, 26 left

Stroke phase: acute

Sale 2014 paper:

67 participants: 33 experimental, 34 control

Inclusion criteria: moderate to severe upper limb paresis, first-ever ischemic stroke, 30 days $( \pm 7)$ after the event, right handed prior to stroke, unilateral brain lesions 
Exclusion criteria: posterior circulation infarction, subarachnoid hemorrhage, severe forms of neglect and anosognosia, impaired comprehension or dementia, history of endogenous depression or serious psychiatric disorders, severe visual deficits, bilateral motor impairment, severe sensory deficits in the paretic upper limb, refusal or inability to provide informed consent, other concomitant severe medical problems

Mean (SD) age: $66.5(12.7)$ years

Stroke details: ischemic

Stroke phase: acute

Interventions

Experimental group: observation of 1 daily routine task (actions) carried out with the upper limb, each action consisted of 3 different meaningful motor sequences ( 3 minutes each). After observing the video, the participant should perform, with their paretic upper limb, the same movement ( 2 minutes each), with help when needed

Control intervention: observation of 5 static images displaying objects, without any animal or human being (different 3-minute sequences). Then, the participants had to perform limb movements for 2 minutes according to a standard sequence, simulating those performed by the other group

Sessions were $2 \times 15$ minute, daily (with 60-minute interval), 5 days/week, for 4 consecutive weeks (in addition to 3 hours of standard rehabilitation)

Outcomes Franceschini 2012 paper:

Outcomes recorded at baseline, post-intervention and at 4 to 5 months from treatment conclusion

Upper limb motor function: FMA- upper limb items, FAT, BBT

Muscle tone: MAS

Functional Independence: FIM- motor items

Sale 2014 paper:

Outcomes recorded at baseline, post-intervention and at 4 to 5 months from treatment conclusion

Upper limb motor function: FMA- upper limb items and BBT

Notes There are 2 publications for this study

\section{Risk of bias}

\begin{tabular}{|c|c|c|}
\hline Bias & Authors' judgement & Support for judgement \\
\hline $\begin{array}{l}\text { Random sequence genera- } \\
\text { tion (selection bias) }\end{array}$ & Low risk & Central randomization \\
\hline $\begin{array}{l}\text { Allocation concealment } \\
\text { (selection bias) }\end{array}$ & Low risk & $\begin{array}{l}\text { Participants and investigators enrolling participants could not foresee assign- } \\
\text { ment because central allocation was used to conceal allocation }\end{array}$ \\
\hline $\begin{array}{l}\text { Blinding of participants } \\
\text { and personnel (perfor- } \\
\text { mance bias) } \\
\text { All outcomes }\end{array}$ & Low risk & No blinding, but the outcome is not likely to be influenced by lack of blinding \\
\hline $\begin{array}{l}\text { Blinding of outcome as- } \\
\text { sessment (detection bias) } \\
\text { All outcomes }\end{array}$ & Low risk & $\begin{array}{l}\text { All assessments were performed by trained professional not involved in the re- } \\
\text { search treatment and blind to group allocation }\end{array}$ \\
\hline
\end{tabular}


Franceschini 2012 (Continued)

Incomplete outcome data High risk 12 participants were excluded post-randomization, 5 from experimental group (attrition bias) and 7 from control group. Reasons were not reported. There was an imbalance

All outcomes of 6 participants in final number of participants in each group considered for analysis

\begin{tabular}{lll}
\hline $\begin{array}{l}\text { Selective reporting (re- } \\
\text { porting bias) }\end{array}$ & Low risk & $\begin{array}{l}\text { There is no trial registration, but the outcomes are significant, and there is no } \\
\text { selective reporting within the study }\end{array}$ \\
\hline Other bias & Low risk & \\
\hline
\end{tabular}

\section{Fu 2017}

Methods Randomized clinical trial

Participants

Stroke patients who were hospitalized in Zhejiang Jiaxing Second Hospital Rehabilitation Center between June 2014 and September 2016 were recruited in this study

70 participants: 35 experimental; 35 control

Inclusion criteria: conformed to cerebral infarction diagnostic criteria formulated by Chinese Society of Neurology, Chinese Medical Association; unilateral hemiplegia; first-episode of cerebral infarction determined by CT and MRI; stable vital signs; disease course of 2 to 6 months; age of 40 to 75 years; MMSE score $\geq 27$ and treatment instructions can be performed; FMA score $\geq 20$ for upper extremity motor function; binocular vision or corrected visual acuity $\geq 1.0$; everyday treatment can be tolerated; and providing informed consent and willingness to participate in the study

Exclusion criteria: cerebral hemorrhage, subarachnoid hemorrhage, venous sinus thrombosis, transient ischemic attack, and progressive or reversible ischemic cerebral apoplexy; lesions located in bilateral cerebral hemisphere, cerebellum, or brain stem; joint and other diseases affecting patients sitting or active; heart, lung, liver, kidney, and other serious diseases; metal implantation in the body; a history of epilepsy; and skull defect

Mean (SD) age: experimental group: 62.04 (9.93) years, control group: 59.76 (10.57) years

Stroke details. etiology - ischemic; hemiplegia: control group: 13 right, 12 left; experimental group: 12 right, 16 left.

Stroke phase: subacute

Interventions

Experimental group: traditional rehabilitation treatment such as Bobath, Brunnstrom, proprioceptive neuromuscular facilitation, and daily activity ability training. In addition participants were requested to watch upper limbs motion video and required to imitate the action in the video. There were 30 actions in the video, including shoulder joint, elbow joint, wrist joints, forearm, and hand movements in all directions

Control group: traditional rehabilitation treatment such as Bobath, Brunnstrom, proprioceptive neuromuscular facilitation, and daily activity ability training. In addition they watched different geometric patterns and digit symbol, and did the action picked from the 30 actions in the video

In both groups sessions were 20 minutes, 6 day per week, for 8 weeks

Outcomes

Outcomes recorded at baseline and post-intervention

Motor function: FMA and WMFT

Ability of daily living activities: MBI

Movement transmission mechanism: MEP - latency and amplitude, CMCT 
Fu 2017 (Continued)

Notes

\section{Risk of bias}

\begin{tabular}{|c|c|c|}
\hline Bias & Authors' judgement & Support for judgement \\
\hline $\begin{array}{l}\text { Random sequence genera- } \\
\text { tion (selection bias) }\end{array}$ & Low risk & Random number table \\
\hline $\begin{array}{l}\text { Allocation concealment } \\
\text { (selection bias) }\end{array}$ & High risk & $\begin{array}{l}\text { Authors did not report if there was allocation concealment, but randomization } \\
\text { type classifies the allocation concealment as high risk }\end{array}$ \\
\hline $\begin{array}{l}\text { Blinding of participants } \\
\text { and personnel (perfor- } \\
\text { mance bias) } \\
\text { All outcomes }\end{array}$ & Low risk & $\begin{array}{l}\text { There was no blinding of participants and personnel, but this item is not es- } \\
\text { sential for this review }\end{array}$ \\
\hline $\begin{array}{l}\text { Blinding of outcome as- } \\
\text { sessment (detection bias) } \\
\text { All outcomes }\end{array}$ & Low risk & $\begin{array}{l}\text { Assessments were made by } 2 \text { trained professional therapists and the whole } \\
\text { process was recorded. Subsequently, the average score from another } 2 \text { trained } \\
\text { professional therapists was used for the analyses }\end{array}$ \\
\hline $\begin{array}{l}\text { Incomplete outcome data } \\
\text { (attrition bias) } \\
\text { All outcomes }\end{array}$ & High risk & $\begin{array}{l}\text { There were } 7 \text { exclusions from the experimental group and } 10 \text { from the control } \\
\text { group after randomization, which corresponded to more than } 10 \% \text { and may } \\
\text { compromise the results. Reasons were not reported }\end{array}$ \\
\hline $\begin{array}{l}\text { Selective reporting (re- } \\
\text { porting bias) }\end{array}$ & Low risk & $\begin{array}{l}\text { There is no trial registration, but the outcomes are significant, and there is no } \\
\text { selective reporting within the study. }\end{array}$ \\
\hline Other bias & Low risk & \\
\hline
\end{tabular}

Harmsen 2015

\begin{tabular}{|c|c|}
\hline Methods & Randomized clinical trial \\
\hline \multirow[t]{7}{*}{ Participants } & $\begin{array}{l}\text { Patients were recruited from the outpatient clinic of Rijndam Rehabilitation Centre in Rotterdam, the } \\
\text { Netherlands }\end{array}$ \\
\hline & 37 participants: 18 experimental group; 19 control group \\
\hline & $\begin{array}{l}\text { Inclusion criteria: Brunnstrom score for upper-extremity function between III and VI, a home-dwelling } \\
\text { status, and at least } 6 \text { months poststroke }\end{array}$ \\
\hline & $\begin{array}{l}\text { Exclusion criteria: presence of neglect, comorbidities that influence voluntary upper-extremity func- } \\
\text { tion, or multiple strokes }\end{array}$ \\
\hline & Mean (SD) age: experimental group: 57 (10.4) years, control group: 60 (8.8) years \\
\hline & $\begin{array}{l}\text { Stroke details: experimental group: } 13 \text { ischemic, } 5 \text { hemorrhagic; control group: } 12 \text { ischemic, } 7 \text { hemor- } \\
\text { rhagic }\end{array}$ \\
\hline & Stroke phase: chronic \\
\hline
\end{tabular}

Interventions

Experimental group (mirror therapy-based action observation): sets of affected-arm reaching movements, alternated with periods of observation. Participants observed mirrored video tapes (the video screen was positioned in the midsagittal plane) of reaching movements performed by their unaffected arm 
Control group: sets of affected-arm reaching movements, alternated with periods of observation. Participants observed static photographs of landscapes (the video screen was positioned in the midsagittal plane)

Participants trained for 1 day: 3 minutes of action observation, 30 repetitions of reaching, 1 minute of action observation, 20 repetitions of reaching, 1 minute of action observation, 20 repetitions of reaching, and 1 last minute of action observation

Outcomes Outcome recorded at baseline and post-intervention

Movement time of reaching: accelerometer

Notes -

\section{Risk of bias}

\begin{tabular}{|c|c|c|}
\hline Bias & Authors' judgement & Support for judgement \\
\hline $\begin{array}{l}\text { Random sequence genera- } \\
\text { tion (selection bias) }\end{array}$ & Low risk & Computer-generated random code using blocks of 20 participants \\
\hline $\begin{array}{l}\text { Allocation concealment } \\
\text { (selection bias) }\end{array}$ & Unclear risk & $\begin{array}{l}\text { Use of sealed envelopes. Authors did not report if envelopes were opaque or } \\
\text { sequentially numbered }\end{array}$ \\
\hline $\begin{array}{l}\text { Blinding of participants } \\
\text { and personnel (perfor- } \\
\text { mance bias) } \\
\text { All outcomes }\end{array}$ & Low risk & No blinding, but the outcome is not likely to be influenced by lack of blinding \\
\hline $\begin{array}{l}\text { Blinding of outcome as- } \\
\text { sessment (detection bias) } \\
\text { All outcomes }\end{array}$ & Unclear risk & Authors did not report if there was blinding of outcome assessment \\
\hline $\begin{array}{l}\text { Incomplete outcome data } \\
\text { (attrition bias) } \\
\text { All outcomes }\end{array}$ & Low risk & No withdraw was reported. There was no loss of data after intervention. \\
\hline $\begin{array}{l}\text { Selective reporting (re- } \\
\text { porting bias) }\end{array}$ & Low risk & $\begin{array}{l}\text { The study protocol is available and the outcomes were reported in accordance } \\
\text { with what has been proposed } \\
\text { DOI } 10.1186 / \text { ISRCTN } 40128145\end{array}$ \\
\hline Other bias & Low risk & \\
\hline
\end{tabular}

Kim 2015

\begin{tabular}{ll}
\hline Methods & Non-equivalent pretest/post-test control group design \\
\hline Participants & Methods of recruitment were not reported by authors \\
& 12 participants: 6 experimental group, 6 control group \\
Inclusion criteria: participants diagnosed as having hemiplegia due to stroke \\
Exclusion criteria: there were no exclusion criteria described in the study \\
Mean (SD) age: not reported by authors
\end{tabular}


Kim 2015 (Continued)

Stroke details: not reported by authors

Stroke phase: not reported by authors

Interventions

Control group participants received traditional occupational treatment and topological treatment in which they performed purposeful action observation program assignments without actually observing the purposeful actions

Experimental group participants received traditional occupational treatment and also performed a purposeful action observation training program

Action observation training was 30 minutes per session, 5 sessions per week for 6 weeks, a total of 30 sessions

Outcome recorded after and before intervention
Upper limb function: WMFT
Kinematic variables: average velocity, trajectory ratio and motion angle by a 3D motion analysis system

Notes

\section{Risk of bias}

\begin{tabular}{|c|c|c|}
\hline Bias & Authors' judgement & Support for judgement \\
\hline $\begin{array}{l}\text { Random sequence genera- } \\
\text { tion (selection bias) }\end{array}$ & Unclear risk & Randomization was done, but there was no information of how it was done \\
\hline $\begin{array}{l}\text { Allocation concealment } \\
\text { (selection bias) }\end{array}$ & Unclear risk & Authors did not report if there was allocation concealment \\
\hline $\begin{array}{l}\text { Blinding of participants } \\
\text { and personnel (perfor- } \\
\text { mance bias) } \\
\text { All outcomes }\end{array}$ & Low risk & No blinding, but the outcome is not likely to be influenced by lack of blinding \\
\hline $\begin{array}{l}\text { Blinding of outcome as- } \\
\text { sessment (detection bias) } \\
\text { All outcomes }\end{array}$ & Unclear risk & Authors did not report if there was blinding of outcome assessment \\
\hline $\begin{array}{l}\text { Incomplete outcome data } \\
\text { (attrition bias) } \\
\text { All outcomes }\end{array}$ & Low risk & There was no loss of outcome data or dropouts \\
\hline $\begin{array}{l}\text { Selective reporting (re- } \\
\text { porting bias) }\end{array}$ & Low risk & $\begin{array}{l}\text { There is no trial registration, but the outcomes are significant, and there is no } \\
\text { selective reporting within the study }\end{array}$ \\
\hline Other bias & High risk & $\begin{array}{l}\text { The article does not say how long after the evaluation the treatment began nor } \\
\text { how long after the intervention the revaluation was performed }\end{array}$ \\
\hline
\end{tabular}

\section{Kim 2016a}

\begin{tabular}{ll}
\hline Methods & Randomized clinical trial \\
\hline Participants & Methods of recruitment were not reported by authors \\
& 22 participants: 11 action observation training group; 11 task-oriented training group \\
\hline
\end{tabular}


Kim 2016a (Continued)

Inclusion criteria: aged between 18 and 70 years with a first-time ischemic or hemorrhagic stroke; stroke experienced more than 1 month and less than 6 months before the study; sufficient cognition to participate in the study: a MMSE scores of 24 or higher; no excessive spasticity, defined as a grade of 3 or higher on the MAS

Exclusion criteria: patients with any comorbidity or disability other than stroke that precluded upper-extremity training; any uncontrolled health condition for which exercise was contraindicated

Mean (SD) age: action observation training group: 60.77 (7.03); task-oriented training group: 59.11 (7.05)

Stroke details: action observation training group: 9 ischemic, 2 hemorrhagic; task-oriented training group: 7 ischemic, 4 hemorrhagic

Stroke phase: subacute

Interventions
Action observation training group participants watched video tasks for 9 minutes, had a 1-minute break to organize their thoughts and practiced the task-oriented training for 30 minutes

Task-oriented training group participants performed tasks based on ADLs for 30 minutes, without watching the video

Action observation training group sessions were 40 minutes and task-oriented training group sessions were 30 minutes. Sessions were 5 times per week for 4 weeks

Outcomes recorded after and before intervention
Upper limb function: upper extremity part of the FMA and BBT
Activities of Daily Living: $\mathrm{MBI}$
Spasticity: MAS

Notes

\section{Risk of bias}

\begin{tabular}{lll}
\hline Bias & Authors' judgement & Support for judgement \\
\hline $\begin{array}{l}\text { Random sequence genera- } \\
\text { tion (selection bias) }\end{array}$ & Low risk & A computer-generated random number was used to allocate participants \\
\hline $\begin{array}{l}\text { Allocation concealment } \\
\text { (selection bias) }\end{array}$ & Low risk & $\begin{array}{l}\text { Authors did not report if there was allocation concealment, but randomization } \\
\text { type classifies the allocation concealment as low risk }\end{array}$ \\
\hline $\begin{array}{l}\text { Blinding of participants } \\
\begin{array}{l}\text { and personnel (perfor- } \\
\text { mance bias) } \\
\text { All outcomes }\end{array}\end{array}$ & Low risk & No blinding, but the outcome is not likely to be influenced by lack of blinding \\
\end{tabular}

\begin{tabular}{|c|c|c|}
\hline $\begin{array}{l}\text { Blinding of outcome as- } \\
\text { sessment (detection bias) } \\
\text { All outcomes }\end{array}$ & Low risk & The evaluator was not aware of the treatment allocation \\
\hline $\begin{array}{l}\text { Incomplete outcome data } \\
\text { (attrition bias) } \\
\text { All outcomes }\end{array}$ & Low risk & There was no exclusion of participants after randomization \\
\hline $\begin{array}{l}\text { Selective reporting (re- } \\
\text { porting bias) }\end{array}$ & Low risk & $\begin{array}{l}\text { There is no trial registration, but the outcomes are significant, and there is no } \\
\text { selective reporting within the study }\end{array}$ \\
\hline
\end{tabular}


Kim 2016a (Continued)

Other bias

Low risk

Kuk 2016

\begin{tabular}{ll}
\hline Methods & Randomized clinical trial \\
\hline Participants & Methods of recruitment were not reported by authors \\
& 22 participants: 11 experimental group, 11 control group \\
& Inclusion criteria: $>6$ months since stroke onset, no other neurological and orthopedic impairments, no \\
cognitive impairment ( $>24$ points in MMSE - Korean version) and ability to grasp a small cube $(2.5 \mathrm{~cm} \times$ \\
$2.5 \mathrm{~cm} \times 2.5 \mathrm{~cm})$. \\
Exclusion criteria: there were no exclusion criteria described in the study \\
Mean (SD) age: experimental group: 60.00 (9.36) years; control group: 59.70 (6.58) years \\
Stroke details: experimental group: 5 ischemic, 5 hemorrhagic; control group: 6 ischemic, 4 hemorrhag- \\
ic \\
Stroke phase: chronic
\end{tabular}

Interventions

Experimental group participants observed the action of placing wooden blocks from 1 side of the box to another for 1 minute followed by performing the same motor task for 3 minutes

Control group participants observed landscapes for 1 minute followed by performing motor task of placing wooden blocks from 1 box to another for 3 minutes

5 sessions with 10-minute rest intervals between the sessions

Outcomes Outcomes recorded at baseline and post-intervention

Hand dexterity: BBT

Notes -

\section{Risk of bias}

\begin{tabular}{lll}
\hline Bias & Authors' judgement & Support for judgement \\
\hline $\begin{array}{l}\text { Random sequence genera- } \\
\text { tion (selection bias) }\end{array}$ & Low risk & Random allocation was generated by flipping a coin \\
\hline $\begin{array}{l}\text { Allocation concealment } \\
\text { (selection bias) }\end{array}$ & Unclear risk & Authors did not report if there was allocation concealment \\
\hline $\begin{array}{l}\text { Blinding of participants } \\
\text { and personnel (perfor- } \\
\text { mance bias) } \\
\text { All outcomes }\end{array}$ & Low risk & No blinding, but the outcome is not likely to be influenced by lack of blinding \\
\hline
\end{tabular}

\begin{tabular}{lll}
\hline $\begin{array}{l}\text { Blinding of outcome as- } \\
\text { sessment (detection bias) } \\
\text { All outcomes }\end{array}$ & Unclear risk & Authors did not report if there was blinding of outcome assessment \\
\hline $\begin{array}{l}\text { Incomplete outcome data } \\
\text { (attrition bias) }\end{array}$ & Low risk & $\begin{array}{l}\text { There was } 1 \text { exclusion for each group after randomization; however, it was less } \\
\text { than } 10 \% \text { of the sample, which did not compromise the results }\end{array}$
\end{tabular}


Kuk 2016 (Continued)

All outcomes

\begin{tabular}{|c|c|c|}
\hline $\begin{array}{l}\text { Selective reporting (re- } \\
\text { porting bias) }\end{array}$ & Low risk & $\begin{array}{l}\text { The study protocol is not available but it is clear that the published reports in- } \\
\text { clude all expected outcomes, including those that were pre-specified }\end{array}$ \\
\hline
\end{tabular}

Other bias Low risk

Lee 2013

\begin{tabular}{ll}
\hline Methods & Randomized clinical trial \\
\hline Participants & Methods of recruitment were not reported by authors \\
& 33 participants: 8 for action observation group; 9 action practice group; 9 combined action observation \\
& and action practice group; 7 control group \\
& Inclusion criteria: patients with stroke at least 6 months earlier who were assessed as having recovered \\
to Brunnstrom stage 5, scored at least 20 points in the Korean MMSE, were able to understand and per- & form instructions, had visual acuity that was sufficient for watching videos, and right hemiplegic pa- \\
& tients \\
& Exclusion criteria: there were no exclusion criteria described in the study \\
& Mean (SD) age: action observation group: 63 (3.7) years, action practice group: 62 (1.5) years, combined \\
action observation and action practice group: 61 (2.3) years, and control group: 60 (5.9) years & \\
Stroke details: not reported by authors \\
Stroke phase: chronic
\end{tabular}

Interventions

Action observation group watched a drinking task video 20 times in 10 minutes and imagined they were performing the same task at the same time as they watched the video

Action practice group repeatedly practiced a drinking task for 10 minutes

Action observation and action practice group watched the task video for 5 minutes and practiced the actions for 5 minutes

Control group neither watched the video nor practiced the actions

Sessions were 10 minutes per day for 3 weeks, 15 days total

Outcomes Outcomes recorded at baseline, post-intervention and 1 week after the end of intervention

Number of drinking motions: number of times the full drinking action was performed in 1 minute

\section{Notes}

\section{Risk of bias}

\section{Bias}

Random sequence genera- Unclear risk tion (selection bias)

Allocation concealment Unclear risk (selection bias)

\section{Authors' judgement Support for judgement}

Randomization was cited in abstract, but there was no information of how it was done

Authors did not report if there was allocation concealment 
Lee 2013 (Continued)

Blinding of participants and personnel (performance bias)

All outcomes

\begin{tabular}{|c|c|c|}
\hline $\begin{array}{l}\text { Blinding of outcome as- } \\
\text { sessment (detection bias) }\end{array}$ & Low risk & $\begin{array}{l}\text { Physical therapist who conducted the assessments did not have any informa- } \\
\text { tion about the experimental group of participants }\end{array}$ \\
\hline
\end{tabular}

Incomplete outcome data Low risk (attrition bias)

All outcomes

\begin{tabular}{|c|c|c|}
\hline $\begin{array}{l}\text { Selective reporting (re- } \\
\text { porting bias) }\end{array}$ & Unclear risk & Insufficient information to permit judgement of 'low risk' or 'high risk' \\
\hline Other bias & Low risk & \\
\hline
\end{tabular}

\section{Zhu 2015}

\begin{tabular}{|c|c|}
\hline Methods & Randomized clinical trial \\
\hline \multirow[t]{7}{*}{ Participants } & Stroke patients hospitalized in Jiaxing Rehabilitation Medical Center were recruited \\
\hline & 70 participants: 35 experimental group; 35 control group \\
\hline & $\begin{array}{l}\text { Inclusion criteria: patients who met the diagnosis for stroke formulated in the } 4 \text { th National Academ- } \\
\text { ic Conference on Cerebrovascular Disease in } 1995 \text {, and were confirmed as having a stroke upon CT or } \\
\text { MRI; first-episode patients who began rehabilitation therapy within } 6 \text { months, for whom the sitting bal- } \\
\text { ance was } \geq \text { Level } 1 \text {, and the FMA score was } \geq 15 \text { for upper extremity motor function; patients with a sta- } \\
\text { ble condition; patients with a normal Kinesthetic and Visual Imagery Questionnaire score; patients who } \\
\text { were } 42 \text { to } 75 \text { years of age; patients who provided informed consent and were willing to participate in } \\
\text { the study }\end{array}$ \\
\hline & $\begin{array}{l}\text { Exclusion criteria: patients with cognitive impairment MMSE score of }<24 \text { in patients with a junior high } \\
\text { school education or }<17 \text { if illiterate; patients with severe upper limb spasticity; patients with severe } \\
\text { bone joint malformation or myopathy; patients with severe diseases of the heart, lung, liver, or kidney }\end{array}$ \\
\hline & Mean (SD) age: experimental group: 57.75 (15.57) years, control group: 56.89 (14.93) years \\
\hline & Stroke details: not reported by authors \\
\hline & Stroke phase: acute \\
\hline \multirow[t]{3}{*}{ Interventions } & $\begin{array}{l}\text { Experimental group additionally watched a video showing a specific action of the upper limb and then } \\
\text { performed the same exercise after watching } 30 \text { videos }\end{array}$ \\
\hline & Control group received conventional drug treatment and traditional physical and occupational therapy \\
\hline & $\begin{array}{l}\text { Control group received conventional therapy } 2 \text { to } 5 \text { hours per day, } 6 \text { times per week for } 8 \text { weeks. Experi- } \\
\text { mental group had additional } 30 \text { minutes per day, } 6 \text { times per week, for } 8 \text { weeks }\end{array}$ \\
\hline
\end{tabular}

\section{Outcomes}

$$
\begin{aligned}
& \text { Outcomes recorded at baseline and post-intervention } \\
& \text { Muscle tone of elbow flexor and forearm pronator: MAS } \\
& \text { Upper limb function: FMA of the upper limb }
\end{aligned}
$$


Zhu 2015 (Continued)

Activities of daily living: $\mathrm{BI}$

Notes -

\section{Risk of bias}

\begin{tabular}{lll}
\hline Bias & Authors' judgement & Support for judgement \\
\hline $\begin{array}{l}\text { Random sequence genera- } \\
\text { tion (selection bias) }\end{array}$ & Low risk & Random number table \\
\hline $\begin{array}{l}\text { Allocation concealment } \\
\text { (selection bias) }\end{array}$ & High risk & $\begin{array}{l}\text { Authors did not report if there was allocation concealment, but randomization } \\
\text { type classifies the allocation concealment as high risk }\end{array}$ \\
\hline $\begin{array}{l}\text { Blinding of participants } \\
\begin{array}{l}\text { and personnel (perfor- } \\
\text { mance bias) } \\
\text { All outcomes }\end{array}\end{array}$ & Low risk & No blinding, but the outcome is not likely to be influenced by lack of blinding \\
\hline
\end{tabular}

\begin{tabular}{lll}
\hline $\begin{array}{l}\text { Blinding of outcome as- } \\
\text { sessment (detection bias) } \\
\text { All outcomes }\end{array}$ & Low risk & $\begin{array}{l}\text { Evaluators were unaware of the participant grouping status and did not partic- } \\
\text { ipate in the treatment }\end{array}$ \\
\hline $\begin{array}{l}\text { Incomplete outcome data } \\
\text { (attrition bias) }\end{array}$ & Low risk & $\begin{array}{l}9 \text { participants were excluded from analysis: } 4 \text { from experimental group and } 5 \\
\text { from control group. Participants were excluded for absence on } 3 \text { consecutive } \\
\text { days of intervention and aggravated condition of the participant. Nevertheless } \\
\text { the reasons were reported and they have no direct relationship with the out- } \\
\text { comes studied, and there is not a substantial imbalance in final number of par- } \\
\text { ticipants in each group considered for analysis }\end{array}$
\end{tabular}

\begin{tabular}{lll}
\hline $\begin{array}{l}\text { Selective reporting (re- } \\
\text { porting bias) }\end{array}$ & Low risk & $\begin{array}{l}\text { The study protocol is not available but it is clear that the published reports in- } \\
\text { clude all expected outcomes, including those that were pre-specified }\end{array}$ \\
\hline Other bias & Low risk & \\
\hline
\end{tabular}

ADLs: activities of daily living

ARAT: Action Research Arm Test

BBT: Box and Block Test

BDI: Beck Depression Inventory

BI: Barthel Index

CG: control group

CMCT: center-motion conduction time

CPT: conventional physical therapy

$\mathrm{CT}$ : computed tomography

EG: experimental group

FAT: Frenchay Arm Test

FAST: Florida Apraxia Screening Test

FIM: Functional Independence Measure

FMA: Fugl-Meyer Assessment

fMRI: functional magnetic resonance

MAL: Motor Activity Log

MAS: Modified Ashworth Scale

MBI: Modified Barthel Index

MEP: motor evoked potential amplitudes

MI: Motricity Index

MMSE: mini-mental state examination

MRI: magnetic resonance imaging

NHPT: Nine Hole Peg test

OTI: observation-to-imitate 
PP: physical practice

SD: standard deviation

SIS: Stroke Impact Scale

TMS: transcranial magnetic stimulation

VAS: visual analogue scale

WMFT: Wolf Motor Function Test

Characteristics of excluded studies [ordered by study ID]

\begin{tabular}{|c|c|}
\hline Study & Reason for exclusion \\
\hline Brunner 2014 & Study design: not an RCT \\
\hline Cha 2015 & Study design: not an RCT \\
\hline Chang 2017 & The intervention was mirror therapy \\
\hline Emmerson 2017 & $\begin{array}{l}\text { The intervention was home exercise programs including techniques such as constraint-induced } \\
\text { movement therapy, repetitive task-specific training, mirror therapy, and bilateral training }\end{array}$ \\
\hline Ertelt 2012 & It is a protocol without results \\
\hline Franceschini 2010 & Study design: not an RCT \\
\hline Frenkel-Toledo 2014 & Study design: not an RCT \\
\hline Kim 2013a & Did not assess upper limb, but trunk and lower-limb function \\
\hline Kim 2013b & Did not assess upper limb, but lower limb \\
\hline Kim 2014 & Study design: not an RCT \\
\hline Kim 2016b & Used AO associated with interface-based electrical stimulation \\
\hline Liepert 2014 & Study design: not an RCT \\
\hline Lubart 2017 & The control and experimental group performed AO therapy \\
\hline Marangon 2014 & Study design: not an RCT \\
\hline Sale 2012 & Study design: not an RCT \\
\hline Sugg 2015 & Study design: not an RCT \\
\hline Sun 2016 & Used $\mathrm{AO}$ associated with motor imagery \\
\hline Szameitat 2012 & Study design: not an RCT \\
\hline Wright 2014 & Used $\mathrm{AO}$ associated with motor imagery \\
\hline
\end{tabular}

AO: action observation

$\mathrm{RCT}$ : randomized controlled trial

Characteristics of studies awaiting assessment [ordered by study ID] 
Gu 2013

\begin{tabular}{ll}
\hline Methods & RCT \\
\hline Participants & 30 stroke patients hospitalized in D Hospital located in Busan \\
\hline Interventions & Experimental group: action-observation training group (15 participants) \\
& Control group: task-oriented training group (15 participants) \\
\hline Outcomes & Activities of daily living performance before and after therapy intervention, K-MBI \\
\hline Notes & Korean language, only abstract in English
\end{tabular}

Jin-Woo 2011

\begin{tabular}{ll}
\hline Methods & Not known \\
\hline Participants & Not known \\
\hline Interventions & Not known \\
\hline Outcomes & Not known \\
\hline Notes & Korean language. There was no English abstract available \\
\hline
\end{tabular}

Kim 2010

\begin{tabular}{ll}
\hline Methods & RCT \\
\hline Participants & 10 stroke patients \\
\hline Interventions & $\begin{array}{l}\text { There were } 3 \text { groups: base condition (Base), physical training (PT), action observational physical } \\
\text { training (AOPT) }\end{array}$ \\
\hline Outcomes & $\begin{array}{l}\text { Changes in the amplitude of motor-evoked potentials (MEPs) elicited in hand muscles by transcra- } \\
\text { nial magnetic stimulation. MEP responses were measured from the first dorsal interosseous. For } \\
\text { manual dexterity, BBT was used }\end{array}$ \\
\hline Notes & Korean language, only abstract in English \\
\hline
\end{tabular}

\section{Ko 2014}

\begin{tabular}{ll}
\hline Methods & RCT \\
\hline Participants & 19 hemiparetic stroke patients \\
\hline Interventions & $\begin{array}{l}\text { An experimental group observed performance actions of purposeful activity task through a video } \\
\text { and imitated actions with traditional occupational therapy, and a control group only observed ac- } \\
\text { tions with the traditional occupational therapy. Training was performed } 3 \text { times a week, } 30 \text { min- } \\
\text { utes for each round, for } 4 \text { weeks. }\end{array}$ \\
\hline
\end{tabular}


Ko 2014 (Continued)

Outcomes

WMFT was performed for an upper extremity function and MBI was performed for activities of daily living

Notes Korean language, only abstract in English

Lee 2016

\begin{tabular}{ll}
\hline Methods & RCT \\
\hline Participants & 15 patients with chronic stroke \\
\hline Interventions & $\begin{array}{l}\text { Experimental group }(n=7), \text { who received distant action-observation training, and the control } \\
\text { group }(n=8), \text { who received a self-exercise program. Each intervention consisted of a 30-minute } \\
\text { session once a day, } 3 \text { times a week, for } 5 \text { weeks }\end{array}$ \\
\hline Outcomes & $\begin{array}{l}\text { To measure the functions of the upper limbs and performance capacities in the activities of daily } \\
\text { living, the FMA scale and the MAL were used }\end{array}$ \\
\hline Notes & Korean language, only abstract in English \\
\hline
\end{tabular}

Yun 2011

\begin{tabular}{ll}
\hline Methods & RCT \\
\hline Participants & 17 participants with stroke (10 men and 7 women) \\
\hline Interventions & $\begin{array}{l}\text { Participants were asked to observe different stimulation conditions for } 80 \text { seconds, picture obser- } \\
\text { vation condition and action observation condition. A 30-second rest period was given between } \\
\text { stimulations }\end{array}$ \\
\hline Outcomes & $\begin{array}{l}\text { The activation of the mirror neuron system (MNS) was assessed by EEG signals from electrodes on } \\
\text { the participant's scalp and recorded during action observation. The difference of activation be- } \\
\text { tween left hemisphere and right hemisphere was evaluated }\end{array}$ \\
\hline Notes & Korean language, only abstract in English \\
\hline
\end{tabular}

BBT: Box and Block Test

EEG: electroencephalography

FMA: Fugl-Mayer Assessment

K-MBI: Korea-modified Barthel index

MAL: Motor Activity Log

MEP: motor-evoked potential

RCT: randomized controlled trial

WMFT: Wolf Motor Function Test

Characteristics of ongoing studies [ordered by study ID]

\section{NCT02235350}

Trial name or title
Study on the effectiveness of action observation treatment (AOT) as a rehabilitation tool in acute stroke patients and in chronic stroke patients with apraxia: a randomized controlled trial 
NCT02235350 (Continued)

Methods RCT
First-ever ischemic or hemorrhagic stroke confirmed by CT/MRI, no later than 30 days from acute event, or chronic stroke patients (more than 3 months from the acute event) with apraxia. Aged 18 to 85 years. Upper limb plegia or paresis with muscle strength in grasping $M R C<4$. Ability to understand and carry out simple verbal instruction. MMSE $=20$

Experimental group: AOT

Control group: observation of videos with no motor content

\begin{tabular}{ll}
\hline Outcomes & FMA of motor recovery after stroke, FIM, and fMRI \\
\hline Starting date & June 2014 \\
\hline Contact information & buccino@unicz.it \\
\hline Notes & Date accessed: October 2017 \\
\hline
\end{tabular}

\begin{tabular}{ll}
\hline NCT02871700 & $\begin{array}{l}\text { Comparative efficacy study of action observation therapy and mirror therapy after stroke: rehabili- } \\
\text { tation outcomes and neural mechanisms by MEG }\end{array}$ \\
\hline Methods & RCT \\
\hline Participants & People with unilateral stroke, 1 to 6 months after stroke onset, from 20 to 80 years of age \\
\hline Interventions & Action observation therapy; customary bilateral UE training and mirror therapy \\
\hline Outcomes & FMA, ABILHAND questionnaire, ActiGraph, BBT, Chedoke Arm and Hand Activity Inventory, FIM, \\
MRC scale, mRS, MAL, Questionnaire Upon Mental Imagery, Revised Nottingham Sensory Assess- & ment, SIS Version 3.0., VAS for fatigue and pain, WMFT, and MEG \\
\hline Starting date & August 2016 \\
\hline Contact information & Yu-Wei Hsieh: ywhsieh@mail.cgu.edu.tw \\
\hline Notes & Date accessed: October 2017 \\
\hline
\end{tabular}

\section{RBR-26q4z9}

\begin{tabular}{ll} 
Trial name or title & $\begin{array}{l}\text { Comparative study between action observation training and hydrotherapy in upper limb recovery } \\
\text { after stroke: randomized clinical trial }\end{array}$ \\
\hline Methods & RCT \\
\hline Participants & $\begin{array}{l}60 \text { adult participants, } 40 \text { to } 80 \text { years old, with diagnosis of a single episode of ischemic or hemor- } \\
\text { rhagic stroke which occurred between } 3 \text { months and } 2 \text { years earlier; with brachial-facial hemipare- } \\
\text { sis; with mild to moderate and independent walking (use of any assistive device for ambulation in- } \\
\text { cluded) }\end{array}$ \\
\hline
\end{tabular}


RBR-26q4z9 (Continued)

Interventions
Experimental group 1: action observation training participants will perform functional movements while watching a video that demonstrates functional movements and perform the movements shown in the video

Experimental group 2: hydrotherapy. Participants will hold exercises in the heated pool, active movements of the upper limbs, strengthening exercises and functional movements that simulate everyday activities and walking

Control group: conventional physiotherapy with exercises in range of motion of the upper and lower limbs, strengthening exercises of the upper limbs, trunk and lower limbs, stretching and balance exercises and walking

All the groups will receive intervention 2 times a week, lasting 40 minutes. The duration of treatment is 6 months

\section{Outcomes} Improvement of upper limb functionality and performance of activities of daily living, verified by FMA scale

fMRI was a secondary outcome.

\begin{tabular}{ll}
\hline Starting date & June 2015 \\
\hline Contact information & angelafisio@yahoo.com.br \\
\hline Notes & Date accessed: October 2017 \\
\hline
\end{tabular}

AOT: action observation treatment

BBT: Box and Block test

BI: Barthel Index

CT: computed tomography

FAT: Function Arm Test

FIM: Functional Independence Measure

FMA: Fugl-Mayer Assessment

fMRI: Functional Magnetic Resonance

MAL: Motor Activity Log

MEG: magnetoencephalography

MMSE: Mini Mental State Examination

MRC: Medical Research Council

MRI: magnetic resonance imaging

mRS: Modified Rankin Scale

RCT: randomized controlled trial

SIS: Stroke Impact Scale

UE: upper extremity

VAS: Visual Analogue Scale

WMFT: Wolf Motor Function Test

\section{DATA AND ANALYSES}

Comparison 1. Action observation therapy versus control: effect on arm function

\begin{tabular}{lllll}
\hline Outcome or subgroup title & No. of studies & $\begin{array}{l}\text { No. of partici- } \\
\text { pants }\end{array}$ & Statistical method & Effect size \\
\hline 1 Arm function & 8 & 314 & $\begin{array}{l}\text { Std. Mean Difference (IV, Random, } \\
95 \% \text { CI) }\end{array}$ & $0.36[0.13,0.60]$ \\
\hline
\end{tabular}




\begin{tabular}{|c|c|c|c|c|}
\hline Outcome or subgroup title & No. of studies & $\begin{array}{l}\text { No. of partici- } \\
\text { pants }\end{array}$ & Statistical method & Effect size \\
\hline 2 Subgroup analysis: age & 8 & 314 & $\begin{array}{l}\text { Std. Mean Difference (IV, Random, } \\
95 \% \mathrm{CI})\end{array}$ & $0.36[0.13,0.60]$ \\
\hline 2.1 Upper 60 years & 3 & 165 & $\begin{array}{l}\text { Std. Mean Difference (IV, Random, } \\
95 \% \mathrm{CI})\end{array}$ & $0.30[-0.01,0.61]$ \\
\hline 2.2 Lower 60 years & 5 & 149 & $\begin{array}{l}\text { Std. Mean Difference (IV, Random, } \\
95 \% \mathrm{CI})\end{array}$ & $0.46[0.04,0.89]$ \\
\hline $\begin{array}{l}3 \text { Subgroup analysis: type of } \\
\text { stroke }\end{array}$ & 8 & 314 & $\begin{array}{l}\text { Std. Mean Difference (IV, Random, } \\
95 \% \mathrm{CI} \text { ) }\end{array}$ & $0.36[0.13,0.60]$ \\
\hline 3.1 Ischemic stroke & 2 & 69 & $\begin{array}{l}\text { Std. Mean Difference (IV, Random, } \\
95 \% \mathrm{CI} \text { ) }\end{array}$ & $0.61[0.13,1.10]$ \\
\hline $\begin{array}{l}3.2 \text { Ischemic and hemorrhagic } \\
\text { stroke }\end{array}$ & 2 & 112 & $\begin{array}{l}\text { Std. Mean Difference (IV, Random, } \\
95 \% \mathrm{CI} \text { ) }\end{array}$ & $0.69[-0.43,1.82]$ \\
\hline 3.3 Type of stroke not stated & 4 & 133 & $\begin{array}{l}\text { Std. Mean Difference (IV, Random, } \\
95 \% \mathrm{CI} \text { ) }\end{array}$ & $0.22[-0.13,0.56]$ \\
\hline $\begin{array}{l}4 \text { Subgroup analysis: time post } \\
\text { stroke }\end{array}$ & 7 & 302 & $\begin{array}{l}\text { Std. Mean Difference (IV, Random, } \\
95 \% \mathrm{CI} \text { ) }\end{array}$ & $0.39[0.15,0.64]$ \\
\hline 4.1 Acute or subacute phase & 5 & 248 & $\begin{array}{l}\text { Std. Mean Difference (IV, Random, } \\
95 \% \mathrm{CI})\end{array}$ & $0.39[0.07,0.72]$ \\
\hline 4.2 Chronic phase & 1 & 16 & $\begin{array}{l}\text { Std. Mean Difference (IV, Random, } \\
95 \% \mathrm{CI})\end{array}$ & $0.77[-0.26,1.79]$ \\
\hline $\begin{array}{l}4.3 \text { Acute, subacute and chron- } \\
\text { ic phase }\end{array}$ & 1 & 38 & $\begin{array}{l}\text { Std. Mean Difference (IV, Random, } \\
95 \% \mathrm{CI} \text { ) }\end{array}$ & $0.37[-0.27,1.02]$ \\
\hline $\begin{array}{l}5 \text { Subgroup analysis: dose of } \\
\text { treatment }\end{array}$ & 8 & 314 & $\begin{array}{l}\text { Std. Mean Difference (IV, Random, } \\
95 \% \mathrm{CI} \text { ) }\end{array}$ & $0.36[0.13,0.60]$ \\
\hline $\begin{array}{l}5.1 \text { More than } 1.000 \text { minutes of } \\
\text { therapy }\end{array}$ & 3 & 115 & $\begin{array}{l}\text { Std. Mean Difference (IV, Random, } \\
95 \% \mathrm{CI})\end{array}$ & $0.34[-0.03,0.71]$ \\
\hline $\begin{array}{l}5.2 \text { Less than } 1.000 \text { minutes of } \\
\text { therapy }\end{array}$ & 5 & 199 & $\begin{array}{l}\text { Std. Mean Difference (IV, Random, } \\
95 \% \mathrm{CI} \text { ) }\end{array}$ & $0.40[0.00,0.80]$ \\
\hline $\begin{array}{l}6 \text { Subgroup analysis: type of } \\
\text { control group }\end{array}$ & 8 & 351 & $\begin{array}{l}\text { Std. Mean Difference (IV, Random, } \\
95 \% \mathrm{CI} \text { ) }\end{array}$ & $0.32[0.08,0.55]$ \\
\hline 6.1 Placebo therapy & 6 & 231 & $\begin{array}{l}\text { Std. Mean Difference (IV, Random, } \\
95 \% \mathrm{CI})\end{array}$ & $0.45[0.13,0.78]$ \\
\hline $\begin{array}{l}6.2 \text { Conventional Physical } \\
\text { Therapy }\end{array}$ & 2 & 83 & $\begin{array}{l}\text { Std. Mean Difference (IV, Random, } \\
95 \% \mathrm{CI} \text { ) }\end{array}$ & $0.20[-0.23,0.63]$ \\
\hline 6.3 No specific training & 1 & 37 & $\begin{array}{l}\text { Std. Mean Difference (IV, Random, } \\
95 \% \mathrm{CI} \text { ) }\end{array}$ & $-0.12[-0.77,0.52]$ \\
\hline
\end{tabular}




\begin{tabular}{|c|c|c|c|c|}
\hline Outcome or subgroup title & No. of studies & $\begin{array}{l}\text { No. of partici- } \\
\text { pants }\end{array}$ & Statistical method & Effect size \\
\hline $\begin{array}{l}7 \text { Subgroup analysis: duration } \\
\text { of observation }\end{array}$ & 6 & 241 & $\begin{array}{l}\text { Std. Mean Difference (IV, Random, } \\
95 \% \mathrm{CI} \text { ) }\end{array}$ & $0.45[0.15,0.75]$ \\
\hline $\begin{array}{l}7.1 \text { More than } 3 \text { minutes of ob- } \\
\text { servation }\end{array}$ & 4 & 129 & $\begin{array}{l}\text { Std. Mean Difference (IV, Random, } \\
95 \% \mathrm{Cl})\end{array}$ & $0.65[0.29,1.00]$ \\
\hline $\begin{array}{l}7.2 \text { Less than } 3 \text { minutes of ob- } \\
\text { servation }\end{array}$ & 2 & 112 & $\begin{array}{l}\text { Std. Mean Difference (IV, Random, } \\
95 \% \mathrm{Cl} \text { ) }\end{array}$ & $0.18[-0.19,0.55]$ \\
\hline $\begin{array}{l}8 \text { Arm function - sensitivity } \\
\text { analysis: without high ROB for } \\
\text { allocation concealment }\end{array}$ & 6 & 200 & $\begin{array}{l}\text { Std. Mean Difference (IV, Random, } \\
95 \% \mathrm{Cl} \text { ) }\end{array}$ & $0.38[0.03,0.73]$ \\
\hline $\begin{array}{l}9 \text { Arm function - sensitivity } \\
\text { analysis: without high ROB for } \\
\text { incomplete outcome data }\end{array}$ & 2 & 38 & $\begin{array}{l}\text { Std. Mean Difference (IV, Random, } \\
95 \% \mathrm{CI})\end{array}$ & $1.08[0.39,1.78]$ \\
\hline $\begin{array}{l}10 \text { Arm function - sensitivity } \\
\text { analysis: home-based action } \\
\text { observation training (video } \\
\text { therapy) }\end{array}$ & 7 & 276 & $\begin{array}{l}\text { Std. Mean Difference (IV, Random, } \\
95 \% \mathrm{CI} \text { ) }\end{array}$ & $0.38[0.10,0.66]$ \\
\hline $\begin{array}{l}11 \text { Arm function - sensitivity } \\
\text { analysis: real demonstration }\end{array}$ & 7 & 292 & $\begin{array}{l}\text { Std. Mean Difference (IV, Random, } \\
95 \% \mathrm{Cl} \text { ) }\end{array}$ & $0.39[0.13,0.66]$ \\
\hline
\end{tabular}

\section{Analysis 1.1. Comparison 1 Action observation therapy versus control: effect on arm function, Outcome 1 Arm function.}

\begin{tabular}{|c|c|c|c|c|c|c|c|}
\hline \multirow[t]{2}{*}{ Study or subgroup } & \multicolumn{2}{|c|}{ AO Therapy } & \multicolumn{2}{|c|}{ Control } & \multirow{2}{*}{$\begin{array}{c}\text { Std. Mean Difference } \\
\text { Random, } 95 \% \mathrm{Cl}\end{array}$} & \multirow[t]{2}{*}{ Weight } & \multirow{2}{*}{$\begin{array}{c}\text { Std. Mean Difference } \\
\text { Random, } 95 \% \mathrm{CI}\end{array}$} \\
\hline & $\mathbf{N}$ & Mean(SD) & $\mathbf{N}$ & $\operatorname{Mean}(S D)$ & & & \\
\hline Kim 2015 & 6 & $39.8(12.2)$ & 6 & $42(11.6)$ & & $4.22 \%$ & $-0.17[-1.31,0.96]$ \\
\hline Cowles 2013 & 9 & $29.8(20)$ & 13 & $27.1(20.2)$ & & $7.39 \%$ & $0.13[-0.72,0.98]$ \\
\hline Franceschini 2012 & 48 & $72.7(31.2)$ & 42 & $66.9(28.4)$ & $\pi$ & $27.95 \%$ & $0.19[-0.22,0.61]$ \\
\hline Zhu 2015 & 31 & $35.5(12.4)$ & 30 & $32.8(11.2)$ & + & $19.82 \%$ & $0.23[-0.28,0.73]$ \\
\hline Dettmers 2014 & 19 & $47.4(11.8)$ & 19 & $43.5(8.3)$ & & $12.65 \%$ & $0.37[-0.27,1.02]$ \\
\hline Ertelt 2007 & 8 & $-7(6.8)$ & 8 & $-16.9(15.9)$ & & $5.13 \%$ & $0.77[-0.26,1.79]$ \\
\hline Kim 2016a & 11 & $52.7(3.3)$ & 11 & $48.4(2.8)$ & & $6.03 \%$ & $1.35[0.41,2.3]$ \\
\hline Total *** & 160 & & 154 & & & $100 \%$ & $0.36[0.13,0.6]$ \\
\hline \multicolumn{8}{|c|}{ Heterogeneity: $\mathrm{Tau}^{2}=0.01 ; \mathrm{Chi}^{2}=7.42, \mathrm{df}=7(\mathrm{P}=0.39) ; \mathrm{I}^{2}=5.65 \%$} \\
\hline \multicolumn{3}{|c|}{ Test for overall effect: $Z=3.04(P=0)$} & & & & & \\
\hline
\end{tabular}


Analysis 1.2. Comparison 1 Action observation therapy versus

control: effect on arm function, Outcome 2 Subgroup analysis: age.

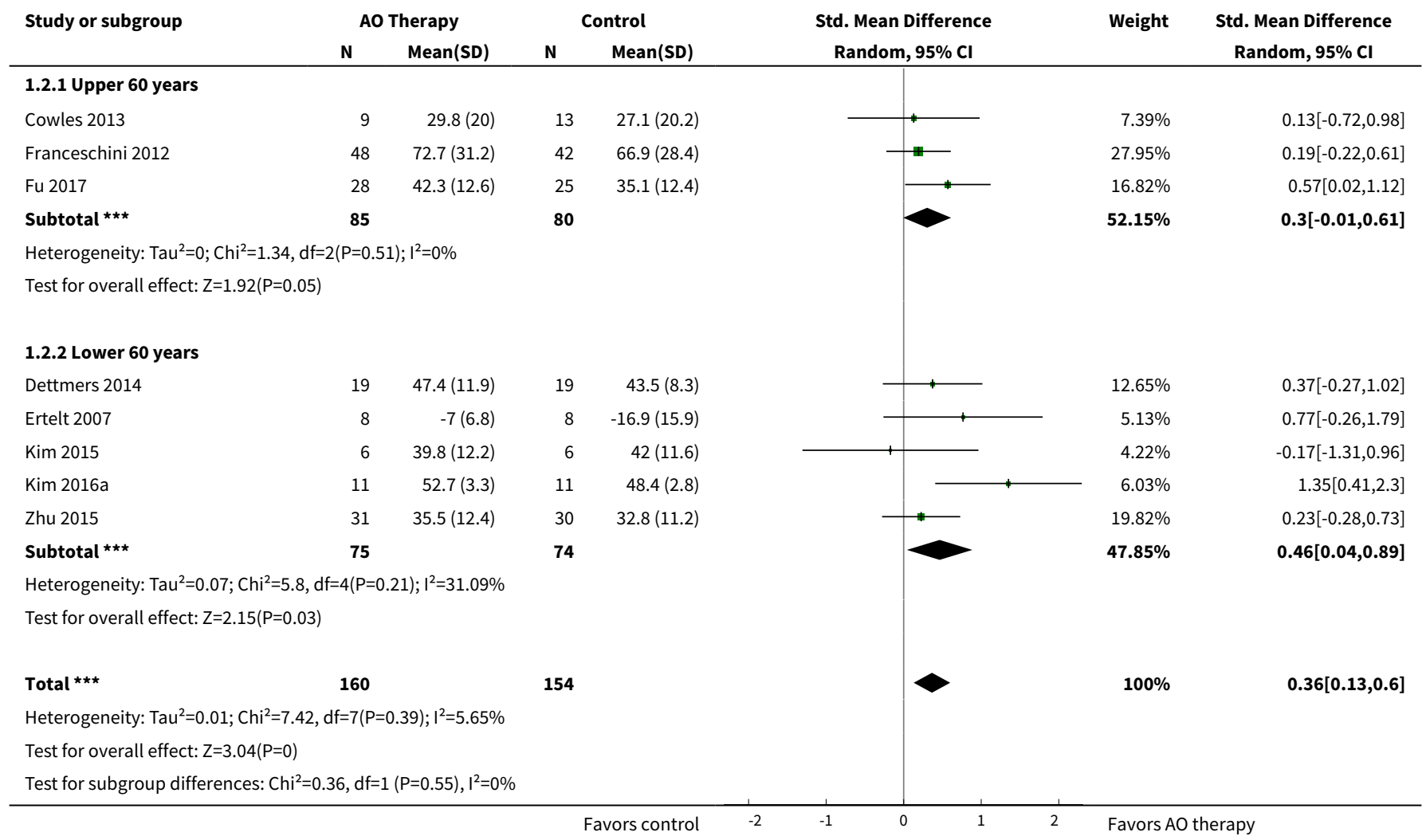

Analysis 1.3. Comparison 1 Action observation therapy versus control: effect on arm function, Outcome 3 Subgroup analysis: type of stroke.

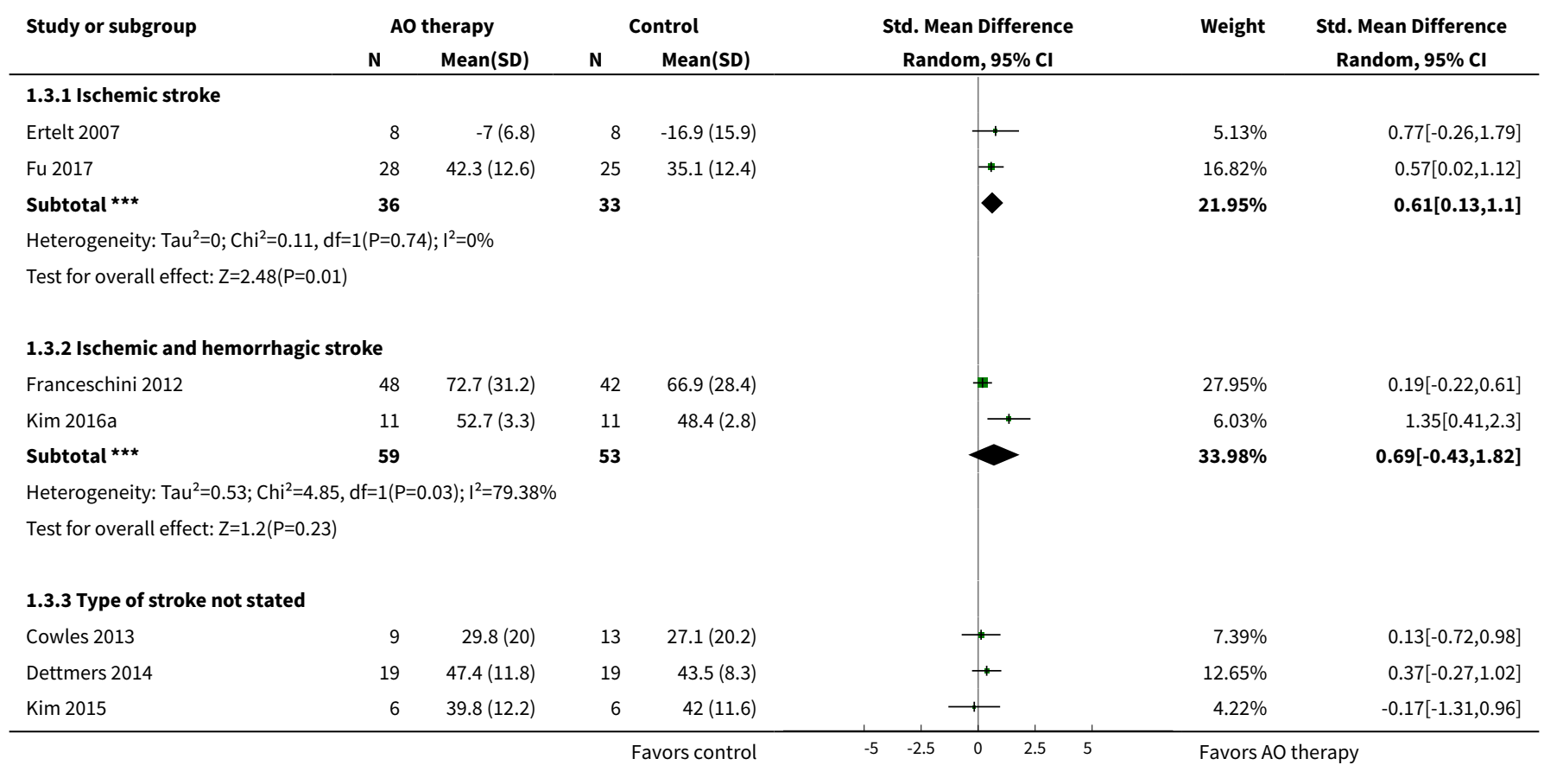




\begin{tabular}{|c|c|c|c|c|c|c|c|}
\hline \multirow[t]{2}{*}{ Study or subgroup } & \multicolumn{2}{|c|}{ AO therapy } & \multicolumn{2}{|c|}{ Control } & \multirow{2}{*}{$\begin{array}{c}\text { Std. Mean Difference } \\
\text { Random, } 95 \% \mathrm{Cl}\end{array}$} & \multirow[t]{2}{*}{ Weight } & \multirow{2}{*}{$\begin{array}{l}\text { Std. Mean Difference } \\
\text { Random, } 95 \% \mathrm{Cl}\end{array}$} \\
\hline & $\mathbf{N}$ & Mean(SD) & $\mathbf{N}$ & Mean(SD) & & & \\
\hline Zhu 2015 & 31 & $35.5(12.4)$ & 30 & $32.8(11.2)$ & *- & $19.82 \%$ & $0.23[-0.28,0.73]$ \\
\hline Subtotal $* \star \star$ & 65 & & 68 & & 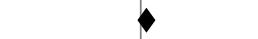 & $44.07 \%$ & $0.22[-0.13,0.56]$ \\
\hline \multicolumn{8}{|c|}{ Heterogeneity: $\mathrm{Tau}^{2}=0 ; \mathrm{Chi}^{2}=0.72, \mathrm{df}=3(\mathrm{P}=0.87) ; \mathrm{I}^{2}=0 \%$} \\
\hline \multicolumn{8}{|c|}{ Test for overall effect: $Z=1.24(P=0.22)$} \\
\hline Total $\star \star \star$ & 160 & & 154 & & $\downarrow$ & $100 \%$ & $0.36[0.13,0.6]$ \\
\hline \multicolumn{8}{|c|}{ Heterogeneity: $\operatorname{Tau}^{2}=0.01 ; \mathrm{Chi}^{2}=7.42, \mathrm{df}=7(\mathrm{P}=0.39) ; \mathrm{I}^{2}=5.65 \%$} \\
\hline \multicolumn{8}{|c|}{ Test for overall effect: $Z=3.04(P=0)$} \\
\hline \multicolumn{8}{|c|}{ Test for subgroup differences: $\mathrm{Chi}^{2}=2.06, \mathrm{df}=1(\mathrm{P}=0.36), \mathrm{I}^{2}=2.89 \%$} \\
\hline & & & & ors control & $-5 \quad-2.5$ & Favors AC & rapy \\
\hline
\end{tabular}

Analysis 1.4. Comparison 1 Action observation therapy versus control: effect on arm function, Outcome 4 Subgroup analysis: time post stroke.

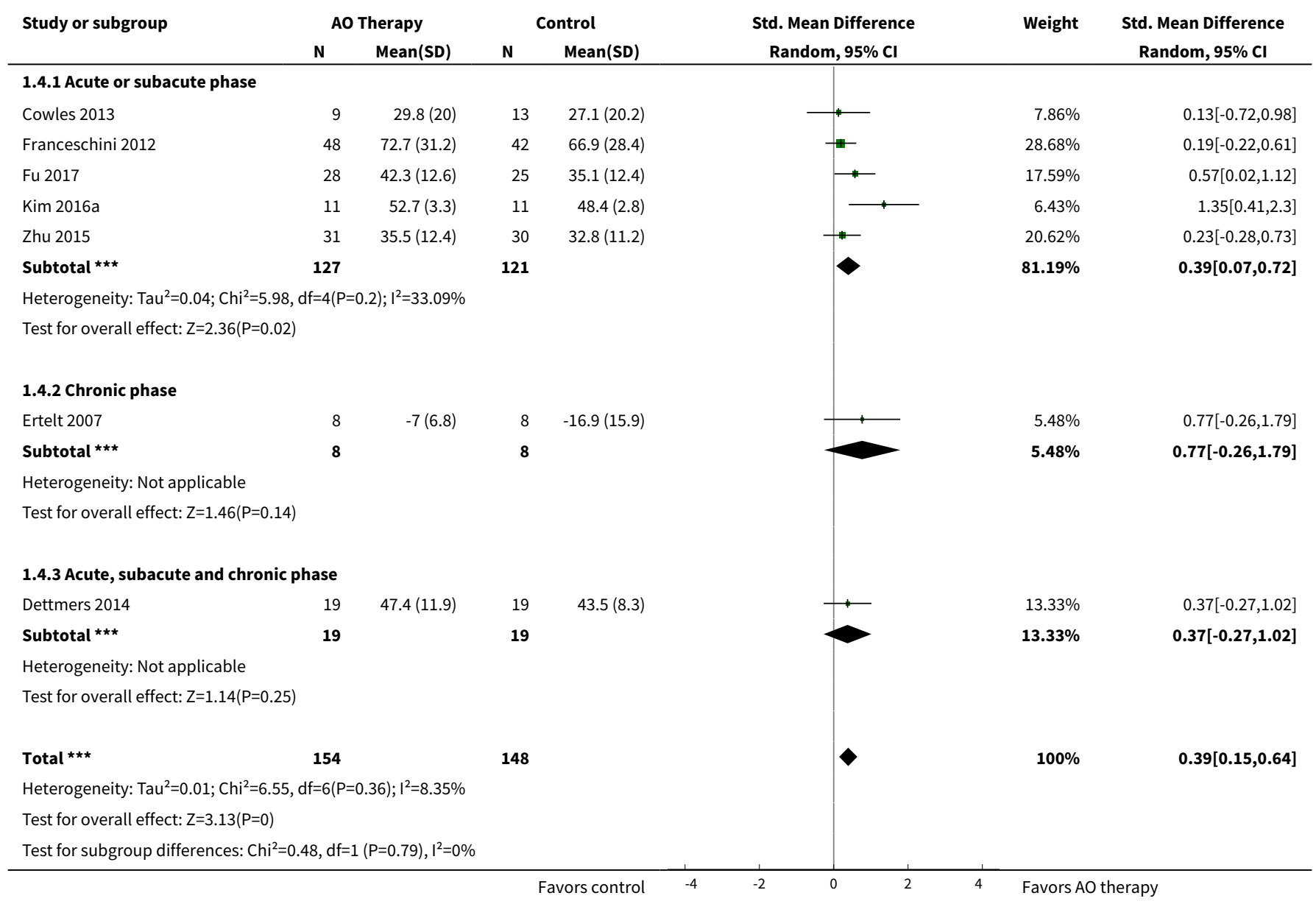


Analysis 1.5. Comparison 1 Action observation therapy versus control: effect on arm function, Outcome 5 Subgroup analysis: dose of treatment.

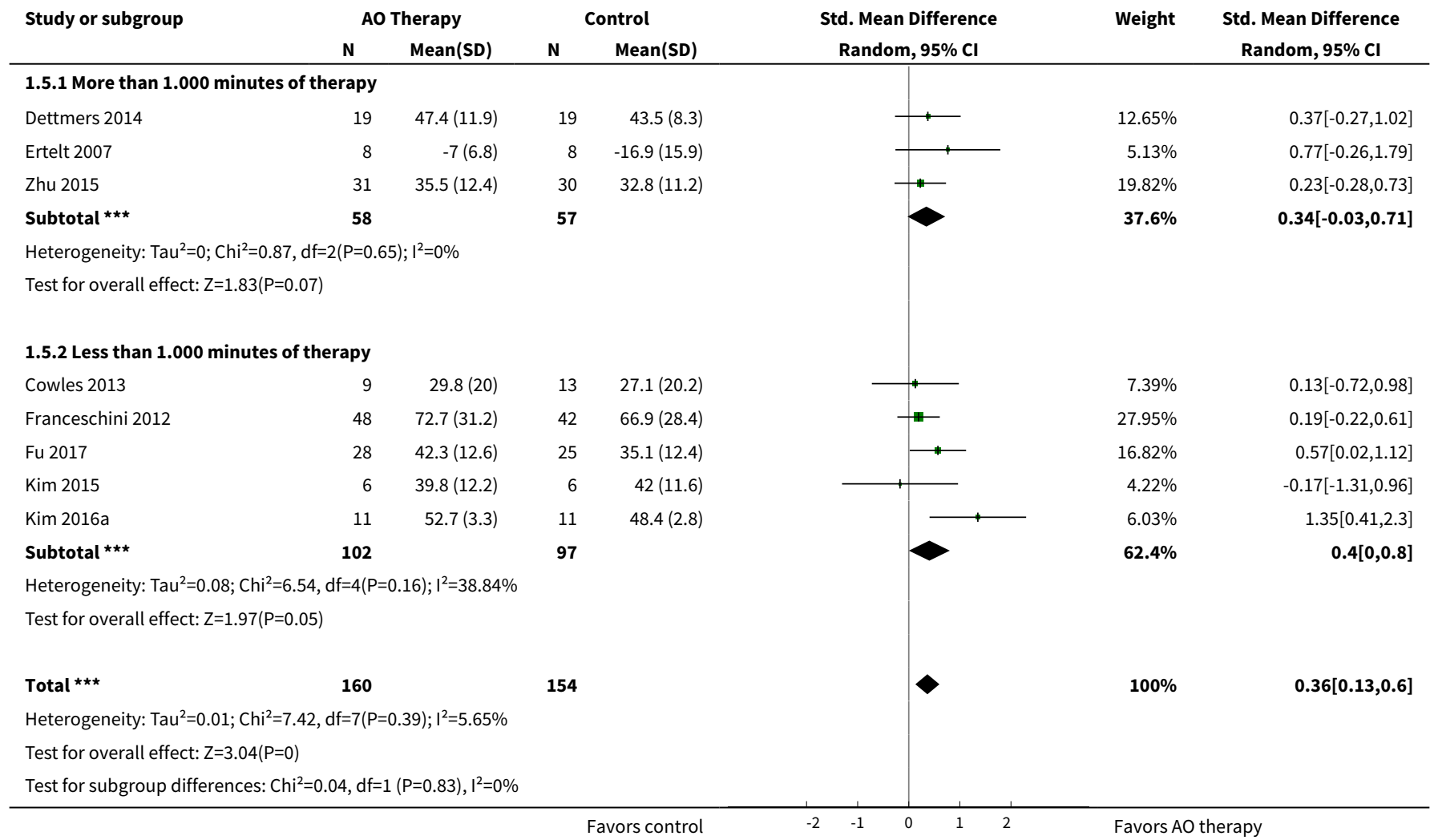

Analysis 1.6. Comparison 1 Action observation therapy versus control: effect on arm function, Outcome 6 Subgroup analysis: type of control group.

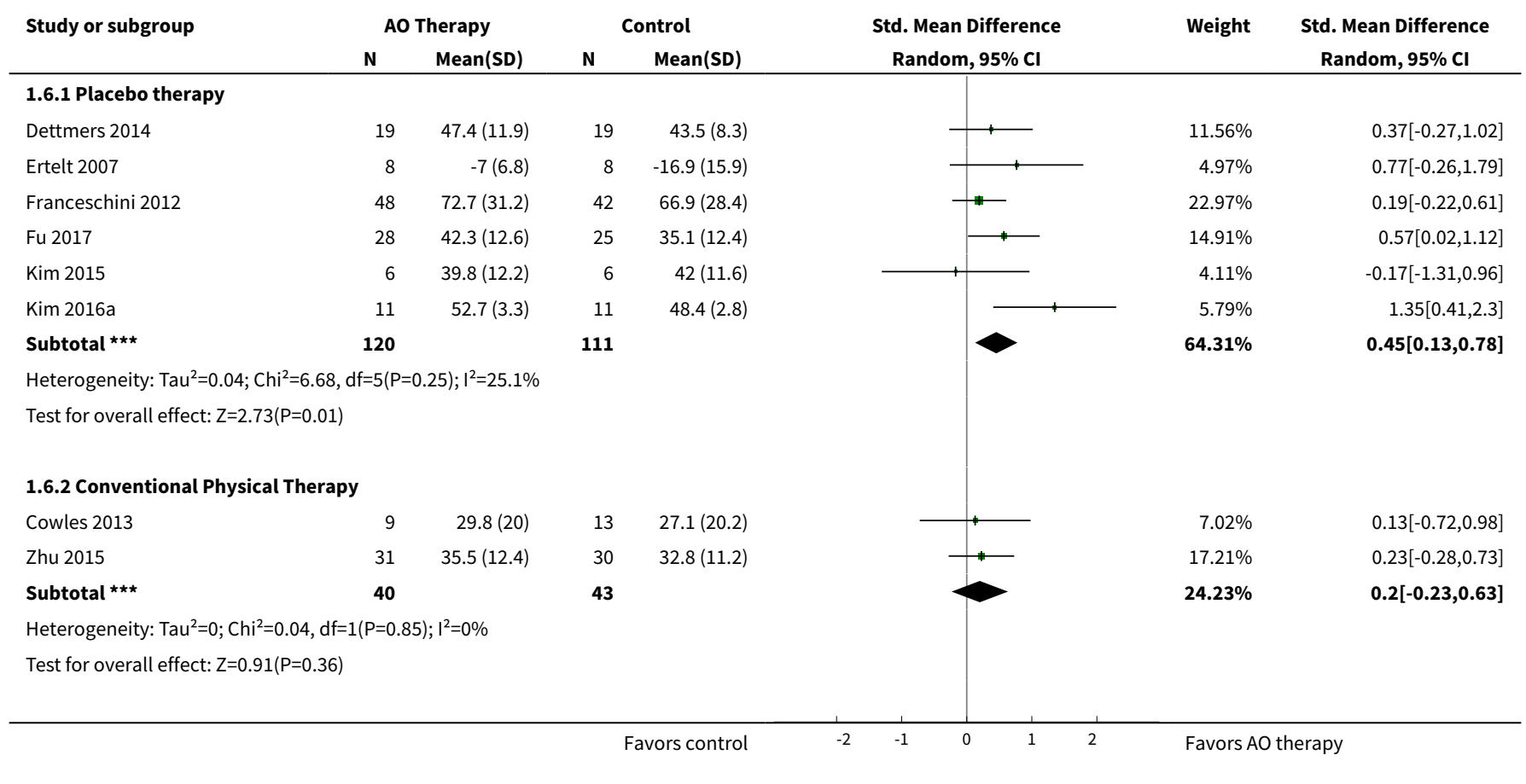




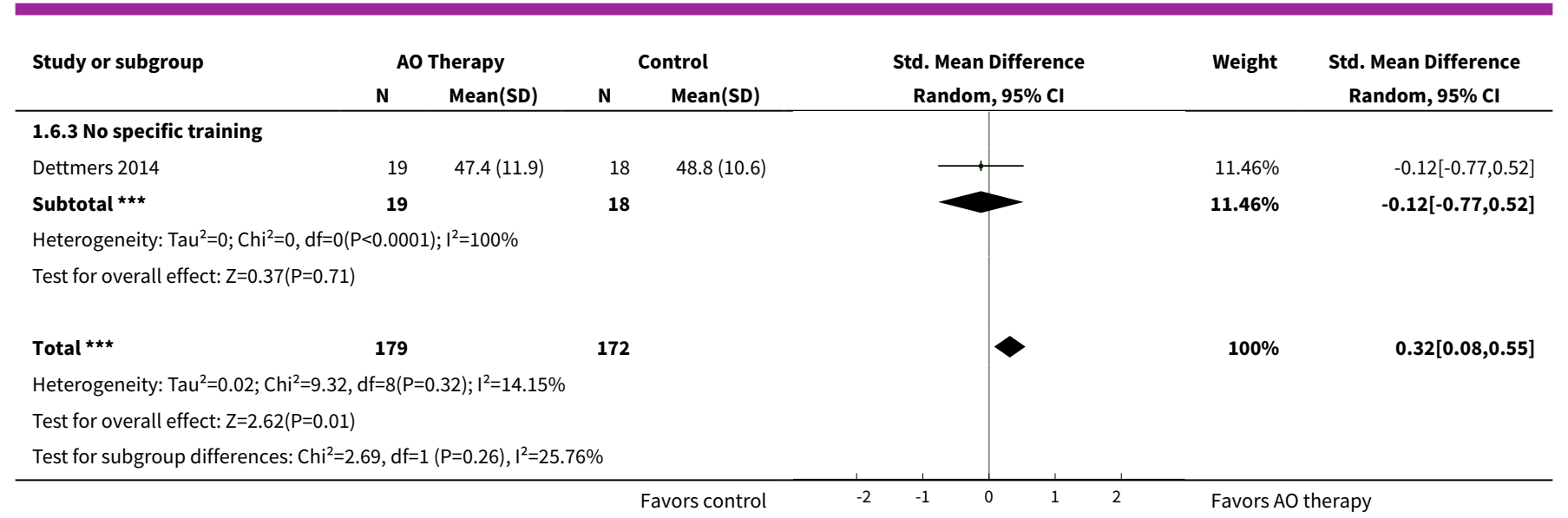

Analysis 1.7. Comparison 1 Action observation therapy versus control: effect on arm function, Outcome 7 Subgroup analysis: duration of observation.

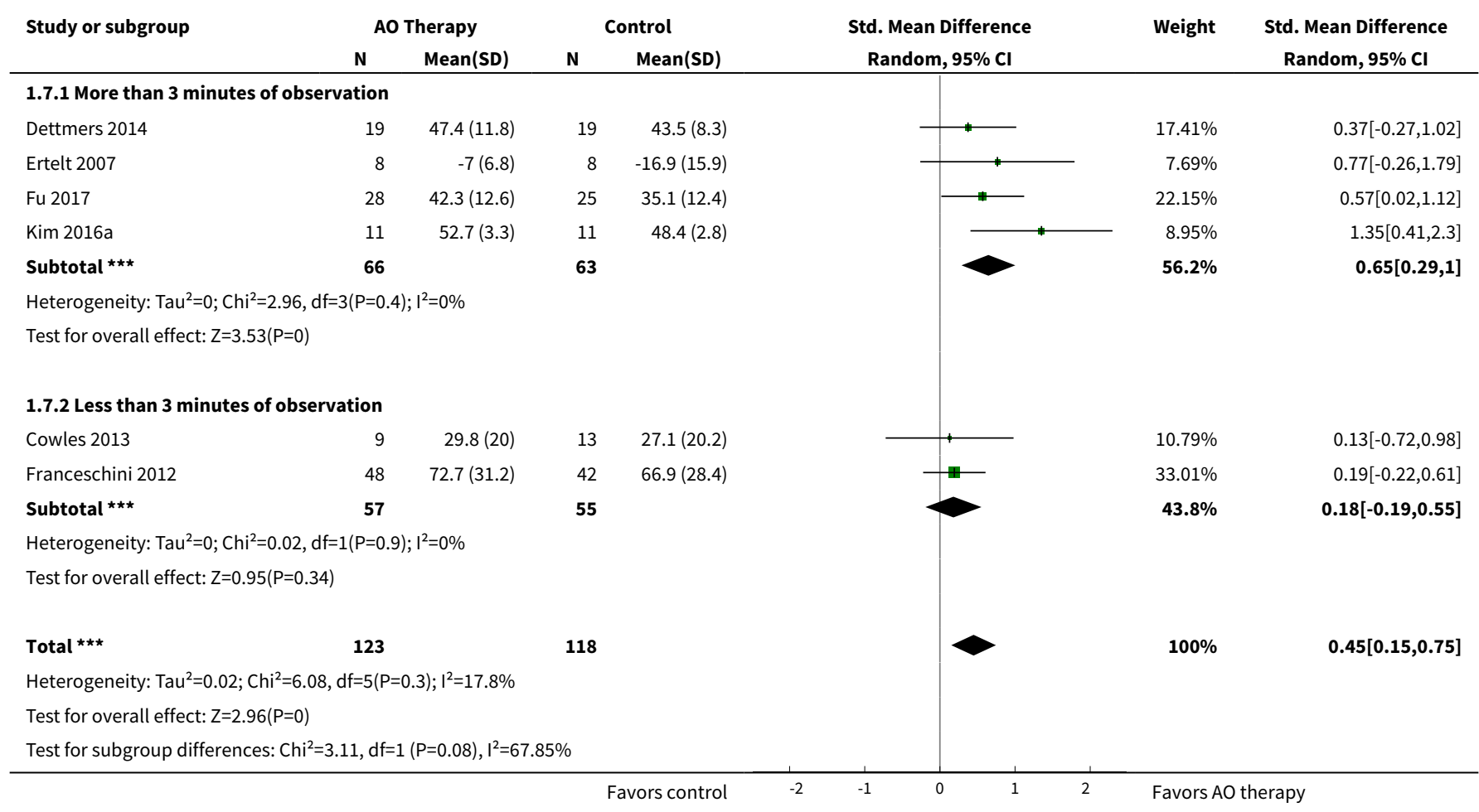

Analysis 1.8. Comparison 1 Action observation therapy versus control: effect on arm function, Outcome 8 Arm function - sensitivity analysis: without high ROB for allocation concealment.

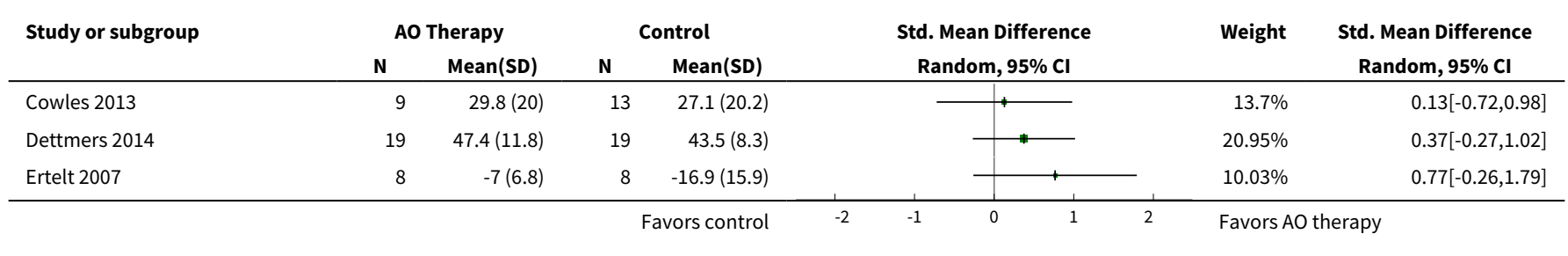




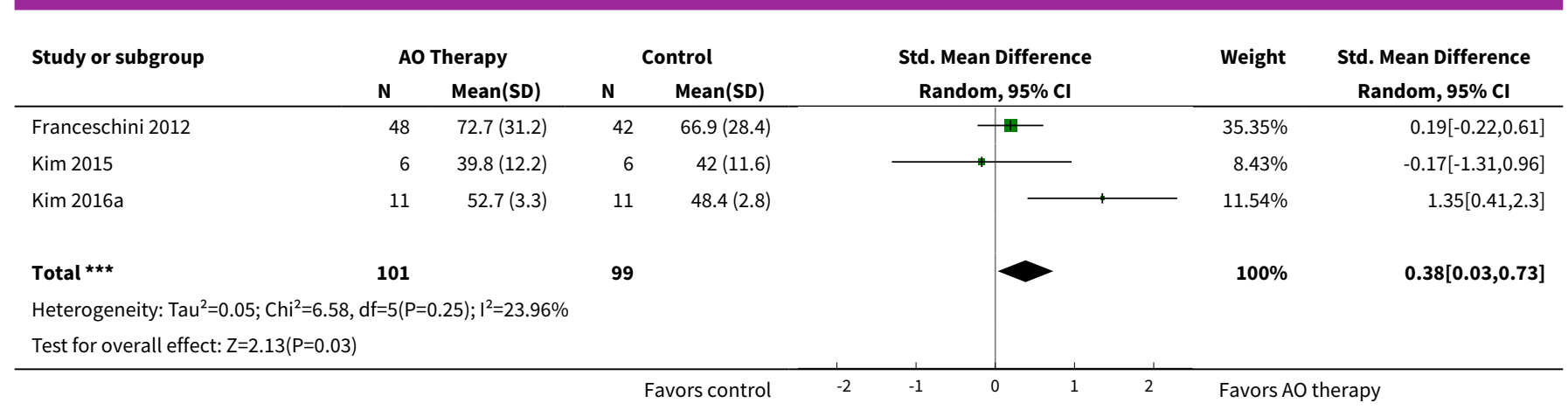

Analysis 1.9. Comparison 1 Action observation therapy versus control: effect on arm function, Outcome 9 Arm function - sensitivity analysis: without high ROB for incomplete outcome data.

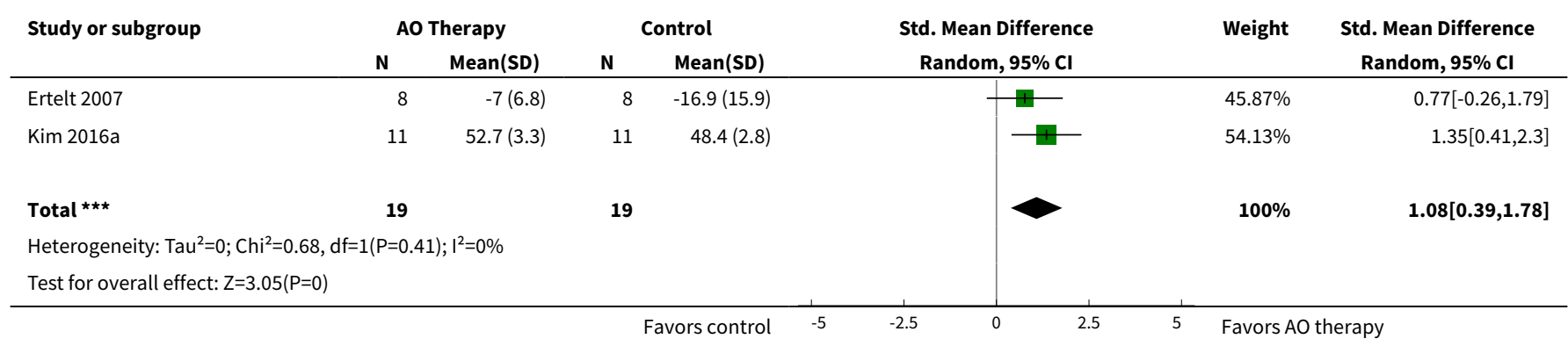

Analysis 1.10. Comparison 1 Action observation therapy versus control: effect on arm function, Outcome 10 Arm function - sensitivity analysis: home-based action observation training (video therapy).

\begin{tabular}{|c|c|c|c|c|c|c|c|}
\hline \multirow[t]{2}{*}{ Study or subgroup } & \multicolumn{2}{|c|}{ AO Therapy } & \multicolumn{2}{|c|}{ Control } & \multirow{2}{*}{$\begin{array}{c}\text { Std. Mean Difference } \\
\text { Random, } 95 \% \mathrm{Cl}\end{array}$} & \multirow[t]{2}{*}{ Weight } & \multirow{2}{*}{$\begin{array}{c}\text { Std. Mean Difference } \\
\text { Random, } 95 \% \mathrm{Cl}\end{array}$} \\
\hline & $\mathbf{N}$ & Mean(SD) & $\mathbf{N}$ & Mean(SD) & & & \\
\hline Cowles 2013 & 9 & $29.8(20)$ & 13 & $27.1(20.2)$ & $\longrightarrow$ & $9.55 \%$ & $0.13[-0.72,0.98]$ \\
\hline Ertelt 2007 & 8 & $-7(6.8)$ & 8 & $-16.9(15.9)$ & 4 & $6.83 \%$ & $0.77[-0.26,1.79]$ \\
\hline Franceschini 2012 & 48 & $72.7(31.2)$ & 42 & $66.9(28.4)$ & $\Psi$ & $28.55 \%$ & $0.19[-0.22,0.61]$ \\
\hline Fu 2017 & 28 & $42.3(12.6)$ & 25 & $35.1(12.4)$ & + & $19.38 \%$ & $0.57[0.02,1.12]$ \\
\hline Kim 2015 & 6 & $39.8(12.2)$ & 6 & $42(11.6)$ & - & $5.68 \%$ & $-0.17[-1.31,0.96]$ \\
\hline Kim 2016a & 11 & $52.7(3.3)$ & 11 & $48.4(2.8)$ & $\longrightarrow$ & $7.93 \%$ & $1.35[0.41,2.3]$ \\
\hline Zhu 2015 & 31 & $35.5(12.4)$ & 30 & $32.8(11.2)$ & + & $22.07 \%$ & $0.23[-0.28,0.73]$ \\
\hline 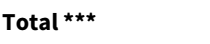 & 141 & & 135 & & $\diamond$ & $100 \%$ & $0.38[0.1,0.66]$ \\
\hline \multicolumn{8}{|c|}{ Heterogeneity: $\mathrm{Tau}^{2}=0.03 ; \mathrm{Chi}^{2}=7.42, \mathrm{df}=6(\mathrm{P}=0.28) ; \mathrm{I}^{2}=19.1 \%$} \\
\hline Test for overall effect & & & & & & & \\
\hline
\end{tabular}


Analysis 1.11. Comparison 1 Action observation therapy versus control: effect on arm function, Outcome 11 Arm function - sensitivity analysis: real demonstration.

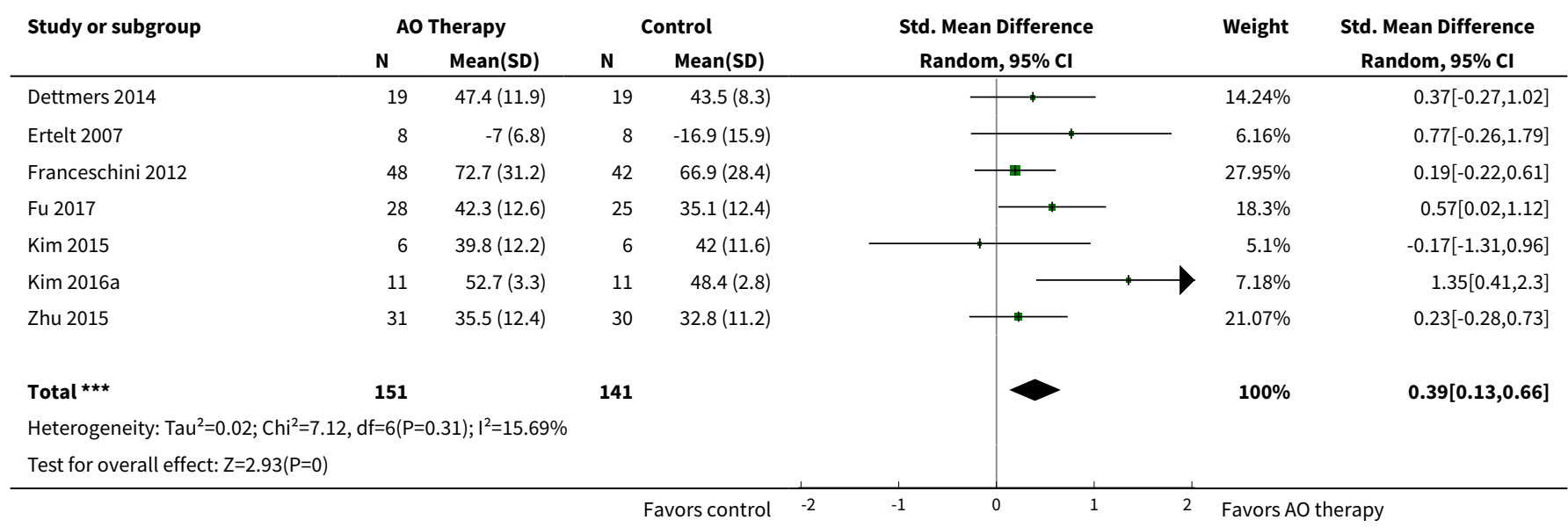

Comparison 2. Action observation therapy versus control: effect on hand function

\begin{tabular}{|c|c|c|c|c|}
\hline Outcome or subgroup title & No. of studies & $\begin{array}{l}\text { No. of partici- } \\
\text { pants }\end{array}$ & Statistical method & Effect size \\
\hline 1 Hand function & 3 & 132 & Mean Difference (IV, Fixed, 95\% CI) & $2.90[1.13,4.66]$ \\
\hline 2 Subgroup analysis: age & 3 & 132 & Mean Difference (IV, Fixed, 95\% CI) & $2.90[1.13,4.66]$ \\
\hline 2.1 Upper 60 years & 1 & 90 & Mean Difference (IV, Fixed, 95\% CI) & $5.5[-1.64,12.64]$ \\
\hline 2.2 Lower 60 years & 2 & 42 & Mean Difference (IV, Fixed, 95\% CI) & $2.73[0.91,4.55]$ \\
\hline $\begin{array}{l}3 \text { Subgroup analysis: time post } \\
\text { stroke }\end{array}$ & 3 & 132 & Mean Difference (IV, Fixed, 95\% CI) & $2.90[1.13,4.66]$ \\
\hline 3.1 Acute or subacute phase & 2 & 112 & Mean Difference (IV, Fixed, 95\% CI) & $2.80[0.94,4.66]$ \\
\hline 3.2 Chronic phase & 1 & 20 & Mean Difference (IV, Fixed, 95\% CI) & $3.80[-1.73,9.33]$ \\
\hline $\begin{array}{l}4 \text { Subgroup analysis: duration } \\
\text { of observation }\end{array}$ & 3 & 132 & Mean Difference (IV, Fixed, 95\% CI) & $2.90[1.13,4.66]$ \\
\hline $\begin{array}{l}4.1 \text { More than } 3 \text { minutes of ob- } \\
\text { servation }\end{array}$ & 1 & 22 & Mean Difference (IV, Fixed, 95\% CI) & $2.60[0.67,4.53]$ \\
\hline $\begin{array}{l}4.2 \text { Less than } 3 \text { minutes of ob- } \\
\text { servation }\end{array}$ & 2 & 110 & Mean Difference (IV, Fixed, 95\% CI) & $4.44[0.07,8.81]$ \\
\hline $\begin{array}{l}5 \text { Hand function - sensitivity } \\
\text { analysis: without high ROB for } \\
\text { incomplete outcome data }\end{array}$ & 2 & 42 & Mean Difference (IV, Fixed, 95\% CI) & $2.73[0.91,4.55]$ \\
\hline
\end{tabular}


Analysis 2.1. Comparison 2 Action observation therapy versus control: effect on hand function, Outcome 1 Hand function.

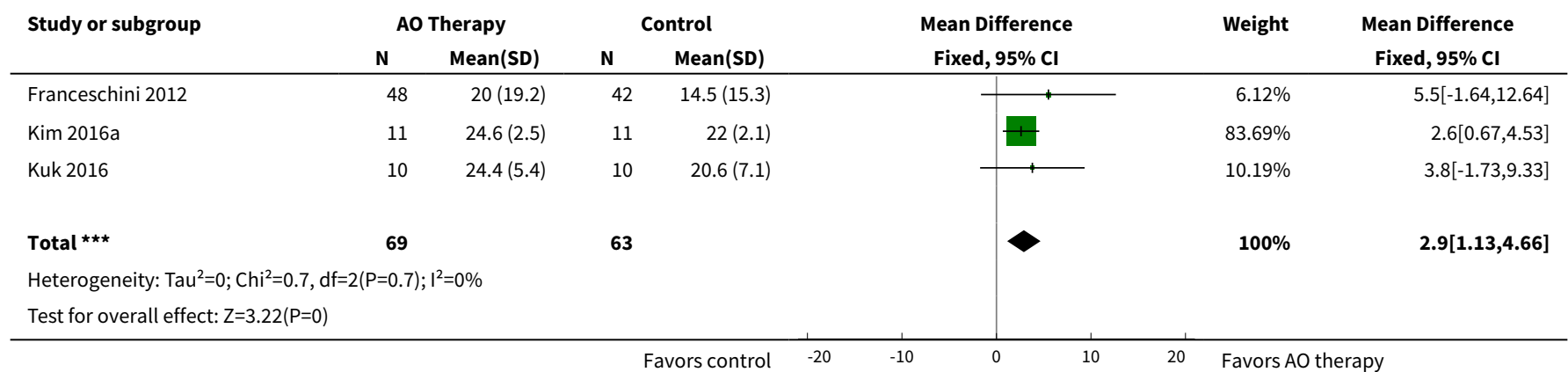

Analysis 2.2. Comparison 2 Action observation therapy versus control: effect on hand function, Outcome 2 Subgroup analysis: age.

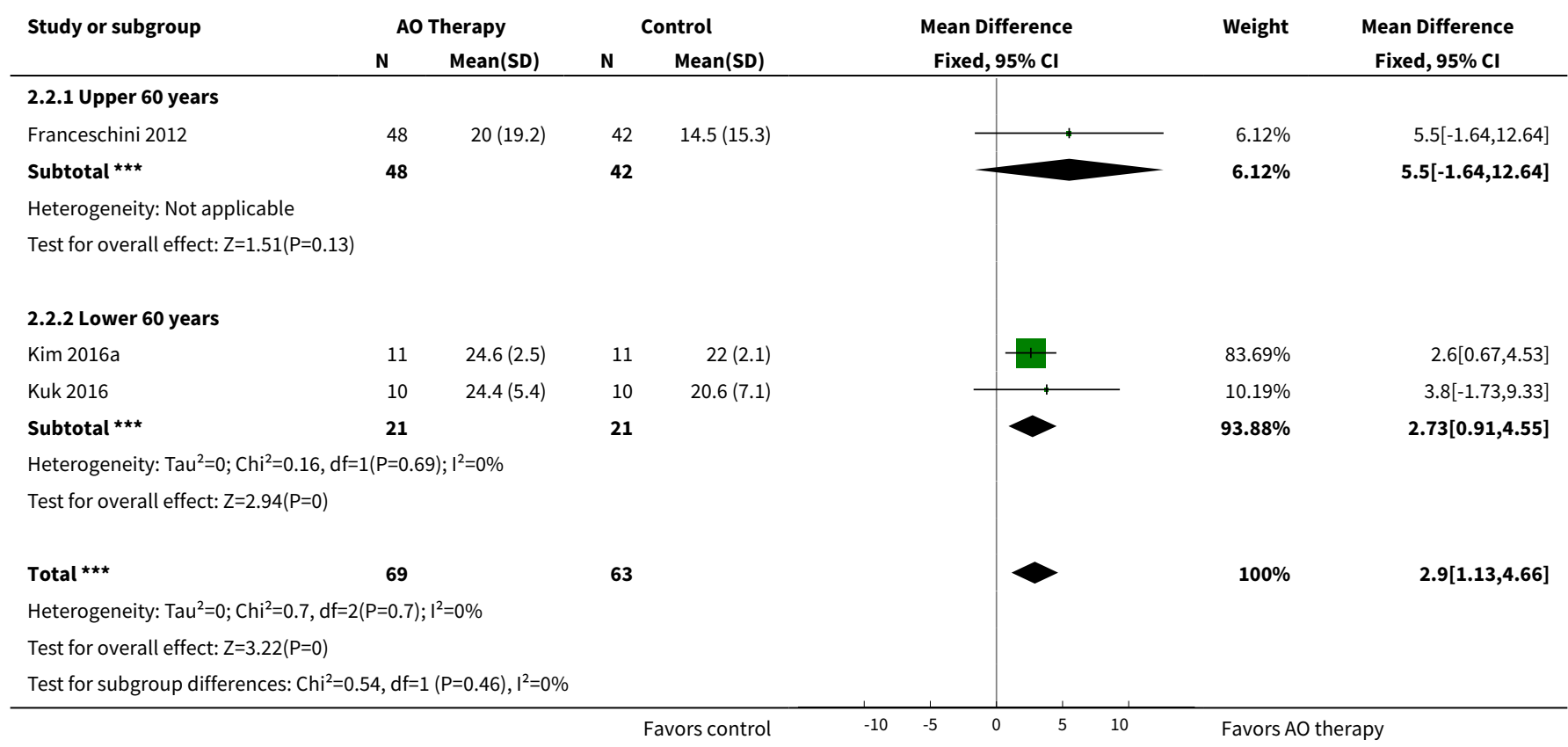

Analysis 2.3. Comparison 2 Action observation therapy versus control: effect on hand function, Outcome 3 Subgroup analysis: time post stroke.

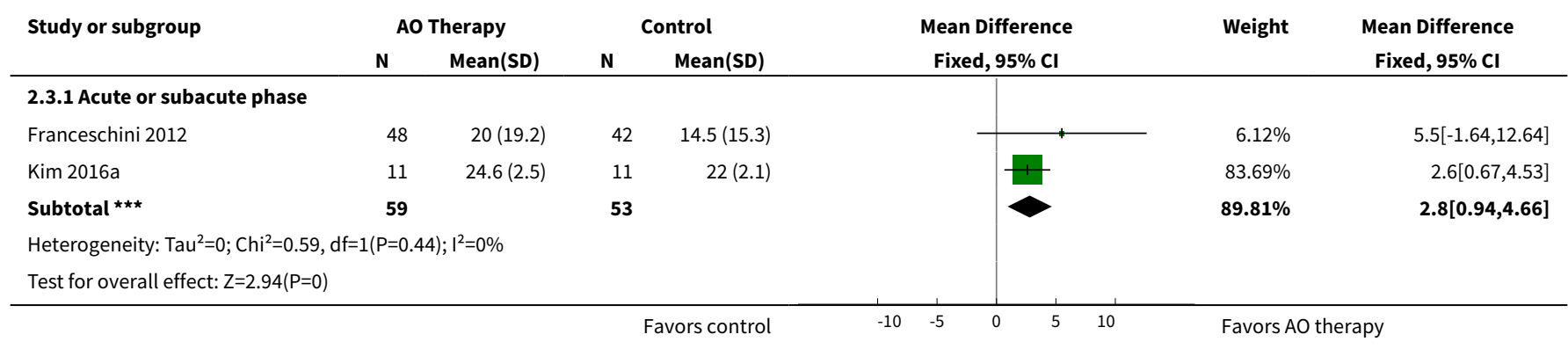




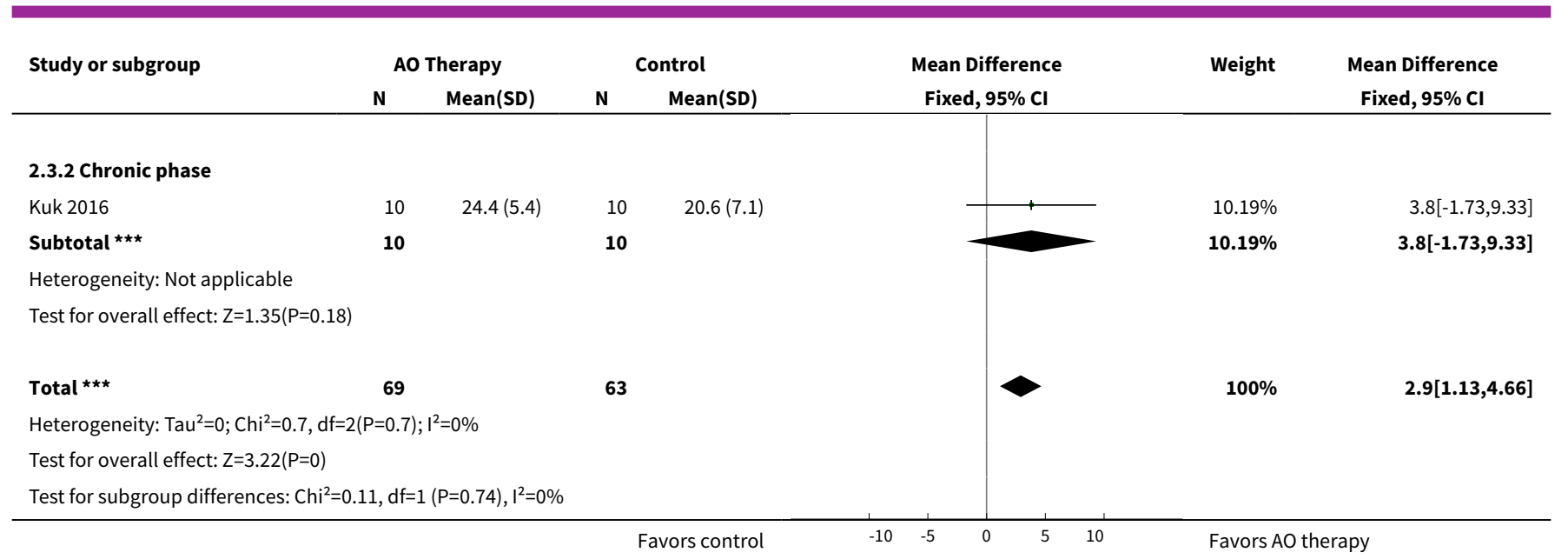

Analysis 2.4. Comparison 2 Action observation therapy versus control: effect on hand function, Outcome 4 Subgroup analysis: duration of observation.

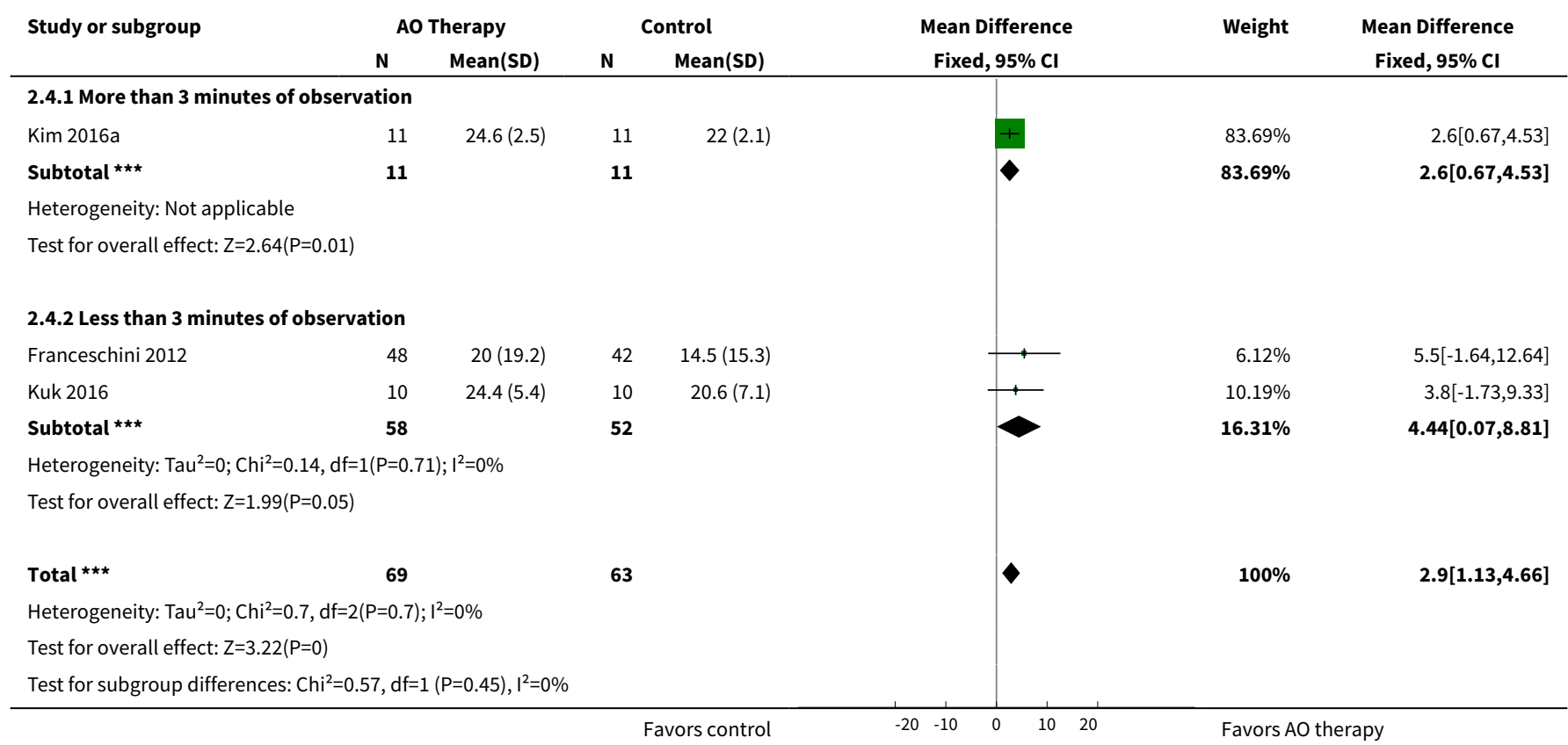

Analysis 2.5. Comparison 2 Action observation therapy versus control: effect on hand function, Outcome 5 Hand function - sensitivity analysis: without high ROB for incomplete outcome data.

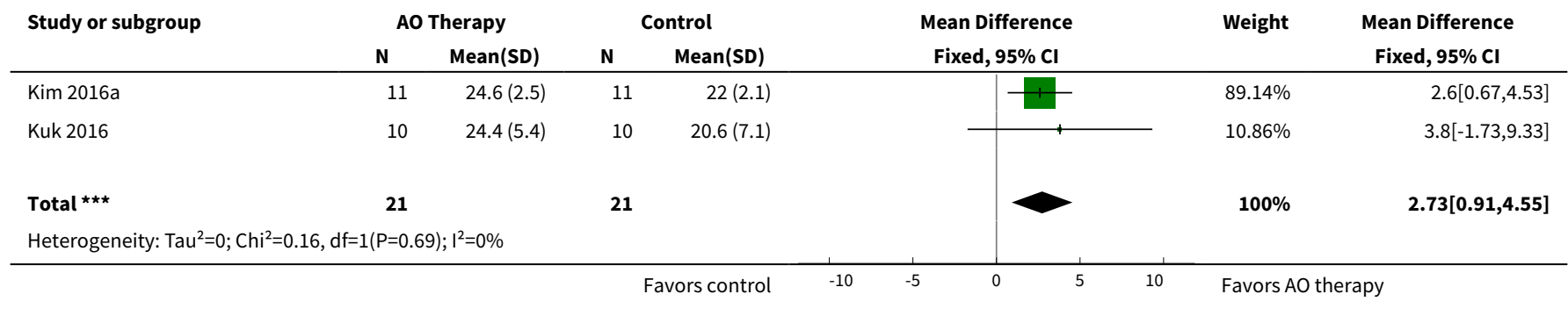




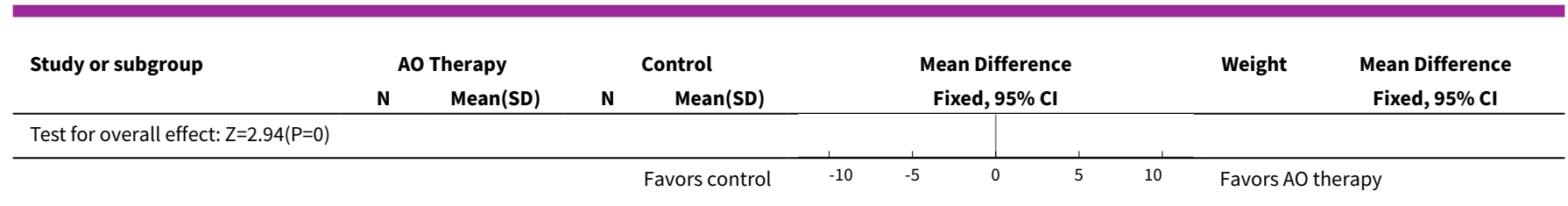

\section{Comparison 3. Action observation therapy versus control: effect on ADL}

\begin{tabular}{lllll}
\hline Outcome or subgroup title & No. of studies & $\begin{array}{l}\text { No. of partici- } \\
\text { pants }\end{array}$ & Statistical method & Effect size \\
\hline $\begin{array}{l}\text { 1 Dependence on activities of daily liv- } \\
\text { ing }\end{array}$ & 4 & 226 & $\begin{array}{l}\text { Std. Mean Difference (IV, } \\
\text { Random, 95\% Cl) }\end{array}$ & $0.86[0.11,1.61]$ \\
\hline $\begin{array}{l}\text { 2 Sensitivity analysis: without high ROB } \\
\text { for allocation concealment }\end{array}$ & 2 & 112 & $\begin{array}{l}\text { Mean Difference (IV, Fixed, } \\
95 \% \text { Cl) }\end{array}$ & $7.39[5.02,9.76]$ \\
\hline $\begin{array}{l}\text { 3 Sensitivity analysis: without high ROB } \\
\text { for incomplete outcome data }\end{array}$ & 2 & 83 & $\begin{array}{l}\text { Mean Difference (IV, Fixed, } \\
95 \% \text { Cl) }\end{array}$ & $7.78[5.41,10.15]$ \\
\hline $\begin{array}{l}\text { 4 Sensitivity analysis: removing periph- } \\
\text { eral studies }\end{array}$ & 2 & 151 & $\begin{array}{l}\text { Mean Difference (IV, Fixed, } \\
95 \% \text { CI) }\end{array}$ & $3.78[-1.55,9.11]$ \\
\hline
\end{tabular}

Analysis 3.1. Comparison 3 Action observation therapy versus control: effect on ADL, Outcome 1 Dependence on activities of daily living.

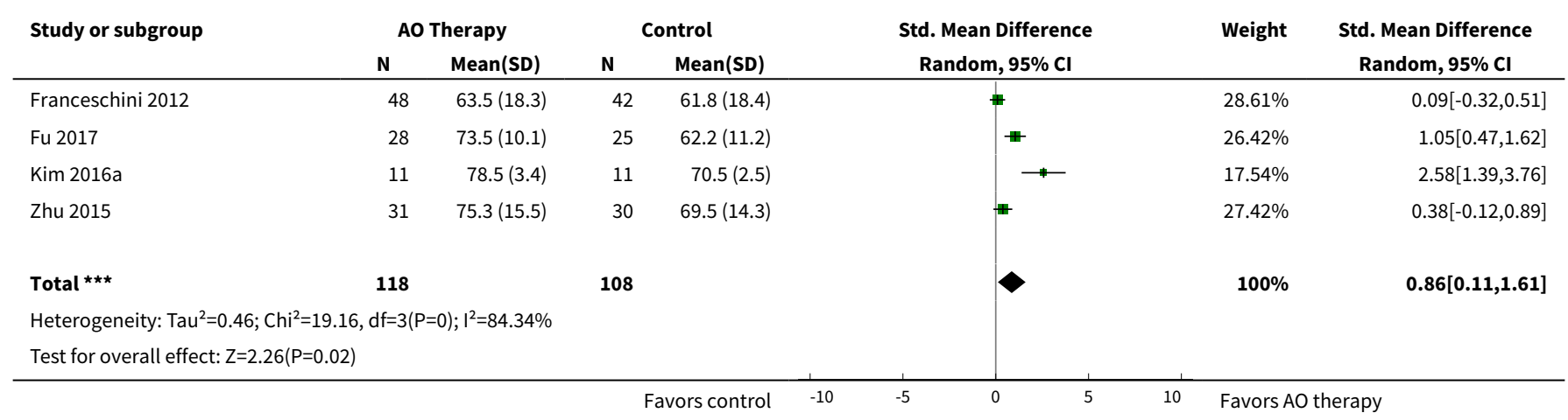

Analysis 3.2. Comparison 3 Action observation therapy versus control: effect on ADL, Outcome 2 Sensitivity analysis: without high ROB for allocation concealment.

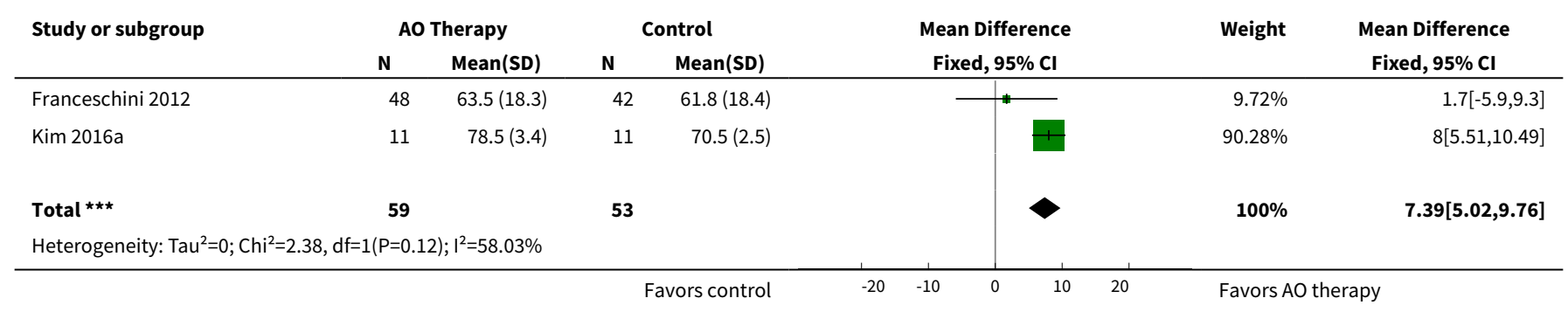




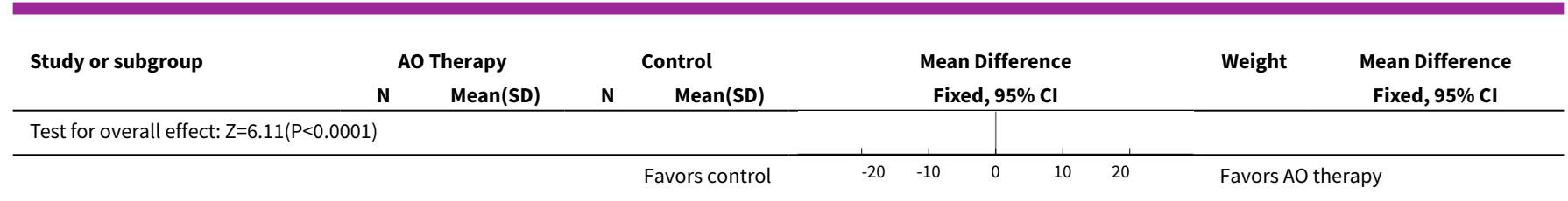

Analysis 3.3. Comparison 3 Action observation therapy versus control: effect on ADL, Outcome 3 Sensitivity analysis: without high ROB for incomplete outcome data.

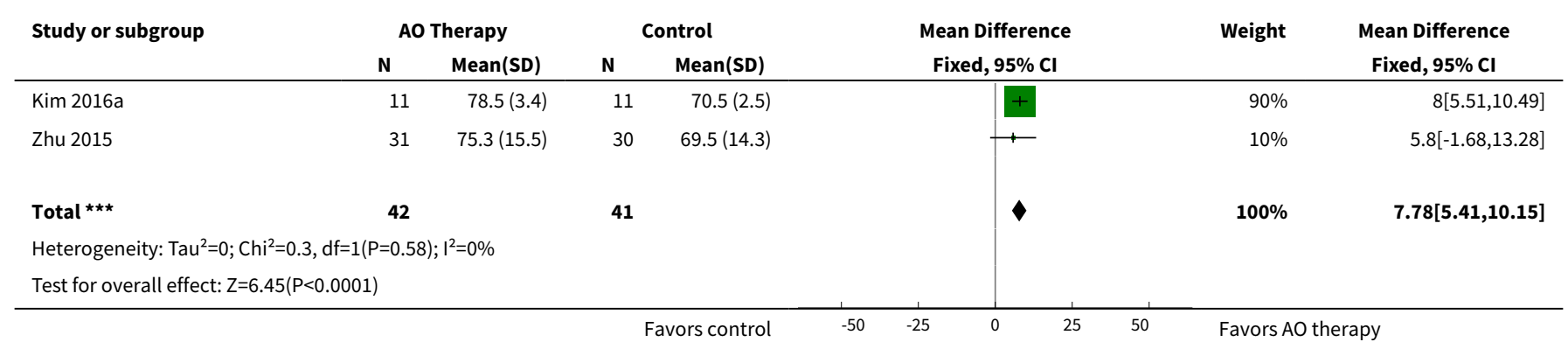

Analysis 3.4. Comparison 3 Action observation therapy versus control: effect on ADL, Outcome 4 Sensitivity analysis: removing peripheral studies.

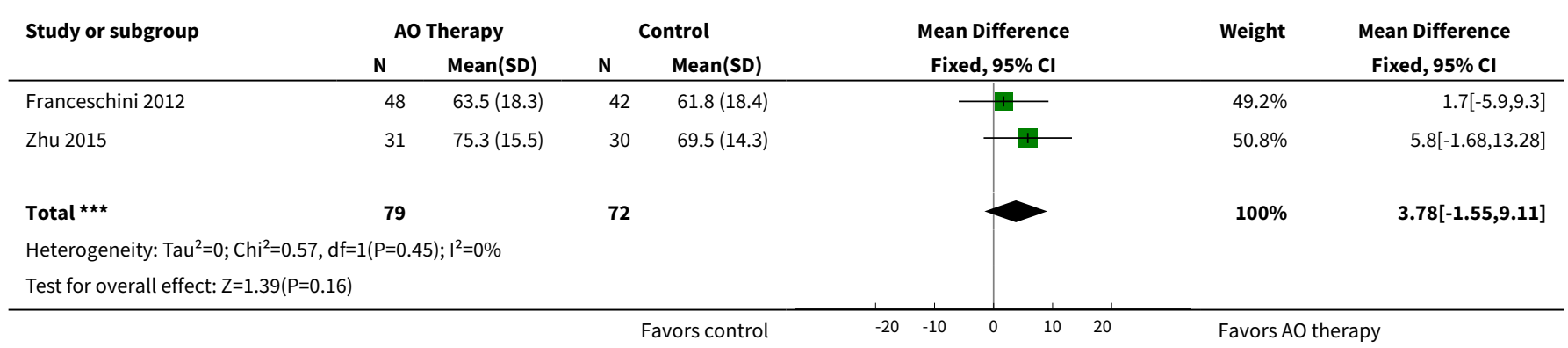

\section{ADDITIONAL TABLES}

\section{Table 1. Table of comparisons}

\begin{tabular}{lll}
\hline Included studies & Experimental group & Control group \\
\hline Celnik 2008 & $\begin{array}{l}\text { 1. Congruent AO simultaneous to PP of thumb } \\
\text { movements }\end{array}$ & PP of thumb movements \\
& $\begin{array}{l}\text { 2. Incongruent AO simultaneous to PP of thumb } \\
\text { movements }\end{array}$ & \\
\hline Cowles 2013 & Conventional PT + AO with OTI followed by PP & Conventional PT \\
\hline Dettmers 2014 & $\begin{array}{l}\text { AO of typical activities of daily living followed by } \\
\text { PP (home-based intervention) }\end{array}$ & $\begin{array}{l}\text { 1. Placebo group: text observation followed by PP of } \\
\text { typical activities of daily living }\end{array}$
\end{tabular}


Table 1. Table of comparisons (Continued)

\section{Usual care: no specific training.}

Ertelt $2007 \quad$ AO of daily life hand and arm actions followed
by PP

Placebo group: observation of geometric symbols and letters followed by PP of daily life hand and arm actions

$\begin{array}{ll}\text { Franceschini } 2012 & \begin{array}{l}\text { Conventional PT + AO of typical activities of daily } \\ \text { living followed by PP }\end{array}\end{array}$
living followed by PP
lonventional PT + AO

Placebo group: conventional PT + observation of objects followed by limb movements (exact order as experimental group)

\begin{tabular}{ll}
\hline Fu 2017 & Traditional rehabilitation treatment + AO with \\
OTI
\end{tabular}

Traditional rehabilitation treatment + observation of geometric patterns and digit symbol and performed one action

\begin{tabular}{|c|c|c|}
\hline Harmsen 2015 & $\begin{array}{l}\text { AO of mirrored arm-reaching activity from unaf- } \\
\text { fected arm, alternated with affected-arm reach- } \\
\text { ing movements }\end{array}$ & $\begin{array}{l}\text { Placebo group: observation of static photographs of } \\
\text { landscapes, alternated with affected-arm reaching } \\
\text { movements }\end{array}$ \\
\hline Kim 2015 & OT + purposeful AO program & $\begin{array}{l}\text { Placebo group: OT + purposeful AO program assign- } \\
\text { ments without actually observing the purposeful ac- } \\
\text { tions }\end{array}$ \\
\hline Kim 2016a & $\begin{array}{l}\text { AO of functional tasks followed by PP of the } \\
\text { same movements }\end{array}$ & PP of functional tasks \\
\hline Kuk 2016 & $\begin{array}{l}\text { AO of an action similar to BBT followed by PP of } \\
\text { the same movements }\end{array}$ & $\begin{array}{l}\text { Placebo group: observation of landscapes followed by } \\
\text { PP of an action similar to BBT }\end{array}$ \\
\hline Lee 2013 & $\begin{array}{l}\text { 1. AO: AO of drinking behavior simultaneous to } \\
\text { action imagination } \\
\text { 2. AO + action practice: } \mathrm{AO} \text { of drinking behavior } \\
\text { followed by PP }\end{array}$ & $\begin{array}{l}\text { 1. Action practice: PP of drinking behavior } \\
\text { 2. Control: no specific training. }\end{array}$ \\
\hline Zhu 2015 & $\begin{array}{l}\mathrm{PT}+\mathrm{OT}+\mathrm{DT}+\mathrm{AO} \text { of upper limb movements fol- } \\
\text { lowed by PP }\end{array}$ & $\mathrm{PT}+\mathrm{OT}+\mathrm{DT}$ \\
\hline
\end{tabular}

AO: action observation

BBT: Box and Block test

DT: drug treatment

OT: occupational therapy

OTI: observation-to-imitate

PP: physical practice

PT: physical therapy

Table 2. AO application to experimental group

\begin{tabular}{llllll}
\hline Included Study & $\begin{array}{l}\text { Time of AO of } \\
\text { each motor ac- } \\
\text { tion (minutes) }\end{array}$ & $\begin{array}{l}\text { Time of exercise or imitation } \\
\text { (minutes) of each motor action }\end{array}$ & $\begin{array}{l}\text { Total AO } \\
\text { (minutes) }\end{array}$ & $\begin{array}{l}\text { Total exercise } \\
\text { (minutes) }\end{array}$ & $\begin{array}{l}\text { Total Session } \\
\text { (minutes) }\end{array}$ \\
\hline Celnik 2008 & 10 & 10 & 30 & 30 & 30 \\
\hline Cowles 2013 & 1 to 2 & 4 to $6(2$ to 4 rest) & 4 to 5 & 16 to 18 & $\begin{array}{l}2 \times 30-\text { minute } \\
\text { sessions (10 } \\
\text { rest) }\end{array}$ \\
\hline
\end{tabular}


Table 2. AO application to experimental group (Continued)

\begin{tabular}{|c|c|c|c|c|c|}
\hline Dettmers 2014 & $\begin{array}{l}5+4 \text { after prac- } \\
\text { tice }\end{array}$ & Not reported & 9 & 20 & 60 \\
\hline Ertelt 2007 & 6 & 6 & 48 & 42 & 90 \\
\hline Franceschini 2012 & 3 & 2 & 9 & 6 & $\begin{array}{l}2 \times 15 \text {-minute } \\
\text { sessions ( } 60 \\
\text { rest) }\end{array}$ \\
\hline Fu 2017 & 10 & 10 & 10 & 10 & 20 \\
\hline Harmsen 2015 & $\begin{array}{l}3 \\
1 \\
1 \\
1\end{array}$ & $\begin{array}{l}30 \text { repetitions of reaching* } \\
20 \text { repetitions of reaching } \\
20 \text { repetitions of reaching }\end{array}$ & 6 & $\begin{array}{l}60 \text { repetitions* } \\
\text { of reaching } \\
\text { (time not in- } \\
\text { formed) }\end{array}$ & Not reported \\
\hline Kim 2015 & Not reported & Not reported & Not reported & Not reported & 30 \\
\hline Kim 2016a & 9 (+1 to rest) & 30 & 9 & 30 & 40 \\
\hline Kuk 2016 & 1 & 3 (10 rest) & 5 & 15 & 60 \\
\hline Lee 2013 & 5 & 5 & 5 & 5 & 10 \\
\hline Zhu 2015 & Not reported & Not reported & Not reported & Not reported & 30 \\
\hline
\end{tabular}

Some of the studies did not provide all the values contained in the table, but based on those presented, it was possible to extrapolate the other values.

${ }^{\star}$ Not minutes

\section{AP PE N D I CES}

\section{Appendix 1. The Cochrane Central Register of Controlled Trials (CENTRAL) search strategy}

\#1MeSH descriptor: [Cerebrovascular Disorders] this term only

\#2MeSH descriptor: [Basal Ganglia Cerebrovascular Disease] this term only

\#3MeSH descriptor: [Brain Ischemia] explode all trees

\#4MeSH descriptor: [Carotid Artery Diseases] explode all trees

\#5MeSH descriptor: [Cerebral Small Vessel Diseases] explode all trees

\#6MeSH descriptor: [Intracranial Arterial Diseases] explode all trees

\#7MeSH descriptor: [Intracranial Embolism and Thrombosis] explode all trees

\#8MeSH descriptor: [Intracranial Hemorrhages] explode all trees

\#9MeSH descriptor: [Stroke] explode all trees

\#10MeSH descriptor: [Vasospasm, Intracranial] this term only

\#11MeSH descriptor: [Vertebral Artery Dissection] this term only

\#12(stroke* or poststroke or apoplex* or cerebral vasc* or brain vasc* or cerebrovasc ${ }^{\star}$ or cva* or SAH):ti,ab,kw (Word variations have been searched)

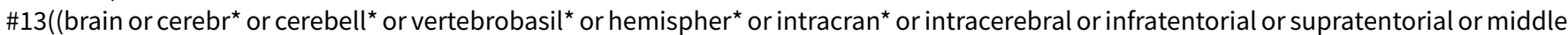
cerebral artery or $\mathrm{MCA}^{\star}$ or anterior circulation or posterior circulation or basilar artery or vertebral artery or space-occupying) near/5 (isch?

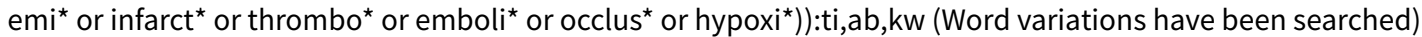

\#14((brain* or cerebr* or cerebell* or intracerebral or intracran* or parenchymal or intraparenchymal or intraventricular or infratentorial or supratentorial or basal gangli* or putaminal or putamen or posterior fossa or hemispher* or subarachnoid) near/5 (h?emorrhag* or h? ematoma* or bleed*)):ti,ab,kw (Word variations have been searched)

\#15MeSH descriptor: [Hemiplegia] this term only 
\#16MeSH descriptor: [Paresis] explode all trees

\#17MeSH descriptor: [Gait Disorders, Neurologic] explode all trees

$\# 18$ (hemipleg* or hemipar* or paresis or paraparesis or paretic):ti,ab,kw (Word variations have been searched)

\#19\{or \#1-\#18\} 51283

\#20MeSH descriptor: [Observation] this term only

\#21MeSH descriptor: [Psychomotor Performance] explode all trees

\#22MeSH descriptor: [Imitative Behavior] this term only

\#23MeSH descriptor: [Motion Perception] this term only

\#24MeSH descriptor: [Learning] this term only

\#25MeSH descriptor: [Anticipation, Psychological] this term only

\#26MeSH descriptor: [Photic Stimulation] this term only

\#27MeSH descriptor: [Mirror Neurons] this term only

\#28action observation or action-observation or AO or AOT:ti,ab,kw (Word variations have been searched)

\#29((observ ${ }^{\star}$ or watch8) near/10 (action ${ }^{\star}$ or movement ${ }^{\star}$ or reach ${ }^{\star}$ or activit ${ }^{\star}$ or task ${ }^{\star}$ or motion ${ }^{\star}$ or motor train* or perform ${ }^{\star}$ or gestur or $^{\star}$ demonstrat $^{\star}$ or video* or TV screen or television screen or computer screen)):ti,ab,kw (Word variations have been searched)

\#30((visual or action or motion) near/5 perception):ti,ab,kw (Word variations have been searched)

\#31(visual-motor matching):ti,ab,kw (Word variations have been searched)

\#32(mirror neur $\left.{ }^{\star}\right): t i, a b, k w$ (Word variations have been searched)

\#33\{or \#20-\#32\}

\#34MeSH descriptor: [Upper Extremity] explode all trees

\#35(upper limb* or upper extremit* or arm or arms or shoulder or shoulders or hand or hands or axilla* or elbow* or forearm or finger* or wrist*):ti,ab,kw (Word variations have been searched)

\#36\#34 or \#35

\#37\#19 and \#33 and \#36 Publication Year from 2016 to 2017

\section{Appendix 2. MEDLINE search strategy}

Medline (Ovid) search strategy

1. cerebrovascular disorders/ or exp basal ganglia cerebrovascular disease/ or exp brain ischemia/ or exp carotid artery diseases/ or exp cerebral small vessel diseases/ or exp intracranial arterial diseases/ or exp "intracranial embolism and thrombosis"/ or exp intracranial hemorrhages/ or stroke/ or exp brain infarction/ or stroke, lacunar/ or vasospasm, intracranial/ or vertebral artery dissection/ or brain injuries/ or brain injury, chronic/

2. (stroke $\$$ or poststroke or apoplex\$ or cerebral vasc\$ or brain vasc\$ or cerebrovasc\$ or cva $\$$ or SAH).tw.

3. ((brain or cerebr\$ or cerebell\$ or vertebrobasil\$ or hemispher $\$$ or intracran $\$$ or intracerebral or infratentorial or supratentorial or middle cerebral artery or MCA $\$$ or anterior circulation or posterior circulation or basilar artery or vertebral artery or space-occupying) adj5 (isch? emi\$ or infarct\$ or thrombo or emboli\$ or occlus\$ or hypoxi\$)).tw.

4. ((brain $\$$ or cerebr $\$$ or cerebell\$ or intracerebral or intracran\$ or parenchymal or intraparenchymal or intraventricular or infratentorial or supratentorial or basal gangli or putaminal or putamen or posterior fossa or hemispher\$ or subarachnoid) adj5 (h?emorrhag\$ or h? ematoma\$ or bleed\$)).tw.

5. hemiplegia/ or exp paresis/

6. (hemipleg\$ or hemipar\$ or paresis or paretic or brain injur\$).tw.

7. or/1-6

8. exp upper extremity/

9. (upper limb\$ or upper extremit\$ or arm or arms or shoulder or shoulders or hand or hands or axilla\$ or elbow\$ or forearm\$ or finger \$ or wrist\$).tw.

10.8 or 9

11. observation/ or psychomotor performance/ or imitative behavior/ or imagination/

12. motion perception/ or visual perception/ or learning/

13. anticipation, psychological/ or photic stimulation/ or mirror neurons/

14. "Imagery (Psychotherapy)"/

15. (action observation or action-observation or $\mathrm{AO}$ or AOT).tw.

16. ((observ\$ or watch\$) adj10 (action\$ or movement\$ or reach\$ or activit\$ or task\$ or motion\$ or motor train $\$$ or perform\$ or gestur\$ or demonstrat $\$$ or video $\$$ or TV screen or television screen or computer screen)).tw.

17. ((visual or action or motion) adj5 perception).tw.

18. visual-motor matching.tw.

19. mirror neur\$.tw.

20. 11 or 12 or 13 or 14 or 15 or 16 or 17 or 18 or 19

21. Randomized Controlled Trials as Topic/

22. random allocation/

23. Controlled Clinical Trials as Topic/

24. control groups/ 
25. clinical trials as topic/ or clinical trials, phase i as topic/ or clinical trials, phase ii as topic/ or clinical trials, phase iii as topic/ or clinical trials, phase iv as topic/

26. double-blind method/

27. single-blind method/

28. Placebos/

29. placebo effect/

30. cross-over studies/

31. randomized controlled trial.pt.

32. controlled clinical trial.pt.

33. (clinical trial or clinical trial phase i or clinical trial phase ii or clinical trial phase iii or clinical trial phase iv).pt.

34. (random\$ or RCT or RCTs).tw.

35. (controlled adj5 (trial\$ or stud\$)).tw.

36. (clinical\$ adj5 trial\$).tw.

37. ((control or treatment or experiment\$ or intervention) adj5 (group\$ or subject\$ or patient\$)).tw.

38. (quasi-random $\$$ or quasi random\$ or pseudo-random $\$$ or pseudo random $\$$ ).tw.

39. ((control or experiment $\$$ or conservative) adj5 (treatment or therapy or procedure or manage\$)).tw.

40. ((singl\$ or doubl\$ or tripl\$ or trebl\$) adj5 (blind\$ or mask\$)).tw.

41. (cross-over or cross over or crossover).tw.

42. (placebo $\$$ or sham).tw.

43. trial.ti.

44. (assign\$ or allocat\$).tw.

45. controls.tw.

46. or/21-45

47.7 and 10 and 20 and 46

48. exp animals/ not humans/

49. 47 not 48

\section{Appendix 3. Embase search strategy}

1. cerebrovascular disease/ or brain disease/ or exp basal ganglion hemorrhage/ or exp brain hemangioma/ or exp brain hematoma/ or exp brain hemorrhage/ or exp brain infarction/ or exp brain ischemia/ or exp carotid artery disease/ or exp cerebral artery disease/ or exp cerebrovascular accident/ or exp cerebrovascular malformation/ or exp intracranial aneurysm/ or exp occlusive cerebrovascular disease/ or exp vertebrobasilar insufficiency/

2. (stroke\$ or poststroke or apoplex\$ or cerebral vasc\$ or brain vasc\$ or cerebrovasc\$ or cva $\$$ or SAH).tw.

3. ((brain or cerebr\$ or cerebell\$ or vertebrobasil\$ or hemispher $\$$ or intracran\$ or intracerebral or infratentorial or supratentorial or middle cerebral artery or MCA $\$$ or anterior circulation or posterior circulation or basilar artery or vertebral artery or space-occupying) adj5 (isch? emi\$ or infarct\$ or thrombo $\$$ or emboli\$ or occlus\$ or hypoxi\$)).tw.

4. ((brain\$ or cerebr\$ or cerebell\$ or intracerebral or intracran\$ or parenchymal or intraparenchymal or intraventricular or infratentorial or supratentorial or basal gangli\$ or putaminal or putamen or posterior fossa or hemispher\$ or subarachnoid) adj5 (h?emorrhag\$ or h? ematoma\$ or bleed\$)).tw.

5. exp hemiplegia/ or exp paresis/ or neurologic gait disorder/

6. (hemipleg\$ or hemipar\$ or paresis or paraparesis or paretic).tw.

7. or/1-6

8. exp upper limb/

9. (upper limb\$ or upper extremit\$ or arm or arms or shoulder or shoulders or hand or hands or axilla\$ or elbow\$ or forearm\$ or finger \$ or wrist\$).tw.

10.8 or 9

11. observation/ or psychomotor performance/ or exp imitation/

12. movement perception/ or vision/ or learning/

13. anticipation/ or photostimulation/ or mirror neuron/

14. (action observation or action-observation or AO or AOT).tw.

15. ((observ\$ or watch\$) adj10 (action\$ or movement\$ or reach\$ or activit\$ or task\$ or motion\$ or motor train $\$$ or perform\$ or gestur\$ or demonstrat $\$$ or video $\$$ or TV screen or television screen or computer screen)).tw.

16. ((visual or action or motion) adj5 perception).tw.

17. visual-motor matching.tw.

18. mirror neur\$.tw.

19. or/11-18

20. Randomized Controlled Trial/ or "randomized controlled trial (topic)"/

21. Randomization/

22. Controlled clinical trial/ or "controlled clinical trial (topic)"/

23. control group/ or controlled study/

24. clinical trial/ or "clinical trial (topic)"/ or phase 1 clinical trial/ or phase 2 clinical trial/ or phase $3 \mathrm{clinical}$ trial/ or phase $4 \mathrm{clinical}$ trial/ 
25. Crossover Procedure/

26. Double Blind Procedure/

27. Single Blind Procedure/ or triple blind procedure/

28. placebo/ or placebo effect/

29. (random\$ or RCT or RCTs).tw.

30. (controlled adj5 (trial\$ or stud\$)).tw.

31. (clinical\$ adj5 trial\$).tw.

32. ((control or treatment or experiment\$ or intervention) adj5 (group\$ or subject\$ or patient\$)).tw.

33. (quasi-random $\$$ or quasi random $\$$ or pseudo-random $\$$ or pseudo random $\$$ ).tw.

34. ((control or experiment\$ or conservative) adj5 (treatment or therapy or procedure or manage\$)).tw.

35. ((singl\$ or doubl\$ or tripl\$ or trebl\$) adj5 (blind\$ or mask\$)).tw.

36. (cross-over or cross over or crossover).tw.

37. (placebo $\$$ or sham).tw.

38. trial.ti.

39. (assign\$ or allocat\$).tw.

40. controls.tw.

41. (exp animal/ or animal.hw. or nonhuman/) not (exp human/ or human cell/ or (human or humans).ti.)

42. or $/ 20-40$

43. 7 and 10 and 19 and 42

\section{Appendix 4. CINAHL search strategy}

S1(MH "Cerebrovascular Disorders") OR (MH "Basal Ganglia Cerebrovascular Disease+") OR (MH "Carotid Artery Diseases+") OR (MH "Cerebral Ischemia+") OR (MH "Cerebral Vasospasm") OR (MH "Intracranial Arterial Diseases+") OR ( (MH "Intracranial Embolism and Thrombosis") ) OR (MH "Intracranial Hemorrhage+") OR (MH "Stroke") OR (MH "Vertebral Artery Dissections") OR (MH "Stroke Patients") OR (MH "Stroke Units")

$\mathrm{S} 2 \mathrm{TI}$ ( stroke or poststroke or post-stroke or cerebrovasc* or brain vasc* or cerebral vasc or cva or apoplex or SAH ) or AB ( stroke or poststroke or post-stroke or cerebrovasc ${ }^{*}$ or brain vasc* or cerebral vasc or cva or apoplex or SAH)

S3TI ( brain* or cerebr ${ }^{\star}$ or cerebell* or intracran* or intracerebral ) or AB ( brain* or cerebr ${ }^{\star}$ or cerebell* or intracran* or intracerebral)

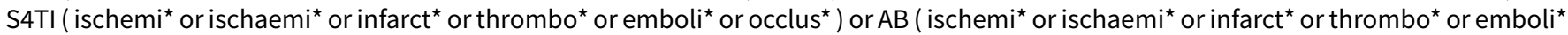
or occlus*)

\section{S5S3 AND S4}

S6TI ( brain* or cerebr* or cerebell* or intracerebral or intracranial or subarachnoid ) or AB ( brain* or cerebr ${ }^{\star}$ or cerebell ${ }^{\star}$ or intracerebral or intracranial or subarachnoid)

S7TI ( haemorrhage* or hemorrhage* or haematoma* or hematoma* or bleed ${ }^{\star}$ ) or AB ( haemorrhage* or hemorrhage* or haematoma* or hematoma* or bleed*)

S8S6 AND S7

S9TI transient ischaemic attack* or TI transient ischemic attack ${ }^{\star}$ or AB transient ischaemic attack ${ }^{\star}$ or $A B$ transient ischemic attack ${ }^{\star}$ or $\mathrm{TI}$

TIA or TI TIA S or AB TIA or AB TIAS

S10S1 OR S2 OR S3 OR S6 OR S9 OR S10

S11(MH "Upper Extremity+")

S12TI ( upper limb* or upper extremit* or arm or arms or shoulder or shoulders or hand or hands or axilla* or elbow* or forearm* or finger* or wrist ${ }^{\star}$ ) OR AB ( upper limb* or upper extremit* or arm or arms or shoulder or shoulders or hand or hands or axilla* or elbow* or forearm* or finger ${ }^{\star}$ or wrist $\left.^{\star}\right)$

S13S11 OR S12

S14(MH "Psychomotor Performance+")

S15(MH "Imitative Behavior")

S16(MH "Visual Perception+")

S17(MH "Learning")

S18(MH "Neurons+")

S19TI ( (action observation or action-observation or AO or AOT) ) OR AB ( (action observation or action-observation or AO or AOT) )

S20TI ( ((observ* or watch $\left.{ }^{\star}\right)$ N10 (action* or movement ${ }^{\star}$ or reach ${ }^{\star}$ or activit* or task* or motion* or motor train ${ }^{\star}$ or perform ${ }^{\star}$ or gestur ${ }^{\star}$ or demonstrat ${ }^{\star}$ or video* or TV screen or television screen or computer screen)) ) OR AB ( ((observ* or watch*) N10 (action* or movement ${ }^{\star}$ or reach ${ }^{\star}$ or activit ${ }^{\star}$ or task ${ }^{\star}$ or motion ${ }^{\star}$ or motor train* or perform ${ }^{\star}$ or gestur ${ }^{\star}$ or demonstrat ${ }^{\star}$ or video* or TV screen or television screen or computer screen)) )

S21TI ( (action observation or action-observation or AO or AOT) ) OR AB ( (action observation or action-observation or AO or AOT). )

S22TI ( ((visual or action or motion) N5 perception). ) OR AB ( ((visual or action or motion) N5 perception). )

S23TI (visual-motor matching) OR AB (visual-motor matching)

S24TI mirror neur* OR AB mirror neur ${ }^{\star}$

S25S14 OR S15 OR S16 OR S17 OR S 18 OR S19 OR S20 OR S21 OR S22 OR S23 OR S24

S26(MH "Randomized Controlled Trials") or (MH "Random Assignment") or (MH "Random Sample+")

S27(MH "Clinical Trials") or (MH "Intervention Trials") or (MH "Therapeutic Trials") 
S28(MH "Double-Blind Studies") or (MH "Single-Blind Studies") or (MH "Triple-Blind Studies")

S29(MH "Control (Research)") or (MH "Control Group") or (MH "Placebos") or (MH "Placebo Effect")

S30(MH "Crossover Design") OR (MH "Quasi-Experimental Studies")

S31PT (clinical trial or randomized controlled trial)

S32TI (random* or RCT or RCTs) or AB (random* or RCT or RCTs)

S33TI (controlled N5 $\left(\right.$ trial $^{\star}$ or stud $\left.{ }^{\star}\right)$ ) or AB (controlled N5 $\left(\right.$ trial $^{\star}$ or stud $\left.{ }^{\star}\right)$ )

S34TI (clinical ${ }^{*}$ N5 trial $\left.{ }^{\star}\right)$ or AB (clinical ${ }^{*}$ N5 trial*)

S35TI ((control or treatment or experiment ${ }^{\star}$ or intervention) N5 (group ${ }^{\star}$ or subject $^{\star}$ or patient $\left.{ }^{\star}\right)$ ) or AB ((control or treatment or experiment ${ }^{\star}$ or intervention) N5 (group* or subject* or patient $\left.{ }^{\star}\right)$ )

S36 ((control or experiment* or conservative) N5 (treatment or therapy or procedure or manage $\left.{ }^{\star}\right)$ ) or AB ((control or experiment ${ }^{\star}$ or conservative) N5 (treatment or therapy or procedure or manage $\left.e^{\star}\right)$ )

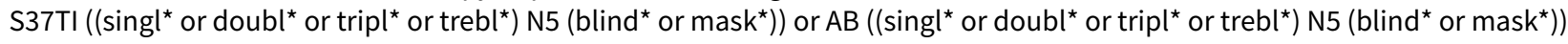

$\mathrm{S} 38 \mathrm{TI}$ (cross-over or cross over or crossover) or AB (cross-over or cross over or crossover)

S39TI (placebo* or sham) or AB (placebo* or sham)

S40TI trial

S41TI (assign* or allocat*) or AB (assign* or allocat*)

S42TI controls or AB controls

S43TI (quasi-random* or quasi random* or pseudo-random* or pseudo random ${ }^{\star}$ ) or AB (quasi-random* or quasi random ${ }^{\star}$ or pseudorandom ${ }^{\star}$ or pseudo random*)

S44S26 OR S27 OR S28 OR S29 OR S30 OR S31 OR S32 OR S33 OR S34 OR S 35 OR S36 OR S37 OR S38 OR S39 OR S40 OR S41 OR S42 OR S43 S45S10 AND S13 AND S25 AND S44

\section{Appendix 5. LILACS search strategy}

(TW:"Brain Vascular Disorders" OR TW:"Intracranial Vascular Disorders" OR TW:"Transtornos Vasculares do Cérebro" OR TW:"Transtornos Vasculares Intracranianos" OR TW:"Doenças Vasculares Intracranianas" OR TW:"Trastornos Vasculares del Cerebro" OR TW:"Trastornos Vasculares Intracraneales" OR TW:"Enfermedades Intracraneales Vasculares" OR MH:C10.228.140.300 OR MH:C14.907.253 OR TW:"Lenticulostriate Vasculopathy" OR TW:"Doença Cerebrovascular dos Gânglios Basais" OR TW:"Doenças Vasculares Lenticulostratais" OR TW:"Vasculopatia Lenticulostriatal" OR TW:"Vasculopatia Lenticuloestriatal" OR TW:"Enfermedad de los Ganglios Basales Cerebrovascular" OR TW:"Enfermedades Vasculares Lenticulostriatales" OR MH:C10.228.140.079.127\$ OR MH:C10.228.140.300.100\$ OR MH:C14.907.253.061\$ OR TW:"Cerebral Ischemia" OR TW:"Ischemic Encephalopathy" OR TW:"Isquemia Cerebral" OR TW:"Encefalopatía Isquémica" OR MH:10.228.140.300.150\$ OR MH:C14.907.253.092\$ OR TW:"Carotid Atherosclerosis" OR TW:"Aterosclerosis de la Carótida " OR TW:"Aterosclerose Carotídea" OR TW:"Aterosclerose da Carótida" OR MH:C10.228.140.300.200\$ OR MH:C14.907.253.123\$ OR MH:C10.228.140.300.275\$ OR MH:C14.907.253.329\$ OR MH:C10.228.140.300.510\$ OR MH:C14.907.253.560\$ OR TW:"Cerebral Embolism and Thrombosis" OR TW:"Brain Embolism and Thrombosis" OR TW:"Embolia e Trombose Cerebral" OR TW:"Embolia e Trombose Encefálica" OR TW:"Embolia y Trombosis Cerebral" OR TW:"Embolia y Trombosis del Cerebro" OR MH:C10.228.140.300.525\$ OR MH:C14.907.253.566\$ OR MH:C14.907.355.590.213\$ OR TW:"Brain Hemorrhage" OR TW:"Hemorragia Encefálica" OR TW:"Hemorragia Intracraniana" OR TW:"Hemorragia del Cerebro" OR TW:"Hemorragia Intracraneal" OR MH:C10.228.140.300.535\$ OR MH:C14.907.253.573\$ OR MH:C23.550.414.913\$ OR TW:"Apoplexy" OR TW:"Cerebral Stroke" OR TW:"Cerebrovascular Accident" OR TW:"Cerebrovascular Apoplexy" OR TW:"Acidente Vascular Cerebral" OR TW:"Derrame Cerebral" OR TW:"Ictus Cerebral" OR TW:"AVC" OR TW:"Apoplexia" OR TW:"Acidente Cerebrovascular" OR TW:"Apoplexia Cerebral" OR TW:"Apoplexia Cerebrovascular" OR TW:"Icto Cerebral" OR TW:"Acidente Vascular Encefálico" OR TW:"AVE" OR TW:"Acidente Vascular do Cérebro" OR TW:"Acidente Cerebral Vascular" OR TW:"Acidentes Cerebrais Vasculares" OR TW:"Acidentes Cerebrovasculares" OR TW:"Acidentes Vasculares Cerebrais" OR TW:"Ataque" OR TW:"Ictus" OR TW:"Ictus Cerebral" OR TW:"Apoplejía" OR TW:"Ataque Cerebral" OR TW:"Apoplejía Cerebral" OR TW:"Apoplejía Cerebrovascular" OR TW:"Accidente Vascular Encefálico" OR TW:"Accidente Vascular del Cerebro" OR TW:"Accidente Vascular Cerebral" OR TW:"Accidente Cerebral Vascular" OR TW:"Accidentes Cerebrovasculares" OR MH:C10.228.140.300.775\$ OR MH:C14.907.253.855\$ OR TW:"Infarto Venoso Encefálico" OR TW:"Infarto Venoso Cerebral" OR TW:"Infarto Venoso do Encéfalo" OR TW:"Infarto do Encéfalo" OR TW:"Infarto Venoso del Encéfalo" OR TW:"Infarto del Encéfalo" OR MH:C10.228.140.300.150.477\$ OR MH:C10.228.140.300.775.200\$ OR MH:C14.907.253.092.477\$ OR MH:C14.907.253.855.200\$ OR TW:"Infarto Lacunar" OR TW:"Acidente Vascular Encefálico Lacunar" OR MH:C10.228.140.300.275.800\$ OR MH:C10.228.140.300.775.600\$ OR MH:C14.907.253.329.800\$ OR MH:C14.907.253.855.600\$ OR MH:C10.228.140.300.90\$ OR MH:C14.907.253.951\$ OR TW:"Cerebral Vasospasm" OR TW:"Intracranial Vasospasm" OR TW:"Angioespasmo Intracraniano" OR TW:"Angiospasmo Intracraniano" OR TW:"Vasoespasmo Cerebral" OR TW:"Vasospasmo Cerebral" OR TW:"Vasospasmo Intracraniano" OR TW:"Angioespasmo Intracraneal" OR TW:"Vasoespasmo Cerebral" OR TW:"Dissecting Vertebral Artery Aneurysm" OR MH:C10.228.140.300.350.875\$ OR MH:C10.900.250.650\$ OR MH:C14.907.055.050.575\$ OR MH:C14.907.253.535.800\$ OR MH:C26.915.200.600\$ OR TW:"Aneurisma Disecante de la Arteria Vertebral" OR TW:"Dissecção da Artéria Vertebral" OR TW:"Aneurisma Dissecante da Artéria Vertebral" OR TW:"Brain Contusion" OR TW:"Brain Lacerations" OR TW:"Traumatic Brain Injury" OR MH:C10.228.140.199\$ OR MH:C10.900.300.087\$ OR MH:C26.915.300.200\$ OR TW:"Lesión Cerebral" OR TW:"Lesiones Encefálicas" OR TW:"Traumatismo Cerebral" OR TW:"Traumatismos Cerebrales" OR TW:"Contusión Encefálica" OR TW:"Lesiones Traumáticas del Encéfalo" OR TW:"Lesiones Encefálicas Traumáticas" OR TW:"Laceraciones del Encéfalo" OR TW:"Laceraciones Encefálicas" OR TW:"Traumatismo Encefálico" OR TW:"Lesiones del Encéfalo Traumáticas" OR TW:"Lesão Cerebral" OR TW:"Lesões Encefálicas" OR TW:"Traumatismo Cerebral" OR TW:"Traumatismos Cerebrais" OR TW:"Contusão Encefálica" OR TW:"Lesões Encefálicas Traumáticas" OR TW:"Lacerações Encefálicas" OR TW:"Traumatismo do Encéfalo" OR TW:"Lesão Encefálica 
Traumática" OR MH:C10.228.140.140.127\$ OR MH:C10.228.140.199.500\$ OR MH:C10.900.300.087.250\$ OR MH:C26.915.300.200.200\$ OR tw:stroke* or tw:poststroke or tw:apoplex* or tw:cerebrovasc* or cva* or tw:SAH OR TW:Monoplegia OR MH:C10.597.622.295\$ OR MH:C23.888.592.636.312\$ OR TW:Hemiparesis OR TW:Muscle Paresis OR MH:C10.597.636\$ OR MH:C23.888.592.643\$ OR TW:"Hemiparesia" OR TW:"Paresia Muscular" OR TW:hemipleg* or TW:hemipar* or TW:paresis or TW:paretic) AND (MH:A01.378.800\$ OR TW:"Extremidade Superior" OR TW:"upper limb" or TW:"upper extremity" or TW:arm or TW:arms or TW:shoulder or TW:shoulders or TW:hand or TW:hands or TW:axilla* or TW:elbow* or TW:forearm* or TW:finger* or TW:wrist*) AND (TW:Observation OR TW:Observación OR TW:Observação OR MH:E05.581.249 OR TW:"Perceptual Motor Performance" OR TW:"Visual Motor Coordination" OR TW:"Sensory Motor Performance" OR MH:F02.808 OR MH:G11.427.700 OR MH:G11.561.623 OR TW:"Desempenho Perceptual-Motor" OR TW:"Coordenação Visiomotora" OR TW:"Desempenho Sensório-Motor" OR TW:"Desempeño Motor Perceptual" OR TW:"Coordinación Motora Visual" OR TW:"Desempeño Motor Sensorial" OR TW:"Imitative Behavior" OR TW:"Conducta Imitativa" OR TW:"Comportamento Imitativo" OR MH:F01.145.510\$ OR TW:"Motion Perception" OR TW:"Percepción de Movimiento" OR TW:"Percepção de Movimento" OR MH:F02.463.593.932.567 OR TW:"Percepción Visual" OR TW:"Percepção Visual" OR TW:"visual perception" OR MH:F02.463.593.932 OR TW:Learning OR TW:Aprendizaje OR TW:Aprendizagem OR TW:Phenomenography OR MH:F02.463.425 OR MH:F02.784.629.529 OR MH:SP4.006.047.453.604 OR TW:Aprendizado OR TW:Fenomenografia OR TW:"Psychological Anticipation" OR TW:"Anticipación Psicológica" OR TW:"Antecipação Psicológica" OR MH:F02.463.093 OR TW:"Photic Stimulation" OR TW:"Estimulación Luminosa" OR TW:"Estimulação Luminosa" OR TW:"Visual Stimulation" OR MH:E05.723.729 OR TW:"Estimulação Fótica" OR TW:"Estimulação Visual" OR TW:"Estimulación Fótica" OR TW:"Estimulación Visual" OR TW:"Mirror Neurons" OR TW:"Neurônios-Espelho" OR TW:"Neuronas Espejo" OR MH:A08.675.500 OR MH:A11.671.487 OR TW:"action observation" OR TW:"action-observation" OR TW:AO OR TW:AOT OR TW:"observación de la acción" OR TW:"observação da ação" OR TW:"visual-motor matching" OR TW:"correspondência visual-motora" OR TW:"coincidente visomotora") AND (((PT:"randomized controlled trial" OR PT:"controlled clinical trial" OR PT:"multicenter study" OR MH:"randomized controlled trials as topic" OR MH:"controlled clinical trials as topic" OR MH:"multicenter study as topic" OR MH:"random allocation" OR MH:"double-blind method" OR MH:"single-blind method") OR ((ensaio\$ OR ensayo\$ OR trial\$) AND (azar OR acaso OR placebo OR control\$ OR aleat\$ OR random\$ OR enmascarado\$ OR simpleciego OR ((simple\$ OR single OR duplo\$ OR doble\$ OR double\$) AND (cego OR ciego OR blind OR mask))) AND clinic\$)) AND NOT (MH:animals OR MH:rabbits OR MH:rats OR MH:primates OR MH:dogs OR MH:cats OR MH:swine OR PT:"in vitro"))

\section{Appendix 6. Allied and Complementary Medicine Database (AMED) search strategy}

1. cerebrovascular disorders/ or cerebral hemorrhage/ or cerebral infarction/or cerebral ischemia/ or cerebrovascular accident/ or stroke/

2. (stroke or poststroke or post-stroke or cerebrovasc $\$$ or brain vasc $\$$ or cerebral vasc $\$$ or $c v a \$$ or apoplex $\$$ or $S A H)$.tw.

3. ((brain $\$$ or cerebr\$ or cerebell\$ or intracran\$ or intracerebral) adj5 (isch?emi\$ or infarct\$ or thrombo $\$$ or emboli\$ or occlus\$)).tw.

4. ((brain $\$$ or cerebr\$ or cerebell\$ or intracerebral or intracranial or subarachnoid) adj5 (haemorrhage $\$$ or hemorrhage $\$$ or haematoma

\$ or hematoma or bleed\$)).tw.

5. hemiplegia/

6. (hemipleg\$ or hemipar\$ or paresis or paretic).tw.

7. or/1-6

8. exp arm/

9. (upper limb\$ or upper extremit\$ or arm or arms or shoulder or shoulders or hand or hands or axilla\$ or elbow\$ or forearm\$ or finger \$ or wrist\$).tw.

10. 8 or 9

11. psychomotor performance/ or Movement/ or Motion/

12. Visual perception/

13. Learning/

14. Photic stimulation/

15. (action observation or action-observation or AO or AOT).tw.

16. ((observ\$ or watch\$) adj10 (action\$ or learn\$ or movement\$ or reach\$ or activit\$ or task\$ or motion\$ or motor train $\$$ or perform\$ or gestur or demonstrat\$ or video $\$$ or TV screen or television screen or computer screen)).tw.

17. ((visual or action or motion) adj5 perception).tw.

18. visual-motor matching.tw.

19. mirror neur\$.tw.

20. or/11-19

21. 7 and 10 and 20

\section{Appendix 7. PEDro search strategy}

Abstract and Title: stroke*

Body part: upper arm, shoulder or shoulder girdle / forearm or elbow / hand or wrist.

Therapy: Neurodevelopmental therapy, neurofacilitation

Methods: Clinical trial

All search terms in the title or abstract were combined with body part descriptors using the AND operator. 


\section{Appendix 8. Rehabdata search strategy}

Abstract: action observation AND stroke

\section{Appendix 9. US National Institutes of Health Ongoing Trials Register (ClinicalTrials.gov)}

action observation AND INFLECT EXACT "Interventional" [STUDY-TYPES] AND ( Cerebrovascular Disorders OR Stroke OR Transient Ischaemic Attack OR Subarachnoid) [DISEASE]

\section{Appendix 10. Stroke Trials Registry}

Key words: "action observation"

\section{Appendix 11. ISRCTN Registry}

Text search: stroke

Interventions: action observation

\section{Appendix 12. Australian New Zealand Clinical Trials Registry}

Search terms: cerebrovascular or cerebral or stroke or "transient ischemic attack or TIA or SAH" Description of intervention(s) / exposure: "action observation"

\section{Appendix 13. WHO International Clinical Trials Registry Platform search strategy}

Condition: stroke

Intervention: action observation

\section{CONTRIBUTIONS OF AUTHORS}

Lorenna Borges (LB) conducted the review, assessed the quality of the evidence, performed statistical analyses, interpreted the results, and was in charge of writing the review.

Aline Fernandes (AF): study selection, data extraction and assessment of risk of bias. She also contributed to writing the review.

Luciana Melo (LM): study selection, data extraction and assessment of risk of bias. She also revised the manuscript.

Ricardo Guerra (RG): contributed to the conception and design of the review, and helped in methodological planning.

Tania Campos (TC): was the reviewing judge, assessed evidence quality, helped interpret the results and corrected the review.

All authors approved the protocol and the final review.

\section{DECLARATIONS OF INTEREST}

Lorenna RDM Borges: none known.

Aline Fernandes: none known.

Luciana Melo: none known.

Ricardo O Guerra: none known.

Tania F Campos: none known.

\section{SOURCES OF SUPPORT}

\section{Internal sources}

- Department of Physical Therapy, Federal University of Rio Grande do Norte, Brazil.

\section{External sources}

- No sources of support supplied

\section{DIFFERENCES BETWEEN PROTOCOL AND REVIEW}

There were a number of differences between what we planned in the protocol and the final review. Sensitivity analysis should be conducted after removing studies with high risk of allocation concealment and blinding of outcome assessment. We did this, disregarding only two studies that exhibited high risk of bias for allocation concealment. In another investigation, sensitivity analysis used only one of the two instruments applied to measure the same outcome. Furthermore we carried out two sensitivity analyses to determine whether the effect 
of AO changed with the mode of application: one removing studies in which therapy took place in the participants' home, and the other in which the action was demonstrated by the therapist and not through video.

We also intended to conduct subgroup analysis considering the type of treatment, as follows: one subgroup in which therapy was based on $\mathrm{AO}$ alone and another where $\mathrm{AO}$ was followed by physical exercise. However there were no studies that applied $\mathrm{AO}$ alone to upper limb motor function; and therefore we decided to conduct subgroup analysis considering the types of control groups (placebo, conventional physiotherapy, and with no specific therapy). We performed another subgroup analysis considering the duration of observation.

We conducted an extensive search and are confident that we identified all relevant studies in the field. However we were unable to search $\mathrm{PhD}$ and MSc theses using Proquest, and there is a small possibility that we did not identify some published or unpublished studies. We hope to be able to search Proquest in a future update of this review. We were also unable to search the LILACS database for 2016 (after May) and 2017 due to technical problems with the database. Another difference was that we searched conference proceedings in Physiotherapy UK 2015 from The Chartered Society of Physiotherapy instead of the Physiotherapy UK Conference 2015, as we initially planned in the protocol.

\section{NDEX TERMS}

\section{Medical Subject Headings (MeSH)}

*Motor Skills; *Neuronal Plasticity; *Upper Extremity; Activities of Daily Living; Hand; Quality of Life; Randomized Controlled Trials as Topic; Recovery of Function; Stroke Rehabilitation [ ${ }^{*}$ methods]

\section{MeSH check words}

Humans 